\title{
Cooling and Heating Season Impacts of Right-Sizing of Fixed- and Variable-Capacity Heat Pumps With Attic and Indoor Ductwork
}

James Cummings, Charles Withers, and Jamie Kono Building America Partnership for Improved Residential Construction 


\section{NOTICE}

This report was prepared as an account of work sponsored by an agency of the United States government. Neither the United States government nor any agency thereof, nor any of their employees, makes any warranty, express or implied, or assumes any legal liability or responsibility for the accuracy, completeness, or usefulness of any information, apparatus, product, or process disclosed, or represents that its use would not infringe privately owned rights. Reference herein to any specific commercial product, process, or service by trade name, trademark, manufacturer, or otherwise does not necessarily constitute or imply its endorsement, recommendation, or favoring by the United States government or any agency thereof. The views and opinions of authors expressed herein do not necessarily state or reflect those of the United States government or any agency thereof.

Available electronically at http://www.osti.gov/bridge

Available for a processing fee to U.S. Department of Energy and its contractors, in paper, from:

U.S. Department of Energy

Office of Scientific and Technical Information

P.O. Box 62

Oak Ridge, TN 37831-0062

phone: 865.576 .8401

fax: 865.576 .5728

email: mailto:reports@adonis.osti.gov

Available for sale to the public, in paper, from:

U.S. Department of Commerce

National Technical Information Service

5285 Port Royal Road

Springfield, VA 22161

phone: 800.553 .6847

fax: 703.605.6900

email: orders@ntis.fedworld.gov

online ordering: http://www.ntis.gov/ordering.htm 


\title{
Cooling and Heating Season Impacts of Right-Sizing of Fixed- and Variable-Capacity Heat Pumps With Attic and Indoor Ductwork
}

\author{
Prepared for: \\ The National Renewable Energy Laboratory \\ On behalf of the U.S. Department of Energy's Building America Program \\ Office of Energy Efficiency and Renewable Energy \\ 15013 Denver West Parkway \\ Golden, CO 80401 \\ NREL Contract No. DE-AC36-08GO28308 \\ Prepared by: \\ James Cummings, Charles Withers, and Jamie Kono \\ BA-PIRC/Florida Solar Energy Center \\ 1679 Clearlake Road \\ Cocoa, FL 32922 \\ NREL Technical Monitor: Stacey Rothgeb \\ Prepared under Subcontract No. KNDJ-0-40339-02
}

June 2015 
The work presented in this report does not represent performance of any product relative to regulated minimum efficiency requirements.

The laboratory and/or field site used for this work are not certified rating test facilities. The conditions and methods under which products were characterized for this work differ from standard rating conditions, as described.

Because the methods and conditions differ, the reported results are not comparable to rated product performance and should only be used to estimate performance under the measured conditions. 


\section{Contents}

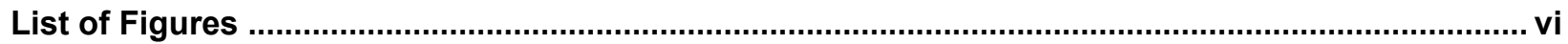

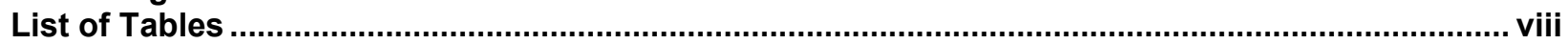

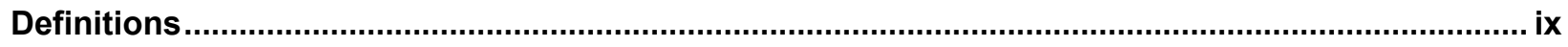

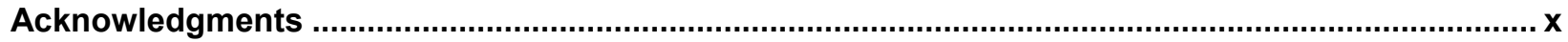

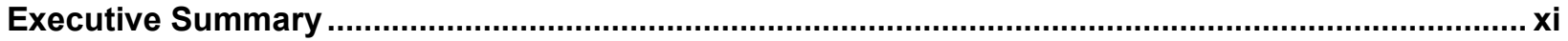

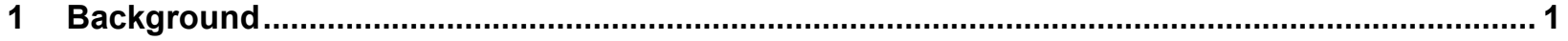

1.1 How the Variable-Capacity iQ Drive Heat Pump Operates ..........................................2

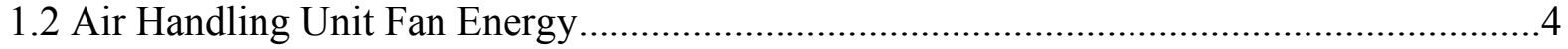

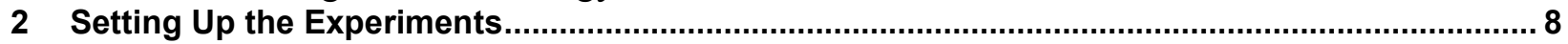

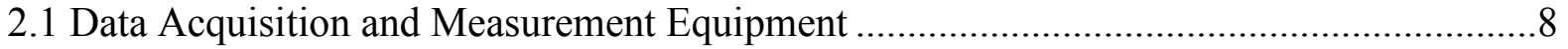

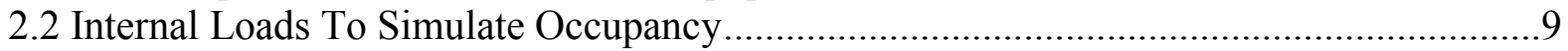

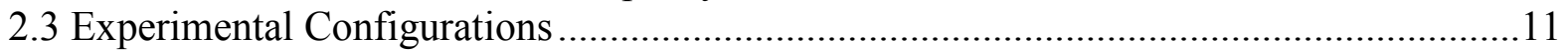

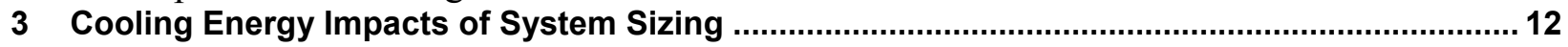

3.1 Performance Mapping the Four Heat Pumps ............................................................... 12

3.2 Indoor and Outdoor Environmental Conditions During the Cooling Season ...................16

3.3 Cooling Energy Impacts of Right-Sized and Oversized Systems.................................21

3.4 Cooling Energy Impacts of System Sizing for a Typical Summer Day ..........................28

4 Impacts of Right-Sizing on Peak Cooling Energy Demand ................................................. 31

4.1 Cooling Peak Demand Associated With System Sizing............................................. 31

4.2 Discussion of System Sizing Impact on Peak Cooling Demand ....................................33

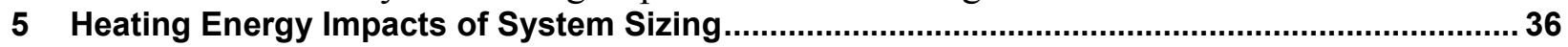

6 Impacts of Right-Sizing on Peak Heating Energy Demand ........................................................ 40

6.1 Discussion of Heating Peak Demand Reduction .......................................................41

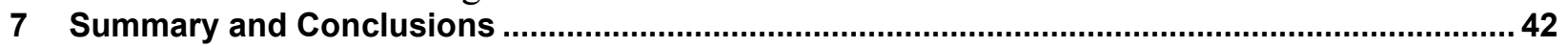

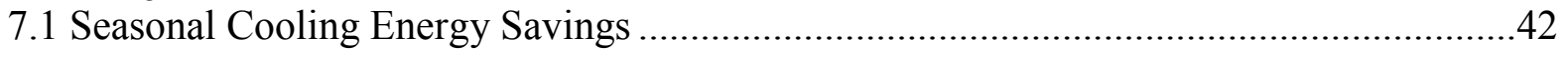

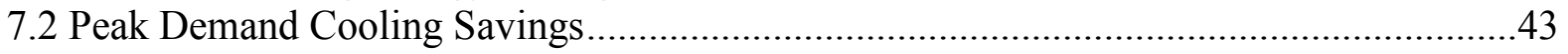

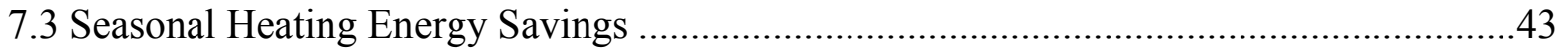

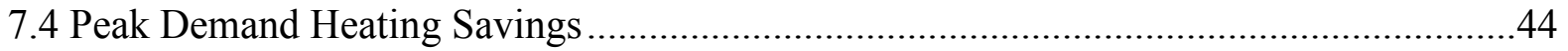

7.5 Additional Conclusions Related to Humidity Control ...................................................44

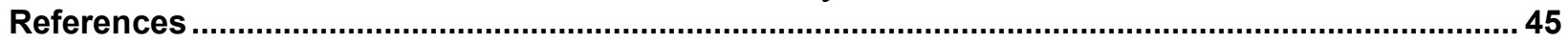

Appendix A: Heating and Cooling Capacities ......................................................................... 46

Appendix B: Cooling and Heating Season Energy Consumption Analysis Using a Multiple Linear

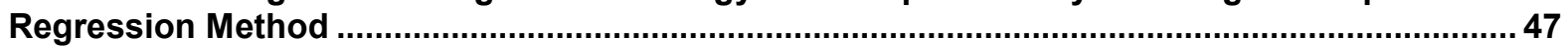




\section{List of Figures}

Figure 1. SEER 22 2-ton heat pump AHU fan power consumption measured in the lab ................... 5 Figure 2. SEER 21 3-ton heat pump AHU fan power consumption measured in the lab ................... 6

Figure 3. Measured cooling COP versus CF for the 3-ton SEER 21 system for various outdoor temperature bins. The best-fit line for the $78^{\circ}-83^{\circ} \mathrm{F}$ temperature bin is marked at $42 \%$ and $63 \%$

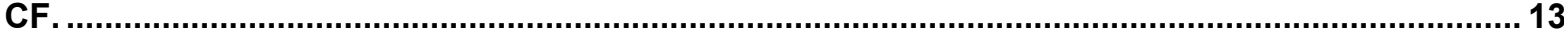

Figure 4. Measured cooling COP versus CF for the 2-ton SEER 22 system for various outdoor temperature bins (15-minute data)................................................................................... 14

Figure 5. Measured system cooling COP for the 2-ton and 3-ton SEER 13 heat pumps as a function of outdoor temperature. At $80^{\circ} \mathrm{F}$ condenser entering temperature the 2-ton system is $5.2 \%$ more energy efficient than the 3-ton system.

Figure 6. Measured system cooling COP for the 2-ton and 3-ton SEER 13 heat pumps as a function of outdoor temperature; the 2-ton AHU blower efficiency was adjusted to match the 3-ton AHU blower efficiency.

Figure 7. Cooling energy use as a function of dT (outdoor minus indoor temperature), including daily data points, best-fit lines, and best-fit equations for the 3-ton systems (Phase 1)........... 21

Figure 8. Cooling energy use as a function of $\mathrm{dT}$, including daily data points, best-fit lines, and best-fit equations for the 2-ton systems (Phase 3) ................................................................. 22

Figure 9. Cooling energy use as a function of $\mathrm{dT}$ for the 2-ton and 3-ton SEER 13 units with attic ducts

Figure 10. Cooling energy use as a function of dT for the 2-ton and 3-ton SEER 13 units with indoor ducts.

Figure 11. Cooling energy use as a function of dT for the 2-ton and 3-ton iQ Drive (SEER 22 and

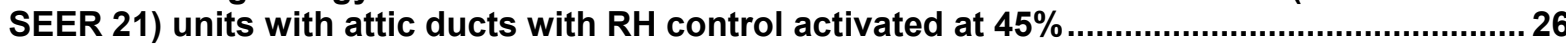

Figure 12. Cooling energy use as a function of $d T$ for the 2-ton and 3-ton iQ Drive (SEER 22 and

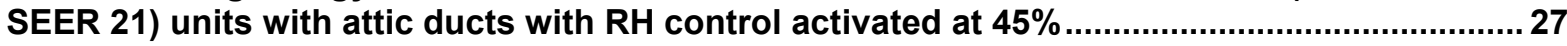

Figure 13. Cooling energy use as a function of dT for the 2-ton and 3-ton iQ Drive (SEER 22 and SEER 21) units with indoor ducts and RH control activated (at $45 \%$ )

Figure 14. Least-squares regression analysis for 2 p.m. to 7 p.m. hourly data from hot summer days for the 2-ton and 3-ton SEER 13 units with attic ducts

Figure 15. Least-squares regression analysis for 2 p.m. to 7 p.m. hourly data from hot summer days for the 2-ton and 3-ton SEER 13 units with indoor ducts

Figure 16. Least-squares regression analysis for 2 p.m. to 7 p.m. hourly data from hot summer days for the 2-ton and 3-ton SEER 22/21 units with attic ducts and without RH control ........... 32

Figure 17. Least-squares regression analysis for hours of 2 p.m. to 7 p.m. from hot summer days

for the 2-ton and 3-ton SEER 22/21 units with attic ducts and 45\% RH control ......................... 33

Figure 18. Least-squares regression analysis for 2 p.m. to 7 p.m. hourly data from hot summer days for the 2-ton and 3-ton SEER 22/21 units, with indoor ducts and 45\% RH control .............33

Figure 19. Heating energy use as a function of dT for the 2-ton and 3-ton SEER 13 units............... 37 Figure 20. Heating energy use as a function of dT for the 2-ton SEER 22 unit and the 3-ton SEER 21 unit

Figure 21. Least-squares best-fit regression analysis for the hours of 2 a.m. to 8 a.m. from cold winter days for the 2-ton and 3-ton SEER 13 systems with attic duct configurations...............40

Figure 22. Regression analysis for the hours of 2 a.m. to 8 a.m. from cold winter days for the 2-ton and 3-ton SEER 22/21 systems with attic duct configurations; each data point was the average value for a 2-hour period .................................................................................................... 41

Figure 23. Cooling energy use as a function of dT, including daily data points, MLR best-fit lines, and equations for the 3 -ton systems (Phase 1).

Figure 24. Cooling energy use as a function of dT, including daily data points, MLR best-fit lines, and equations for the 2-ton systems (Phase 3) ...................................................................51

Figure 25. Cooling energy use as a function of dT for the 2-ton and 3-ton SEER 13 units with attic ducts based on MLR

Figure 26. Cooling energy use as a function of dT for the 2-ton and 3-ton SEER 13 units with indoor ducts based on MLR 
Figure 27. Cooling energy use as a function of $\mathrm{dT}$ for the 2-ton and 3-ton iQ Drive (SEER 22 and SEER 21) units with attic ducts with RH control activated at $45 \%$ based on MLR

Figure 28. Cooling energy use as a function of $d T$ for the 2-ton and 3-ton iQ Drive (SEER 22 and

SEER 21) units with attic ducts with RH control deactivated based on MLR ...........................53

Figure 29. Cooling energy use as a function of dT for the 2-ton and 3-ton iQ Drive (SEER 22 and

SEER 21) units with indoor ducts and RH control activated (at $45 \%$ ) based on MLR...............54

Figure 30. Cooling energy use as a function of dT for the 2-ton and 3-ton iQ Drive (SEER 22 and SEER 21) units with indoor ducts and RH control deactivated based on MLR ......................... 54

Figure 31. Heating energy use as a function of dT for the 2-ton and 3-ton SEER 13 units based on MLR analysis.

Figure 32. Heating energy use as a function of dT for the 2-ton SEER 22 unit and the 3-ton SEER 21 unit based on MLR analysis

Unless otherwise noted, all figures were created by BA-PIRC. 


\section{List of Tables}

Table 1. Lab Testing and Monitoring Equipment Used in the Phase 1 and Phase 3 Experiments.... 9

Table 2. Phase 1 Average Outdoor and Indoor Temperatures, Indoor RH, and Cooling System

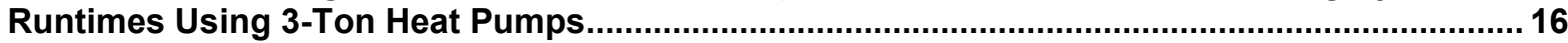

Table 3. Average Outdoor and Indoor Temperatures, Indoor RH, and Cooling System Runtimes for Hot and Humid Days Using 3-Ton Heat Pumps.

Table 4. Average Outdoor and Indoor Temperatures, Indoor RH, and Cooling System Runtimes Using 2-Ton Heat Pumps

Table 5. Average Outdoor and Indoor Temperatures, Indoor RH, and Cooling System Runtimes for Hot and Humid Days Using 2-Ton Heat Pumps.

Table 6. Average Outdoor and Indoor Temperatures, Indoor RH, and Cooling System Runtimes for Hot and Humid Days Using 3-Ton Heat Pumps With Similar Outdoor Conditions* ................... 20

Table 7. Average Outdoor and Indoor Temperatures, Indoor RH, and Cooling System Runtimes for Hot and Humid Days Using 2-Ton Heat Pumps With Similar Outdoor Conditions*....

Table 8. Regression Analysis Results and Energy Consumption for 2-Ton (Right-Sized) and 3-Ton (Oversized) Heat Pumps ${ }^{\text {a }}$...

Table 9. Regression Equations Used To Calculate COP *

Table 10. Peak Demand Best-Fit Equation and Coefficients for Each SEER 13 Experimental Configuration*

Table 11. Peak Demand Best-Fit Equations and Coefficients for Each SEER 22/21 Experimental Configuration*...

Table 12. Phase 1 Average Indoor Temperatures, Indoor RH, and Heating System Runtimes for Heating Days From February 11, 2010 Through February 16, 2011.

Table 13. Phase 3 Average Indoor Temperatures, Indoor RH, and Heating System Runtimes for Heating Days From December 21, 2012 Through March 30, 2013

Table 14. Best-Fit Equation Intercepts and Coefficients in the Form of $Y=A+B(X)+C\left(X^{2}\right)$ for the 2-Ton and 3-Ton SEER 13 and SEER 21/22 Systems ${ }^{a}$...

Table 15. Peak Heating Demand Savings Calculated From the Best-Fit Equation*..........................41

Table 16. System Cooling Capacities: 22 SEER. Ultra High Efficiency, Single Phase ....................... 46

Table 17. System Heating Capacities, 22 SEER, Ultra High Efficiency, Single Phase........................ 46

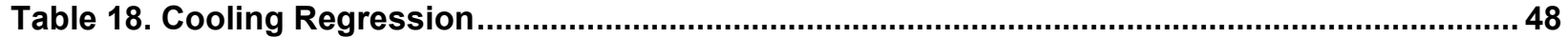

Table 19. Heating Regression ....................................................................................................... 48

Table 20. MLR Results for Cooling Energy Use Models Developed for 2-Ton (Right-Sized) and 3Ton (Oversized) Heat Pumps for Six Experimental Configurations.

Table 21. MLR Results for Heating Energy Use Models Developed for 2-Ton (Right-Sized) and 3Ton (Oversized) Heat Pumps, for SEER 13 and SEER 21/22 Systems. 


\section{Definitions}

$\mathrm{A} / \mathrm{C}$

AHU

ASHRAE

BARBD

CF

COP

dT

ECM

EER

FSEC

HSPF

MH Lab

MLR

$\mathrm{R}^{2}$

$\mathrm{RH}$

SEER

SEER 13; S13

SEER 21; S21

SEER 21 (45\%)

SHR
Air Conditioning

Air Handling Unit

American Society of Heating, Refrigerating and Air-Conditioning Engineers

Building America Research Benchmark Definition report

Capacity fraction

Coefficient of Performance; heating or cooling energy produced divided by the electrical energy input

Delta Temperature (outdoor minus indoor temperature)

Electronically Commutated Motor

Energy-Efficiency Ratio; Btu of cooling produced per watt-hour of electrical energy consumed at specific test conditions

Florida Solar Energy Center

Heating Seasonal Performance Factor

Manufactured Housing Laboratory (on FSEC campus)

Multiple linear regression

Coefficient of Determination

Relative Humidity

Seasonal Energy-Efficiency Ratio

Fixed-capacity heat pump with cooling efficiency rating of SEER 13

Variable-capacity heat pump with cooling efficiency rating of SEER 21

SEER 21 heat pump when operated with RH control set to $45 \%$

Sensible Heat Ratio; fraction of cooling energy applied to lowering the dry bulb temperature of the room air 


\section{Acknowledgments}

The authors appreciate the encouragement and support of the late Dr. Subrato Chandra, former project leader for the U.S. Department of Energy's Building America program at the Florida Solar Energy Center (FSEC).

The authors would also like to express thanks to FSEC staff: David Hoak for the high level of technical support and daily maintenance of the lab facility, internal load systems, data acquisition system, heat pump systems, and day-to-day management of the Manufactured Housing Laboratory (MH Lab) and the seasonal energy-efficiency ratio (SEER) 21 experiments, all of which were critical to successful experimental outcomes; Neil Moyer for his excellent work in developing the robust instrumentation and automation controls package in the MH Lab and assistance in readying the MH Lab for the SEER 21 experiments; Eric Martin for his continued support of this work; and Craig Muccio of Florida Power \& Light for his continued support and encouragement of this work. 


\section{Executive Summary}

A new generation of full variable-capacity air-conditioning $(\mathrm{A} / \mathrm{C})$ and heat pump units has come on the market that promises to deliver very high cooling and heating efficiency. The units are controlled differently than standard single-capacity (fixed-capacity) systems. Instead of cycling on at full capacity and cycling off when the thermostat is satisfied, the new units can vary their capacity over a wide range (approximately 40\%-118\% of nominal full capacity) and stay on for $60 \%-100 \%$ more hours per day than the fixed-capacity systems depending on load-to-capacity ratios. Two-stage systems were not evaluated in this research effort.

Two major factors impact the efficiency of the variable-capacity systems relative to fixedcapacity systems:

- Conditioned air dwells in the ductwork (often located in the attic) for $60 \%-100 \%$ longer in variable-capacity systems relative to fixed-capacity systems. This causes greater conductive losses when ducts are outside the conditioned space.

- Variable-capacity systems operate at a much higher efficiency at their lowest capacity, which suggests that oversized variable-capacity systems may yield significant energy savings compared to right-sized systems.

This research addresses two primary energy-efficiency questions:

- Does an oversized variable-capacity heat pump system (in this case seasonal energyefficiency ratio [SEER] 22 or SEER 21) yield higher or lower energy-efficiency cooling and/or heating performance than a right-sized system?

- Does an oversized fixed-capacity SEER 13 system yield higher or lower energyefficiency cooling and/or heating performance than a right-sized system?

Two additional questions relate to peak demand:

- Does an oversized variable-capacity system yield greater cooling and heating peak demand savings relative to a right-sized system?

- Does an oversized fixed-capacity SEER 13 system yield greater cooling and heating peak demand savings relative to a right-sized system?

The U.S. Department of Energy's research team Building America Partnership for Advanced Residential Construction implemented two phases of experiments to examine the cooling and heating seasonal and peak demand performance of a variable-capacity 2-ton SEER 22 heat pump versus a 3-ton variable-capacity SEER 21 heat pump with attic ducts and indoor ducts. The experiments also compared the cooling and heating seasonal and peak demand performance of 2-ton versus 3-ton fixed-capacity SEER 13 heat pumps with attic ducts and indoor ducts.

The experiments were conducted in a highly instrumented 1,600- $\mathrm{ft}^{2}$ lab house on the Florida Solar Energy Center (FSEC) campus. Internally generated sensible and latent loads were installed and activated throughout the cooling and heating seasons. 
The research team expected that oversized fixed-capacity systems (SEER 13) would reduce energy efficiency, increase annual cooling and heating energy use, and elevate peak cooling and heating demand compared to right-sized systems. The experimental results generally supported these expectations.

During the cooling season, a right-sized SEER 13 system consumed $9.8 \%$ and $10.5 \%$ less annual cooling energy with attic ducts and with indoor ducts, respectively. Adjusting for the $4.8 \%$ differences in the rated SEER of the two units, right-sizing yielded $4.2 \%$ and $5.9 \%$ annual cooling energy savings for attic ducts and indoor ducts, respectively. The right-sized fixedcapacity SEER 13 heat pumps also reduced peak cooling demand by $9.2 \%$ with attic ducts and by $17.1 \%$ with indoor ducts. However, after differences in the rated energy-efficiency ratio were adjusted between the 2-ton and 3-ton systems, the results were mixed. Right-sizing apparently increased peak cooling demand by $3 \%$ with attic ducts and reduced peak cooling demand by $4.9 \%$ with indoor ducts.

During the heating season (using attic ducts only), a right-sized fixed-capacity SEER 13 system yielded 3.4\% energy savings compared to an oversized SEER 13 system. The right-sized SEER 13 system also reduced peak heating demand by $10.6 \%$.

The research team expected that oversized variable-capacity systems (SEER 22 and SEER 21) would increase energy efficiency, increase annual energy savings, and reduce peak demand over right-sized systems during cooling and heating periods. The experimental results generally supported these expectations.

The smaller capacity iQ Drive heat pump had a slightly higher SEER rating than the 3-ton iQ Drive heat pump. During the cooling season (when the 4.8\% SEER advantage of the 2-ton heat pump equipment versus the 3-ton unit was accounted for), the oversized system had $11.7 \%$ greater average seasonal energy savings than the right-sized system. Furthermore, the oversized system reduced the average cooling peak demand by $15.7 \%$ when differences in equipment efficiency were considered.

During the heating season (using attic ducts only), annual heating energy consumption was about $3 \%$ lower for the oversized SEER 21 system. However, the oversized variable-capacity system reduced peak heating demand by $10.1 \%$.

The experiments also characterized the ability of the various fixed-capacity and variable-capacity systems to control indoor relative humidity $(\mathrm{RH})$ in a leaky house $(\mathrm{ACH} 50=10.2)$ that had no mechanical ventilation. To a large extent, the experiments pointed to the tested systems that controlled indoor RH more effectively than is often expected. The fixed-capacity systems produced the lowest indoor $\mathrm{RH}$ (the average indoor $\mathrm{RH}$ was $49 \%$ during hot and humid weather even when the 3-ton system was used). This system was oversized by $65 \%-100 \%$ depending on which duct system was used. The variable-capacity (SEER 22 and SEER 21) systems produced an average indoor $\mathrm{RH}$ of $52 \%-55 \%$. When the variable-capacity systems implemented an enhanced RH control strategy, average indoor RH declined to $51 \%-53 \%$. The manufacturers could easily implement small alterations to the control algorithms, which could produce lower supply air temperatures and considerably lower indoor RH without significant energy penalties. 


\section{Background}

Three air-conditioning (A/C) manufacturers - Nordyne, Carrier, and Lennox - have introduced new lines of variable-capacity A/C and heat-pump systems. Nordyne uses the "iQ Drive" system, which is marketed through a number of brand names. The Nordyne product was selected for this study because it was the first available variable-capacity and central-ducted-system product line. This system has achieved very high efficiency ratings. The straight cool units have a seasonal energy-efficiency ratio (SEER) of 22-24.5. The heat pump units have ratings of SEER 21-22. The U.S. Department of Energy's research team Building America Partnership for Advanced Residential Construction examined 2-ton and 3-ton Nordyne heat pumps with SEER 22 and 21 ratings, respectively. Carrier has also introduced a line of variable-capacity $\mathrm{A} / \mathrm{C}$ and heat pump products with capacities that are $40 \%-100 \%$ of nominal capacity. The Nordyne variable-capacity units were tested in a side-by-side configuration with fixed-capacity SEER 13 units of 2-ton and 3-ton capacity.

Traditional cooling systems cycle on and off - either on at full capacity or off. In contrast, the iQ Drive system modulates capacity from about $40 \%$ to $118 \%$ of nominal capacity. The 2 -ton iQ Drive heat pump used in these experiments has nominal 23,000 Btu/h cooling capacity and $22,600 \mathrm{Btu} / \mathrm{h}$ nominal heating capacity. At its lowest cooling capacity, the 2-ton unit produces $11,300 \mathrm{Btu} / \mathrm{h}$ (0.94 tons) of cooling. At its highest cooling capacity, this unit produces 26,900 $\mathrm{Btu} / \mathrm{h}$ (2.24 tons) of cooling. Its cooling capacity varies by a factor of 2.4 (from $42 \%$ to $100 \%$ of maximum capacity).

The 3-ton iQ Drive heat pump has nominal 35,000 Btu/h cooling capacity and 34,000 Btu/h heating capacity. At its lowest cooling capacity, this unit produces $14,200 \mathrm{Btu} / \mathrm{h}$ (1.18 tons) of cooling. At its highest cooling capacity, it produces $40,700 \mathrm{Btu} / \mathrm{h}$ (3.39 tons) of cooling. Its cooling capacity varies by a factor of 2.9 (from $35 \%$ to $100 \%$ of maximum capacity).

Nordyne also makes a 4-ton iQ Drive heat pump (not tested in these experiments) that has nominal $44,500 \mathrm{Btu} / \mathrm{h}$ cooling capacity and $46,000 \mathrm{Btu} / \mathrm{h}$ heating capacity. At its lowest cooling capacity, this unit produces $14,300 \mathrm{Btu} / \mathrm{h}$ (1.19 tons) of cooling. At its highest cooling capacity, it produces $48,000 \mathrm{Btu} / \mathrm{h}$ (4.0 tons) of cooling. Its cooling capacity varies by a factor of 3.4 (from $30 \%$ to $100 \%$ of maximum capacity).

Capacity varies based on the degree of variance of room temperature from the set point. In cooling mode the "steps" of cooling range from 1 to 11 over a thermostat range of $3^{\circ} \mathrm{F}$ below set point to $3^{\circ} \mathrm{F}$ above set point. Heating capacity is controlled over a $6^{\circ} \mathrm{F}$ band from $3^{\circ} \mathrm{F}$ above set point to $3^{\circ} \mathrm{F}$ below set point.

This system achieves very high energy efficiency when it operates at a small fraction of its total capacity because the evaporator and condenser coils are considerably oversized, which allows for efficient heat exchange. An additional factor improves efficiency - the compressor operates more efficiently when it operates at lower speeds (as low as $15 \mathrm{~Hz}$ ). Thus, cooling energy efficiency is about $33 \%$ higher when the unit operates at minimum capacity compared to full nominal capacity $(85 \%$ of maximum capacity $=$ full nominal capacity) for an ambient temperature of $83^{\circ}-88^{\circ} \mathrm{F}$. 
In these experiments, the Manufactured Housing Laboratory (MH Lab) on the campus of the Florida Solar Energy Center (FSEC) was fitted with 2-ton and 3-ton heat pumps. The design cooling load of the MH Lab is about $21,000 \mathrm{Btu} / \mathrm{h}$ when an attic duct system is used and about $18,000 \mathrm{Btu} / \mathrm{h}$ when interior ducts are used. With the attic ductwork, the 2-ton systems are then oversized by about $12 \%$ and the 3 -ton systems are oversized by about $67 \%$.

Throughout most of the day the unit does not turn off but rather shifts to a lower capacity. This high-efficiency heat pump technology achieves high SEER values by fundamentally altering the equipment design and the way the equipment operates. These changes lead to long runtimes that may affect the duct system's conductive and air leakage losses. The fixed-capacity SEER 13 3ton unit operated about $35 \%-40 \%$ of the time on a typical Florida summer day; the Nordyne iQ Drive 3-ton unit operated about $70 \%-80 \%$ of the time on similar days. (This percentage varies depending upon the load-to-capacity ratio for individual homes.) Thus, cold air remains in the ductwork most of the time. Conductive heat losses are expected to be greater than with a traditional fixed-capacity system. In fact, Phase 1 research revealed that operation with attic ducts (in a hot attic) increased cooling energy use by $13 \%$ for the SEER 13 system and by $21 \%$ for the SEER 21 system compared to indoor ducts, which confirms that expectation.

The iQ Drive system has two operation modes: standard control and relative humidity (RH) control. In standard control mode, the average airflow rate of the air handling unit (AHU) is relatively high ( $600 \mathrm{cfm} /$ ton based on monitored data) when the compressor is operating at low capacity. The sensible heat ratio (SHR) is therefore high. In the RH control mode, an indoor RH set point can be selected that prompts the AHU to operate with reduced airflow, which in turn lowers the equipment SHR and yields a lower indoor RH. Section 1.1 covers additional detail regarding how the iQ Drive system operates.

\subsection{How the Variable-Capacity iQ Drive Heat Pump Operates}

The SEER 21 heat pump's iQ Drive system allows three elements of the cooling system to vary: AHU fan speed, compressor speed, and condenser fan speed. AHU and compressor speed vary from 15 to $60 \mathrm{~Hz}$. The full airflow range of the 3-ton iQ Drive (SEER 21) AHU is 770-1,270 $\mathrm{cfm}$ in standard control mode and 230-1,270 cfm in RH control mode. Airflow rates for the 2ton iQ Drive unit (SEER 22) are approximately two-thirds of those amounts. The condenser fan speed also varies but the control method is unclear. The thermostat provides a proportional band control that calls for specific heating or cooling steps that are proportional to the difference between the room temperature and the set point. Cooling consists of 11 steps, but steps 10-11 occur only when the room temperature is $3^{\circ} \mathrm{F}$ or more higher than set point (Nordyne Elite Training 2009). Cooling operation occurs mostly between steps 1 and 8 - step 8 is $100 \%$ of nominal rated capacity.

As discussed earlier, the iQ Drive heat pumps have two cooling modes: standard control (no RH control set point) and RH control (user-selectable RH set point). In standard mode the compressor capacity declines in response to a reduction in cooling load. This decline is detected based on the room air temperature deviation from the set point. As the room temperature falls lower than the set point (in cooling mode), the unit does not (at first) turn off; rather, the compressor slows until it reaches lowest capacity (about $40 \%$ of nominal capacity). The AHU fan speed also declines; however, it does not fall below about $770 \mathrm{cfm}$ for the 3-ton system and $515 \mathrm{cfm}$ for the 2 -ton system (about $60 \%$ of full flow) when it operates at minimum capacity. In 
this circumstance, the supply air temperature is relatively warm (typically about $12^{\circ}-13^{\circ} \mathrm{F}$ cooler than the return air) and the system SHR is fairly high (about 0.9). Because the AHU fan uses an electronically commutated motor (ECM), the fan's energy consumption is much lower than a standard shaded-pole motor-particularly when it operates at fractional speed.

In RH control mode, compressor capacity declines in response to a reduction in cooling load; however, AHU fan speed declines proportionally even more. Even though measured AHU airflow (at minimum capacity) for the 2-ton system is approximately $570 \mathrm{cfm}$ in standard mode (average of about $650 \mathrm{cfm} / \mathrm{ton}$ ), airflow declines to as low as $150 \mathrm{cfm}$ in RH control mode (about $160 \mathrm{cfm} /$ ton). The transition to low airflow in the RH control mode (with minimum cooling capacity of about $11,300 \mathrm{Btu} / \mathrm{h}$ ) occurs gradually over a period of about 10 minutes. The AHU fan is programmed to slow by $5 \%$ of the full speed of the active cooling step every 30 seconds. This downward trend occurs until the evaporator's coil temperature reaches $37^{\circ} \mathrm{F}$ or the fan speed reaches $40 \%$ of full rated speed for the cooling capacity level at which the system is currently operating.

As the airflow rate declines, the supply air temperature also falls steadily to $55^{\circ} \mathrm{F}, 50^{\circ} \mathrm{F}, 45^{\circ} \mathrm{F}$, and even to as low as $37^{\circ} \mathrm{F}$. The SHR drops sharply at these lower airflow rates and lower supply air temperatures. If the coil temperature reaches $37^{\circ} \mathrm{F}$, a low temperature limit is triggered (to prevent the coil from icing) and the fan airflow rate increases suddenly to about $530 \mathrm{cfm}$ (system capacity typically at 0.95 tons). This raises the supply air temperature to almost $60^{\circ} \mathrm{F}$ within about 1 minute. After the system operates at this higher fan speed for a short time, it reverts to $\mathrm{RH}$ control mode with gradually slowing fan speed and declining supply air temperature. The entire cycle often takes about 15-20 minutes from start to finish and repeats itself many times throughout the day as long as the indoor RH level (measured by the humidity sensor in the thermostat) exceeds the RH set point. The $\mathrm{RH}$ control mode allows cooling operation to continue until the indoor temperature declines to $2^{\circ} \mathrm{F}$ below the set point.

The desired RH set point can be selected in 5\% increments (e.g., 55\%, 50\%, 45\%). Although the iQ Drive system tries to achieve the desired RH level, it cannot necessarily achieve or maintain the RH set point during any given time period. For example, in the Phase 1 experiments the RH control set point was $45 \%$, but the resulting 24 -hour monitored indoor $\mathrm{RH}$ averaged $52 \%$ (about $2 \%$ lower than the standard control mode produced). The iQ Drive thermostat has an onboard humidity sensor. As long as the room RH (as sensed by the thermostat) exceeds the RH set point, the iQ Drive control algorithms lower the AHU fan speed to produce a colder coil and reduced SHR. Furthermore, the RH control set point will not activate the cooling system - it will simply optimize latent performance when space cooling is called for based on the thermostat dry bulb temperature setting. Therefore, the iQ Drive system does not control indoor RH during the hours of the day when the system has cycled off.

In the heating mode, the iQ Drive heat pump capacity and the AHU fan speed vary in much the same manner as in the standard cooling mode. Instead of cycling off, compressor speed and capacity decline as the room air temperature rises relative to the thermostat set point. The AHU fan speed also declines but less precipitously than the compressor speed and capacity. Heating has 12 steps of heat delivery during which the system goes to step 11 if the room temperature decreases more than $4^{\circ} \mathrm{F}$ lower than the set point. If the heat pump cannot satisfy the demand after 10 minutes at step 11 (106\% of rated capacity) then step 12 is called for. This step enables 
electric strip auxiliary heating or use of a hydronic coil, neither of which was installed on the system used in these experiments.

This report presents the results of Phase 1 (3-ton systems) and Phase 3 (2-ton systems) of a proposed multiyear and multiphase research project that was designed to characterize how a variable-capacity SEER 21 or SEER 22 heat pump performs compared to a SEER 13 heat pump when it operates with various duct configurations. Phase 2 experiments examined the impacts of duct leaks on the relative performance of the 3-ton SEER 21 and SEER 13 systems; however, those results (except for a few comments about humidity control in Section 7.5) are not presented in this report.

- In Phase 1, both heat pumps were 3-ton units that operated during the cooling and heating seasons with indoor ducts and airtight attic ducts (Cummings and Withers 2011). The iQ Drive system operated with and without the RH control activated.

- In Phase 3, both heat pumps were 2-ton units that operated during the cooling and heating seasons with indoor ducts and airtight attic ducts and with and without the RH control activated. The 2-ton iQ Drive system has a higher SEER rating-SEER 22 versus SEER 21 for the 3-ton unit.

- The Phase 1 and Phase 3 experiments allowed the research team to examine the impact of conductive losses of an attic duct system on the energy efficiency of a variable-capacity (SEER 22 or SEER 21) heat pump compared to a fixed-capacity SEER 13 heat pump. (The indoor duct system was used as the baseline.) The team anticipated that the variablecapacity system would demonstrate greater duct conductive losses because system operation time might have been about double that of the SEER 13 system. However, the Phase 1 research revealed that conductive duct losses increased the energy consumption of the 3-ton SEER 21 system by $20.6 \%$ compared to only $12.6 \%$ for the SEER 13 system.

- In Phase 3, the 2-ton iQ Drive variable-capacity SEER 22 and 2-ton fixed-capacity SEER 13 heat pumps were installed to assess the energy impacts of right-sized systems. In Phase 1, significant evidence suggested that a substantially oversized variable-capacity system might be significantly more energy efficient than a right-sized system. That hypothesis is tested in this report based on data from Phase 1 and Phase 3.

\subsection{Air Handling Unit Fan Energy}

AHU fan energy power was characterized for the 2-ton and 3-ton heat pumps.

The 2-ton SEER 13 AHU consumed $120 \mathrm{~W}$ when it operated at a fixed $829 \mathrm{cfm}$. The research team requested a shaded-pole fan motor for this system so it would be as similar as possible to the 3-ton SEER 13 system (which was tested in Phase 1). However, after the 2-ton SEER 13 system was installed the team discovered that the system had an ECM. Even though the 2-ton SEER 13 system does not operate with variable fan speed, the AHU fan nevertheless operated much more efficiently because of the ECM - especially because the AHU fan was substantially oversized. When the 2-ton SEER 13 system was installed, the fan speed control had to be set (by means of dip switches) to the ECM's lowest speed setting. This led to much more energyefficient fan operation than the 3-ton SEER 13 AHU fan. (ECMs operate much more efficiently at their lowest speed.) Normalized fan energy consumption for this system was $6.90 \mathrm{cfm} / \mathrm{W}$. 
The 3-ton SEER 13 AHU had a shaded pole motor and consumed $444 \mathrm{~W}$ when it operated at a fixed 1,286 cfm. Normalized fan energy consumption for the SEER 13 systems was $2.90 \mathrm{cfm} / \mathrm{W}$.

AHU fan energy power was characterized for the 2-ton and 3-ton variable-capacity (SEER 22 and SEER 21) heat pumps. Each heat pump had an ECM.

The 2-ton SEER 22 heat pump AHU fan operated at high efficiency. Figure 1 characterizes fan flow versus power. When the SEER 22 system operated in standard system control (no RH set point employed), the AHU airflow rate typically averaged about $570 \mathrm{cfm}$ when it operated at minimum capacity (which it did much of the time). When the 2-ton SEER 22 system operated in $\mathrm{RH}$ control mode, the AHU fan speed was further reduced to lower the supply air temperature and operating equipment SHR - especially at low system cooling capacity (approximately $11,300 \mathrm{Btu} / \mathrm{h}$; see Appendix A). Flow rates were as low as $155 \mathrm{cfm}$ for brief periods of time. At $155 \mathrm{cfm}$, the AHU power consumption was a remarkably low $0.9 \mathrm{~W}$; this yielded a robust 161 $\mathrm{cfm} / \mathrm{W}$.

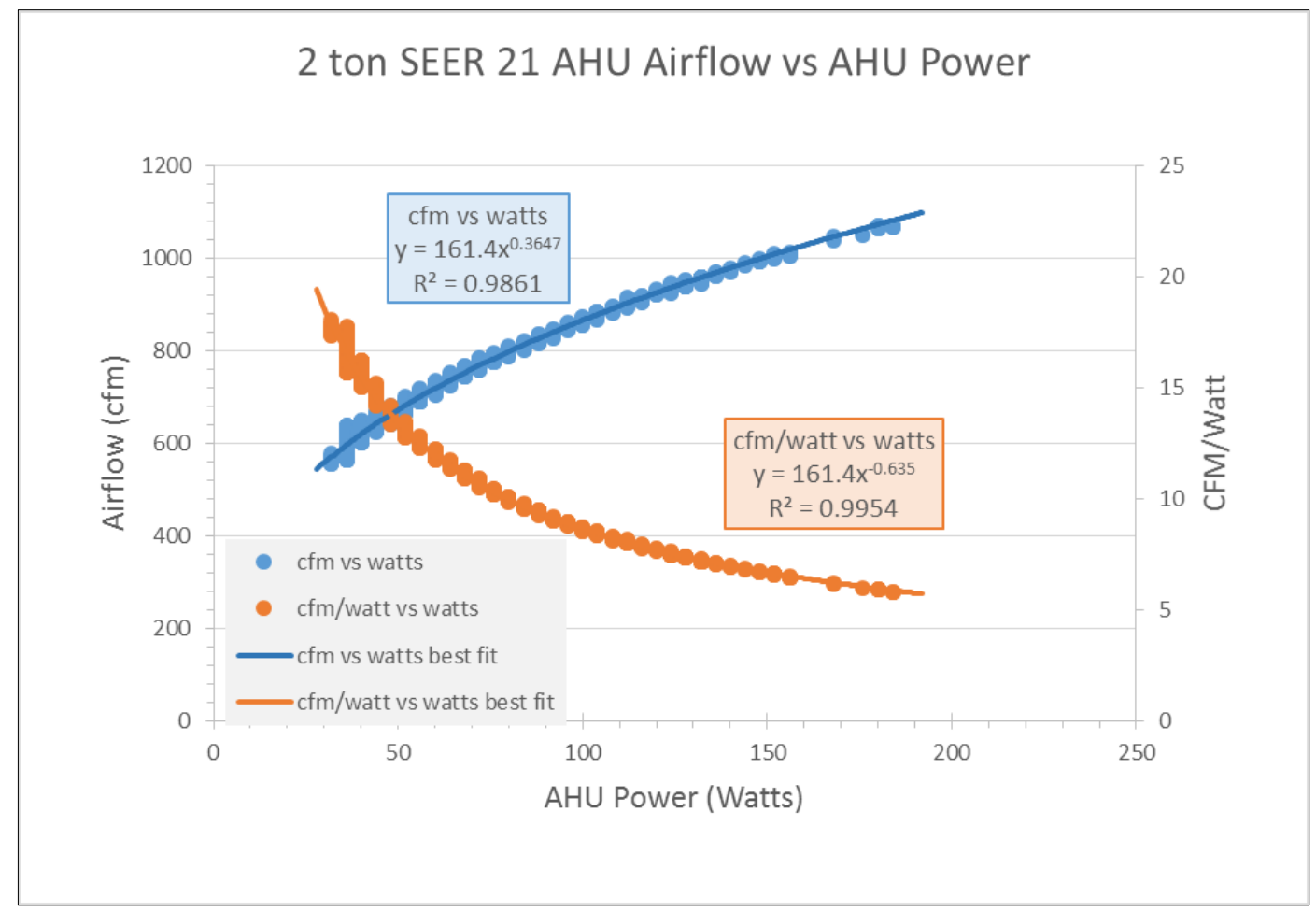

Figure 1. SEER 22 2-ton heat pump AHU fan power consumption measured in the lab

The 3-ton SEER 21 heat pump AHU fan also operated at high efficiency and with similar energy performance (in terms of $\mathrm{cfm} / \mathrm{W}$ ) compared to the 2-ton system. The AHU fan performance for the 3-ton SEER 21 unit is shown in Figure 2. When the SEER 21 system operated at standard system control (no RH set point employed), the AHU airflow rate typically averaged about 770 $\mathrm{cfm}$ when it operated at minimum capacity (which it did most of the time). Hence, although the cooling capacity was about $40 \%$ of nominal full capacity, the AHU airflow rate was about $61 \%$ of nominal full capacity. Fan power at $770 \mathrm{cfm}$ was about $101 \mathrm{~W}$ (Figure 12). In contrast, the 3ton SEER 13 AHU fan consumed $444 \mathrm{~W}$ when it operated at its fixed 1,286 cfm. The SEER 21 AHU fan consumed $390 \mathrm{~W}$ at $1,270 \mathrm{cfm}$ (at full nominal capacity), which is $12.2 \%$ lower than 
the 3-ton SEER 13 fan motor power. Stated otherwise, the SEER 13 AHU fan produced 2.90 $\mathrm{cfm} / \mathrm{W}$ and the SEER $21 \mathrm{AHU}$ fan provided $3.26 \mathrm{cfm} / \mathrm{W}$ when they operated at full nominal speed. Therefore, if the SEER 21 system operated at full capacity, normalized fan energy efficiency was only slightly higher than that of the SEER 13 system. However, the SEER 21 system virtually never operated at maximum capacity. In fact, because the 3-ton system was substantially oversized the SEER 21 AHU's fan energy consumption was almost always lower than $7 \mathrm{cfm} / \mathrm{W}$ - or more than twice as efficient as the fixed-capacity SEER 13 system. When the SEER 21 system operated at its lowest capacity in standard control mode, the fan moved about $770 \mathrm{cfm}$ using $79 \mathrm{~W}$; it produced about $9.7 \mathrm{cfm} / \mathrm{W}$.

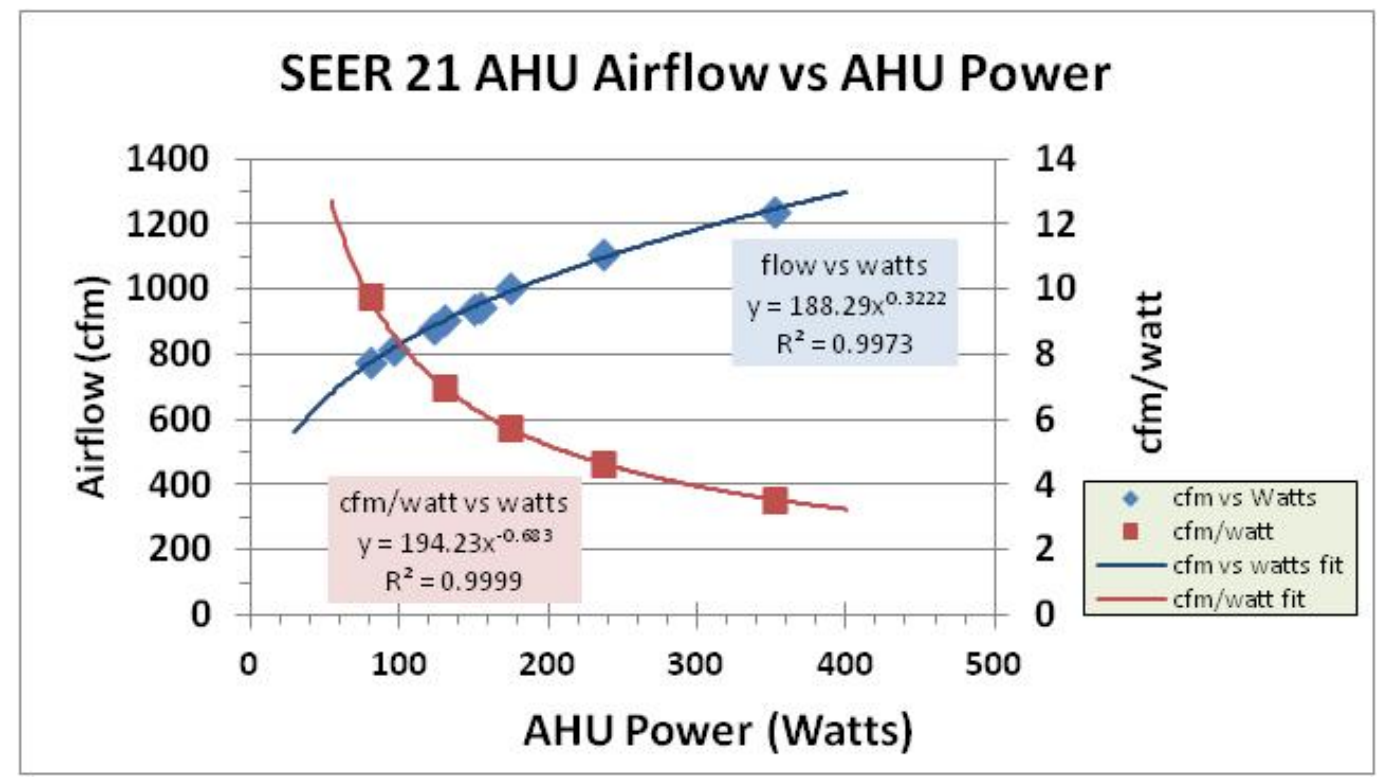

Figure 2. SEER 21 3-ton heat pump AHU fan power consumption measured in the lab

When the 3-ton SEER 21 operated in RH control mode, the AHU fan speed was further reduced to lower the supply air temperature and operating equipment SHR-especially at low system cooling capacity with flow rates as low as $230 \mathrm{cfm}$. At $230 \mathrm{cfm}$, the AHU power consumption was a remarkably low $2 \mathrm{~W}$; this produced a robust $115 \mathrm{cfm} / \mathrm{W}$.

When the iQ Drive system operated in standard mode (and at relatively low capacity) with a relatively high $\mathrm{cfm} /$ ton, it produced relatively warm supply air and somewhat elevated indoor RH (about 53\%-55\% was typical). To fully understand the iQ Drive system performance, the team also examined the system operation when it operated in RH control mode (which at times had very low cfm/ton and very cold supply air) in Phase 1 and Phase 3.

The 3-ton system size was selected for the MH Lab for the following reasons:

- When the indoor ducts were used and the internally generated heat and humidity were included, the design cooling load (at $94^{\circ} \mathrm{F}$ outdoors) was about $18,000 \mathrm{Btu} / \mathrm{h}$.

- When the system was operated with the attic duct system with near zero duct leakage, the design load was about $21,000 \mathrm{Btu} / \mathrm{h}$. (The 3 -ton units were about $67 \%$ oversized and the 2-ton units were about $10 \%$ oversized - in other words, right-sized.) 
The 2-ton systems would thus have been arguably the most appropriate choice for this research; however, various duct leaks were introduced during a specific experimental phase. The equipment also had to be able to meet the added load caused by the duct leaks. Calculations indicated that approximately 1 ton of added cooling load could be expected from the maximum duct leaks, which yielded a total cooling load of 2.75 tons. Because the Nordyne iQ Drive product is not available in increments smaller than 1-ton, 3-ton systems were selected for these experiments. 


\section{Setting Up the Experiments}

An experimental facility called the MH Lab was selected to carry out these experiments. This structure is a $1,600-\mathrm{ft}^{2}$ double-wide manufactured home with a crawlspace, a vented attic, three bedrooms, and two bathrooms. The house was manufactured in January 2002 and designed to meet Energy Star Homes Program performance criteria of that time. In 2009, a 3-ton SEER 13 fixed-capacity heat pump and a 3-ton SEER 21 variable-capacity heat pump were installed in the lab; the AHUs were placed side-by-side inside the conditioned utility room. In 2012, the two 3ton heat pumps were removed and replaced by two 2-ton heat pumps; one was a SEER 13 fixedcapacity system and the other was a SEER 22 iQ Drive variable-capacity system. (The smaller capacity iQ Drive heat pump has a slightly higher SEER rating than the 3-ton iQ Drive heat pump.)

The lab has two duct systems - one in the attic and one indoors. The heat pumps can be attached to either duct system. The ductwork's static pressure affects the AHU fan airflows and energy consumption. Adjustments were made to the air distribution systems to minimize and equalize static pressure in the two duct systems. Supply plenums were constructed to minimize static pressure and make the pressure drop between the two duct systems as similar as possible.

The same two duct systems were used in the Phase 1 and Phase 3 experiments. Return air for both was completely within the conditioned space adjacent to the AHUs. The duct leakage to outdoors $\left(\mathrm{Q}_{25, \text { out }}\right)$ for the return ducts was therefore $0.0 \mathrm{cfm}$. A small section of the supply ductwork is located in the conditioned utility room. Most supply ducts (for the attic duct system) are in the attic. The supply ducts of the attic system have nominal R-6 insulation. The airtightness of the attic supply duct system was measured. For the Phase 1 and Phase 3

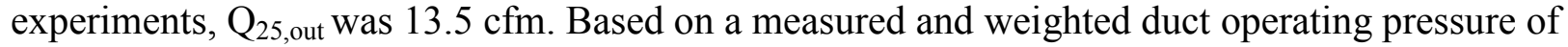
17.5 Pascals (measured during the Phase 1 experiments with the 3-ton fixed-capacity system operating), operational supply duct leakage to outdoors (attic) was determined to be $11 \mathrm{cfm}$ or $0.85 \%$ of system flow.

\subsection{Data Acquisition and Measurement Equipment}

A data acquisition system was installed to record information about the heat pump operation, energy consumption of various items in the house (including internally generated sensible and latent loads), and indoor and outdoor conditions for the Phase 1 and Phase 3 experiments. Temperature and RH of air flowing into and out of the heat pump system were recorded only when the heat pump operated (conditionally). Table 1 includes a list of test equipment and monitoring sensors.

- Data were collected when the system operated and temperatures were recorded conditionally at the entry to the return plenum, the discharge from the AHU, and at five supply registers - the latter for the attic duct system only. Temperatures were recorded entering the condenser coil (outdoor unit) when the system operated.

- Temperatures were also recorded unconditionally (continuously) at various indoor locations, in the attic, in the crawlspace, and at various locations on the roof system.

- RH was recorded conditionally at the entrance to the return and at the discharge from the AHU. 
- RH was also recorded at various indoor locations, in the attic, in the crawlspace, and outdoors-all unconditionally (continuously).

- The airflow rates of the two systems were recorded at the entrance to the return.

- Power meters were installed to record energy use for the house, the heat pump outdoor units, the heat pump AHUs, the refrigerator, the water heater, the oven, the air circulation fans, the heat lamps that simulate internal loads, and the dishwasher.

- Condensate draining from the AHU was measured by a pair of tipping buckets that provided redundant measurement of moisture that was removed by the cooling coils.

- Weather conditions of air temperature, $\mathrm{RH}$, rainfall, wind speed and direction, and solar radiation on the horizontal were measured.

Table 1. Lab Testing and Monitoring Equipment Used in the Phase 1 and Phase 3 Experiments

\begin{tabular}{|c|c|}
\hline Measurement & Equipment \\
\hline Data Collection & $\begin{array}{l}\text { Campbell Scientific CR10 with (2) AM416 } \\
\text { multiplexers and (1) SW8A pulse expansion module }\end{array}$ \\
\hline $\begin{array}{c}\text { Pressure Differentials (Airflow } \\
\text { Sensors, Air Distribution Pressures) }\end{array}$ & DG-2 digital pressure gauge with analog output \\
\hline $\begin{array}{c}\text { Return System Airflow (in situ } \\
\text { Calibration) }\end{array}$ & Shortridge Velgrid \\
\hline $\begin{array}{c}\text { Duct Leak Airflow } \\
\text { (in situ Calibration) }\end{array}$ & Continental Fan Manufacturing Iris Damper \\
\hline Airflow Calibration & TSI Model 8390 Bench Top Wind Tunnel \\
\hline Temperature & Type T thermocouple \\
\hline $\begin{array}{l}\text { RH (Return, Supply, Blended Duct } \\
\text { Leak, Indoor, Outdoor, Attic) }\end{array}$ & Vaisala HM34 and HMP50 \\
\hline A/C Condensate & Texas Electronic TR-4 and TR-525I tipping buckets \\
\hline $\begin{array}{l}\text { Energy (Whole House, AHU, } \\
\text { Condenser Unit, DHW,* Oven, } \\
\text { Refrigerator, Dishwasher, Heat } \\
\text { Lamp Circuit) }\end{array}$ & $\begin{array}{l}\text { Continental Wattnode and Ohio Semitronics Inc. } \\
\text { energy transducers with current transformers from } 5 \\
\text { to } 200 \text { amps }\end{array}$ \\
\hline DHW Consumption & Kent C700 Flow Meter \\
\hline Latent Delivery & FMI Lab Pump Jr. model RHSY \\
\hline Building Envelope Air Leakage & $\begin{array}{c}\text { Minneapolis Blower Door System with DG-700 } \\
\text { digital gauge }\end{array}$ \\
\hline Duct System Air Leakage & Minneapolis DuctBlaster System with DG-700 \\
\hline Automation Internal Loads & $\begin{array}{l}\text { Insteon based load switches controlled by ISY-99i } \\
\text { Automation controller }\end{array}$ \\
\hline
\end{tabular}

* DHW $=$ domestic hot water

\subsection{Internal Loads To Simulate Occupancy}

The MH Lab is an unoccupied home. In occupied homes, the activities of occupants and appliances generate heat, which adds to the cooling load and reduces the heating load. This added heat is in the form of sensible heat and latent heat. These loads also have a particular latent versus sensible relationship that affects the total load SHR and indoor RH. To carry out these 
experiments in the MH Lab, the team determined that sensible and latent cooling loads should be realistically representative of an occupied residence.

An automation system was installed to control the production of sensible and latent internal loads to simulate occupancy of a three-person family. (See Cummings and Withers [2011], Appendix A for a detailed discussion of internally generated loads and occupant activities.) This report contains schedules of occupant activities and internal loads. A briefer discussion of internal loads follows in this section. In most cases, the source for the occupancy or load schedule is Building America Research Benchmark Definition (BARBD) (Hendron 2008). Throughout this report, the acronym BARBD refers to the December 2008 version. Though more recent versions of this BARBD are available, internal loads continue to be based on the 2008 version for experimental continuity.

Internal loads can be generated by automatically operating various appliances on a schedule. In the MH Lab, operation of the oven, dishwasher, and showers was automated. The electric water heater in the utility room and the refrigerator also operated (cycled) normally except that the refrigerator's doors remained closed. The dishwasher door also remained closed.

Internal loads can also be simulated by means of alternative heat and water vapor sources. The kitchen oven and heat lamps were used to simulate all other sources of sensible heat, including the occupants. The oven cycled on 11 times each day (the MH Lab operated as if all days were weekdays) typically for 20-40 minutes at a time. Each oven "on" cycle was sufficiently short so that the oven did not reach its target temperature setting; the oven heating element therefore operated continuously at full capacity during the "on" cycle. Two floor fans and a ceiling fan operated continuously to help distribute heat from the kitchen to other spaces. The heat lamps were in the living room, kitchen, and master bedroom. They ran continuously throughout the day; their energy output schedule varied from $44 \mathrm{~W}$ to $472 \mathrm{~W}$.

Latent heat was added to the space-in part by operating the master bedroom shower and in part by operating the dishwasher. Together these two appliances consumed approximately 46 gallons per day. Only a small fraction of the water consumed by the shower and dishwasher entered the indoor air in the form of water vapor; most water went down the drain. Latent heat was also added to the space by means of water metered into an evaporation pan in the oven. This represented the latent load that would come from the occupants (perspiration and respiration), cooking, and the refrigerator (moisture from food in the refrigerator that would enter the space when its door opened). A floor fan that operated near the oven and a ceiling fan in the living room about 18 feet from the oven helped to mix the oven-generated latent and sensible heat throughout the house. The hall bathroom exhaust fan was cycled on for prescribed periods to induce a modest amount of air infiltration; this measure simulated occupants opening and closing the exterior doors.

Based on Equation 16 from BARBD, the dishwasher would normally be operated 215 times per year or 4.1 times per week. To reduce day-to-day variability in internal loads, the research team determined that the dishwasher should be operated once each day. The dishwasher's electric heat drying cycle was not activated. 


\subsection{Experimental Configurations}

The results of the energy and peak demand impacts of heat pump sizing are presented in Section 3 through Section 6 and are based on experimental data from Phase 1 experiments (3-ton heat pumps) and Phase 3 experiments (2-ton heat pumps).

Six experimental cooling configurations with 3-ton heat pumps were examined in Phase 1:

- SEER 13 unit with attic ducts

- SEER 13 unit with indoor ducts

- SEER 21 unit with attic ducts

- SEER 21 unit with indoor ducts

- SEER 21 unit with attic ducts and RH control set to $45 \%$

- SEER 21 unit with indoor ducts and RH control set to $45 \%$.

Four experimental heating configurations with 3-ton heat pumps were examined in Phase 1. Central Florida had much colder-than-normal winter weather during Phase 1 that allowed a greater range of test configurations. The four configurations were:

- SEER 13 unit with attic ducts

- SEER 13 unit with indoor ducts

- SEER 21 unit with attic ducts

- SEER 21 unit with indoor ducts.

Five experimental cooling configurations with 2-ton heat pumps were examined in Phase 3. (SEER 22 with indoor ducts data could not be obtained because of time delays caused by equipment failure that limited cooling season data.) The five configurations were:

- SEER 13 unit with attic ducts

- SEER 13 unit with indoor ducts

- SEER 22 unit with attic ducts

- SEER 22 unit with attic ducts and RH control set to $45 \%$

- SEER 22 unit with indoor ducts and RH control set to $45 \%$.

Two experimental heating configurations with 2-ton heat pumps were examined in Phase 3:

- SEER 13 unit with attic ducts

- SEER 22 unit with attic ducts.

SEER $22(45 \%)$ and SEER $21(45 \%)$ refer to operation of the 2-ton and 3-ton iQ Drive systems, respectively, in RH control mode set to 45\%. The SEER 22 (45\%) and SEER 21 (45\%) configurations are important experimental variations because the standard control mode of the iQ Drive system is optimized for energy savings and may not achieve the desired level of indoor humidity in some circumstances. 


\section{Cooling Energy Impacts of System Sizing}

Two primary research questions were to be answered by the data obtained from the Phase 1 and Phase 3 research:

- Does an oversized variable-capacity (SEER 22 or SEER 21) system yield higher or lower efficiency cooling and heating performance than a right-sized system?

- Does an oversized fixed-capacity SEER 13 system yield higher or lower efficiency cooling and heating performance than a right-sized system?

The oversized fixed-capacity system might be expected to have lower operating efficiency because on/off cycling is more frequent. On the other hand, oversized conditioned air in the ducts would likely experience fewer conductive energy losses (in the attic or other unconditioned space) because the dwell time in the ducts would be reduced. The team did not know which effect would be greater; the Phase 3 experiments were not designed to determine the individual impact of each variable.

The same two concepts apply to the variable-capacity system but to substantially different degrees. The 3-ton iQ Drive unit (which is oversized by $60+\%$ compared to the peak load) experiences only 11 cycles on a typical summer day. In contrast, the fixed-capacity system cycled on and off about 60-70 times per day. Because of its smaller size, the 2-ton iQ Drive system would be expected to stay on longer and cycle fewer times. On the other hand, the 2-ton iQ Drive system would increase the supply air dwell time in the attic ducts, which would tend to reduce system efficiency. However, a system sizing-related factor for the variable-capacity system may have a much larger effect on system efficiency. Data that show the performance of four heat pumps and evidence of higher variable-capacity efficiency at the lowest capacity are presented in Section 3.1.

\subsection{Performance Mapping the Four Heat Pumps}

Data collected from Phase 1 experiments showed that the 3-ton SEER 21 system operates at about $33 \%$ higher efficiency at its lowest capacity versus full nominal capacity. Oversizing the system would logically cause the system to operate at a smaller capacity fraction (CF) where system efficiency is higher. Figure 3 illustrates this and shows plots of the coefficient of performance (COP) data versus CF. The figure also shows plots of the five best-fit lines (and equations) for five outdoor temperature bins. Indoor conditions during this period were approximately $76.6^{\circ} \mathrm{F}$ with $53 \% \mathrm{RH}$. Return air conditions were $74.8^{\circ} \mathrm{F}$ and $56 \%$. For each outdoor temperature bin, the COP is considerably higher when the system is operating at its lowest capacity. These data points do not consider the inefficiencies related to cycling or conductive duct losses because they represent 15-minute data for which the system operated $100 \%$ of the time. 


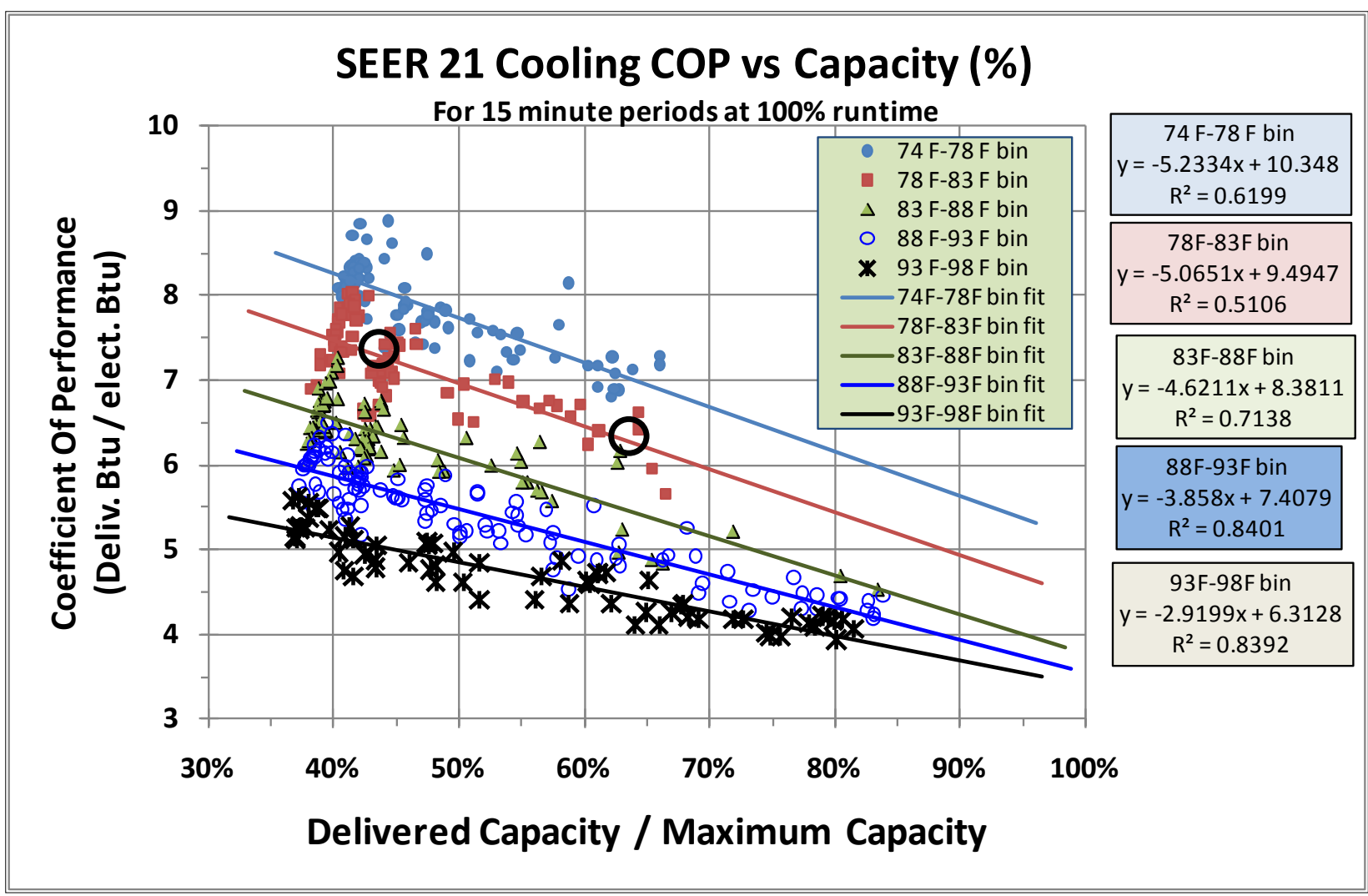

Figure 3. Measured cooling COP versus CF for the 3-ton SEER 21 system for various outdoor temperature bins. The best-fit line for the $78^{\circ}-83^{\circ} \mathrm{F}$ temperature bin is marked at $42 \%$ and $63 \%$ CF.

The data set used in Figure 3 indicates that the 3-ton iQ Drive system operated at an average of about $42 \%$ of nominal full capacity. For the $78^{\circ}-83^{\circ} \mathrm{F}$ bin, the COP at $42 \%$ of full capacity (see left black circle in Figure 3) is 7.37 (calculation: $-5.0651 * 0.42+9.4947=7.37$ ). Before the experiments were carried out using the 2-ton iQ Drive system, the team anticipated that the 2-ton iQ Drive system operating in the same lab house would operate at an average CF of $63 \%$ of maximum $(0.42 /[2$-ton $/ 3$-ton $]=0.63)$. At a $63 \% \mathrm{CF}$ for the $78^{\circ}-83^{\circ} \mathrm{F}$ bin, $\mathrm{COP}$ would be 6.30 (calculation: $-5.0651 * 0.63+9.4947=6.30$ ). The 3 -ton system would thus be expected to operate at about $16.9 \%$ higher efficiency than the 2-ton system $(7.37 \mathrm{COP} / 6.30 \mathrm{COP}=1.169)$ under these specific conditions.

The 2-ton SEER 22 unit was performance mapped based on data from the Phase 3 experiments. Fifteen-minute COP data are plotted versus CF (Figure 4). As before, five best-fit lines and equations are plotted for five temperature bins. For each bin, COP is considerably higher when the system is operating at its lowest capacity. 


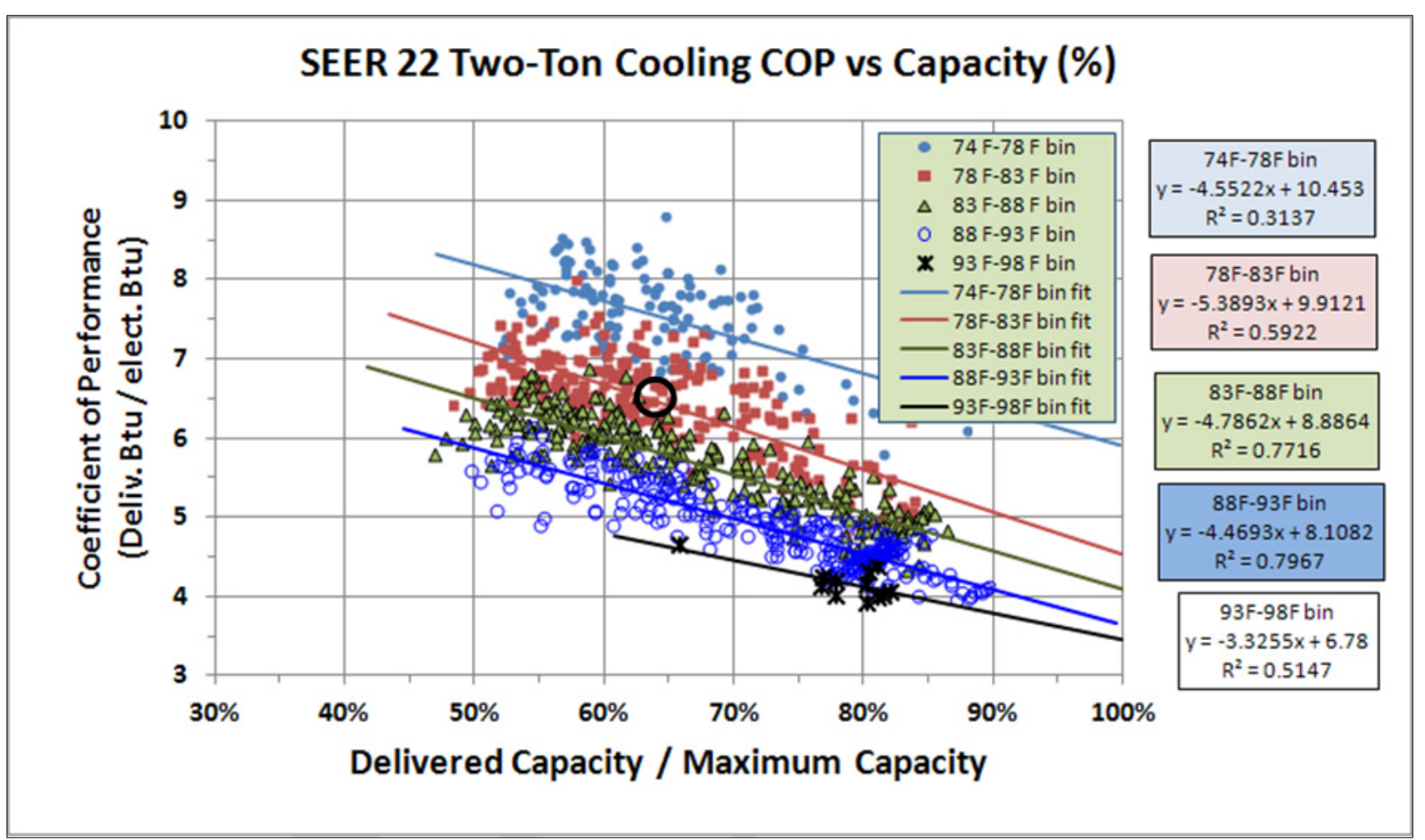

Figure 4. Measured cooling COP versus CF for the 2-ton SEER 22 system for various outdoor temperature bins (15-minute data)

When the 2-ton iQ Drive system was installed in the same lab house, the average capacity point was expected to be $63 \%$ of maximum. For the $78^{\circ}-83^{\circ} \mathrm{F}$ bin, COP at $63 \%$ of maximum capacity (see black circle in Figure 4) is calculated to be 6.52 (calculation: $-5.3893 * 0.63+9.9121=$ 6.52). This COP of 6.52 is $3.5 \%$ higher than the 6.30 estimated (predicted) from the 3-ton system performance map, which suggests that the 2-ton SEER 22 unit is somewhat more energy efficient than the 3-ton SEER 21 unit.

Figure 5 presents the measured system COP for the 2-ton and 3-ton SEER 13 heat pumps based on monitored data. As shown, the 2-ton unit has a slightly higher COP. Based on the best-fit equations and an outdoor temperature of $80^{\circ} \mathrm{F}$, the 2-ton unit has a COP of 4.07 and the 3-ton unit has a COP of 3.87. The 2-ton unit then has a COP at $80^{\circ} \mathrm{F}$ that is $5.2 \%$ higher than that of the 3-ton. This might be largely because of the higher AHU fan efficiency. (The rated energyefficiency ratio values of the 2-ton and 3-ton SEER 13 heat pumps are 11.6 and 10.8, respectively.) 


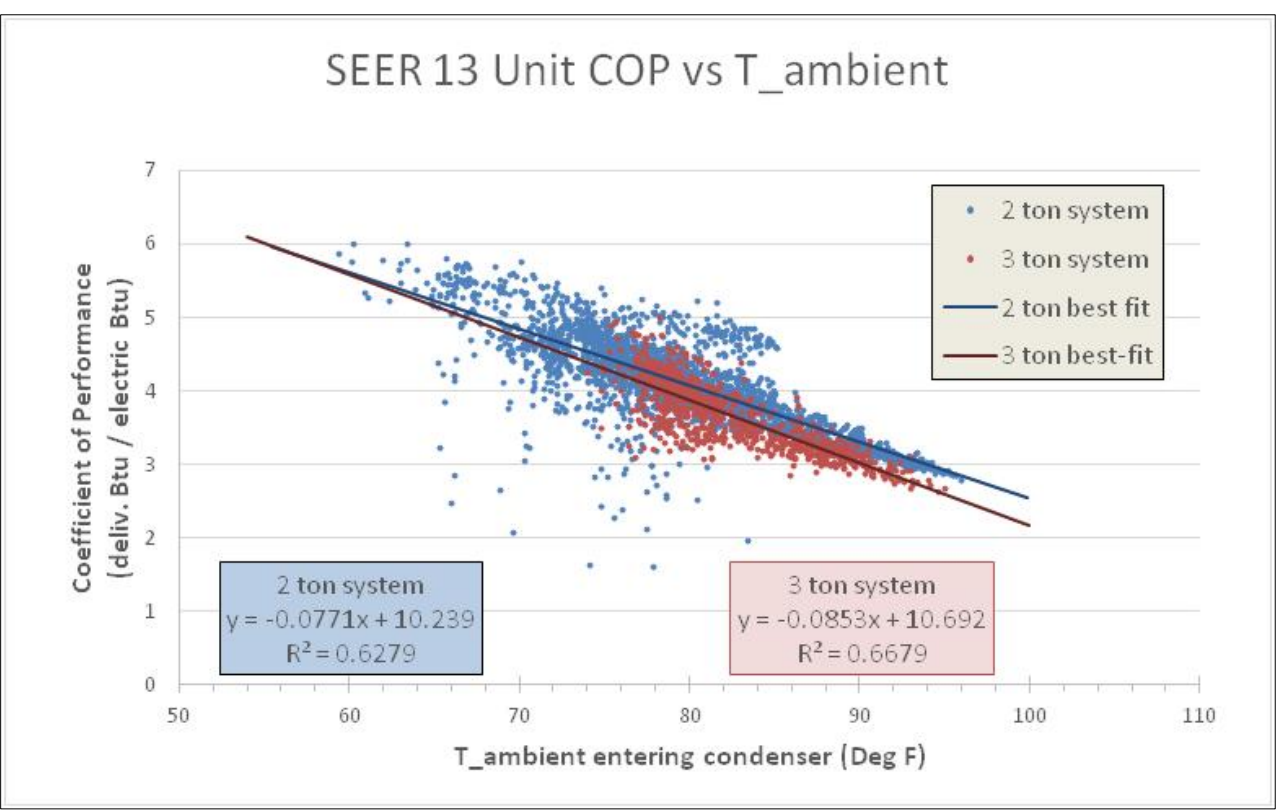

Figure 5. Measured system cooling COP for the 2-ton and 3-ton SEER 13 heat pumps as a function of outdoor temperature. At $80^{\circ} \mathrm{F}$ condenser entering temperature the 2-ton system is $5.2 \%$ more energy efficient than the 3-ton system.

As indicated earlier, the AHU fan is much more efficient in the 2-ton SEER 13 system; the fan produced $6.90 \mathrm{cfm} / \mathrm{W}$ in the 2-ton system compared to $2.90 \mathrm{cfm} / \mathrm{W}$ in the 3 -ton system. If the AHU blower in the 2-ton system had the same lower efficiency as the 3-ton system, the resulting performance maps would be those shown in Figure 6 and the 2-ton system would have a COP (at an outdoor temperature of $80^{\circ} \mathrm{F}$ ) that was $6.6 \%$ lower than that of the 3-ton system. As shown, the very high-efficiency ECM in the 2-ton system made an approximately $11.2 \%$ difference in the 2-ton SEER 13 system efficiency.

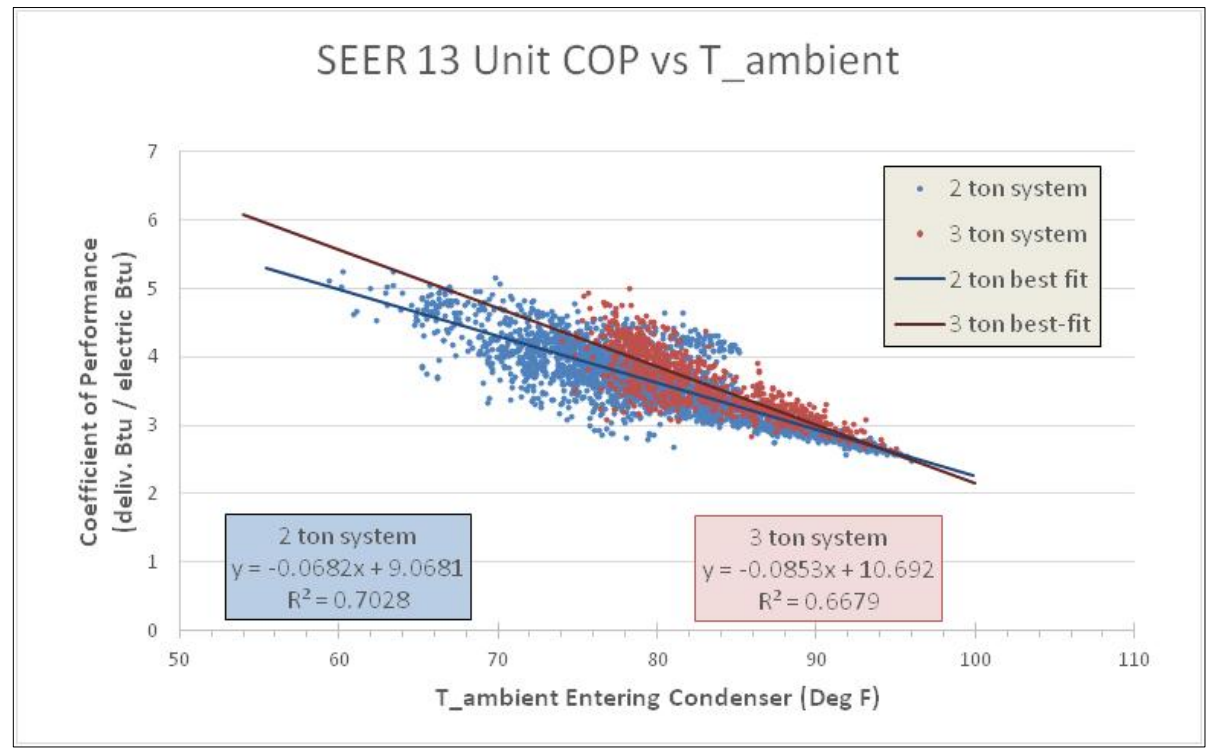

Figure 6. Measured system cooling COP for the 2-ton and 3-ton SEER 13 heat pumps as a function of outdoor temperature; the 2-ton AHU blower efficiency was adjusted to match the 3-ton AHU blower efficiency 


\subsection{Indoor and Outdoor Environmental Conditions During the Cooling Season}

The runtimes of the SEER 13 and SEER 21 systems differ substantially. This section summarizes the average runtimes and environmental conditions for diverse system configurations during different seasonal periods. Table 2 through Table 7 summarize indoor and outdoor environmental conditions during the Phase 1 and Phase 3 experiments. In Table 4 and Table 5 (Phase 3 results) the "SEER 22 indoor ducts" configuration was unavailable because repair problems and eventual equipment replacement for the 2-ton SEER 22 unit shortened the data collection periods.

Table 2 summarizes Phase 1 data using 3-ton heat pumps. It also provides average daily indoor and outdoor temperatures, $\mathrm{RH}$, and system runtime for each experimental configuration for all experiment days from May 1 through November 30, 2010. This period includes a substantial number of days that would not be considered typical hot and humid summer weather-especially in early May and throughout parts of October and November. The average values for temperatures, RHs, and runtimes are based on the number of space cooling days identified in the last rows of Table 2 through Table 7.

Table 2. Phase 1 Average Outdoor and Indoor Temperatures, Indoor RH, and Cooling System Runtimes Using 3-Ton Heat Pumps

\begin{tabular}{|c|c|c|c|c|c|c|}
\hline & $\begin{array}{l}\text { S13 }^{\mathrm{a}} \\
\text { Attic }\end{array}$ & $\begin{array}{l}\text { S21 } \\
\text { Attic }\end{array}$ & $\begin{array}{c}\text { S21 } \\
(45)^{\mathrm{c}} \text { Attic }\end{array}$ & $\begin{array}{c}\text { S13 } \\
\text { Indoor }\end{array}$ & $\begin{array}{c}\text { S21 } \\
\text { Indoor }\end{array}$ & $\begin{array}{l}\text { S21 (45) } \\
\text { Indoor }\end{array}$ \\
\hline $\begin{array}{c}\text { Average Outdoor Dry Bulb } \\
\text { Temperature }\left({ }^{\circ} \mathbf{F}\right)\end{array}$ & 75.2 & 79.5 & 81.4 & 80.5 & 78.1 & 75.0 \\
\hline $\begin{array}{c}\text { Average Outdoor Dew Point } \\
\text { Temperature }\left({ }^{\circ} \mathbf{F}\right)\end{array}$ & 65.2 & 70.1 & 70.7 & 68.8 & 67.9 & 64.3 \\
\hline Average Indoor Temperature $\left({ }^{\circ} \mathbf{F}\right)$ & 76.9 & 76.6 & 77.0 & 77.8 & 76.3 & 76.0 \\
\hline$d T^{d}\left({ }^{\circ} F\right)$ & -1.7 & 2.9 & 4.4 & 2.7 & 1.8 & -1.0 \\
\hline Indoor RH & 48.4 & 52.9 & 50.9 & 48.7 & 54.9 & 53.2 \\
\hline Cooling System Runtime (\%) & 25.2 & 60.7 & 67.4 & 29.4 & 52.1 & 44.7 \\
\hline Number of Days Included & 45 & 38 & 21 & 25 & 32 & 23 \\
\hline
\end{tabular}

${ }^{\mathrm{a}} \mathrm{S} 13=$ SEER 13 system

${ }^{\mathrm{b}} \mathrm{S} 21$, SEER 21 system

${ }^{\mathrm{c}} \mathrm{S} 21(45)=$ SEER 21 system set to $45 \%$ RH control

${ }^{\mathrm{d}}$ Delta temperature (outdoor temperature minus indoor temperature)

Table 3 summarizes Phase 1 data using 3-ton heat pumps of average daily indoor and outdoor dry bulb temperature, outdoor dew point temperature, indoor $\mathrm{RH}$, and system runtime for each experimental configuration for all experiment days from May 1 through November 30, 2011, when the outdoor dew point temperature was $70^{\circ} \mathrm{F}$ or higher-in other words, for days that can be considered primarily hot and humid. 
Table 3. Average Outdoor and Indoor Temperatures, Indoor RH, and Cooling System Runtimes for Hot and Humid Days Using 3-Ton Heat Pumps

\begin{tabular}{|c|c|c|c|c|c|c|}
\hline & $\begin{array}{c}\text { S13 } \\
\text { Attic }\end{array}$ & $\begin{array}{c}\text { S21 } \\
\text { Attic }\end{array}$ & $\begin{array}{l}\text { S21 (45) } \\
\text { Attic }\end{array}$ & $\begin{array}{c}\text { S13 } \\
\text { Indoor }\end{array}$ & $\begin{array}{c}\text { S21 } \\
\text { Indoor }\end{array}$ & $\begin{array}{l}\text { S21 (45) } \\
\text { Indoor }\end{array}$ \\
\hline $\begin{array}{c}\text { Average Outdoor Dry Bulb } \\
\text { Temperature }\left({ }^{\circ} \mathbf{F}\right)\end{array}$ & 81.2 & 80.4 & 82.1 & 83.9 & 82.9 & 81.3 \\
\hline $\begin{array}{c}\text { Average Outdoor Dew Point } \\
\text { Temperature }\left({ }^{\circ} \mathrm{F}\right)\end{array}$ & 72.4 & 71.9 & 72.4 & 73.4 & 72.5 & 72.1 \\
\hline Average Indoor Temperature $\left({ }^{\circ} \mathbf{F}\right)$ & 77.4 & 76.7 & 77.1 & 77.9 & 76.7 & 76.6 \\
\hline dT $\left({ }^{\circ} \mathbf{F}\right)$ & 3.8 & 3.7 & 5.0 & 6.0 & 6.2 & 4.7 \\
\hline Indoor RH & 48.7 & 53.1 & 50.7 & 49.6 & 54.9 & 53.4 \\
\hline Cooling System Runtime (\%) & 35.8 & 66.2 & 70.0 & 35.4 & 69.6 & 64.7 \\
\hline Number of Days Included & 14 & 28 & 13 & 14 & 17 & 6 \\
\hline
\end{tabular}

Table 4 summarizes Phase 3 data using 2-ton heat pumps of average daily outdoor dry bulb and dew point temperature, indoor dry bulb temperature and $\mathrm{RH}$, and system runtime for each experimental configuration for all experiment days when cooling occurred from May 25, 2012 through July 22, 2013. This includes a substantial number of days that would not be considered typical hot and humid summer weather.

Table 4. Average Outdoor and Indoor Temperatures, Indoor RH, and Cooling System Runtimes Using 2-Ton Heat Pumps

\begin{tabular}{|c|c|c|c|c|c|c|}
\hline & $\begin{array}{l}\text { S13 } \\
\text { Attic }\end{array}$ & $\begin{array}{c}\text { S21 } \\
\text { Attic }\end{array}$ & $\begin{array}{c}\text { S21 (45) } \\
\text { Attic }\end{array}$ & $\begin{array}{c}\text { S13 } \\
\text { Indoor }\end{array}$ & $\begin{array}{c}\text { S22 } \\
\text { Indoor }\end{array}$ & $\begin{array}{l}\text { S22 (45) } \\
\text { Indoor }\end{array}$ \\
\hline $\begin{array}{c}\text { Average Outdoor Dry Bulb } \\
\text { Temperature }\left({ }^{\circ} \mathbf{F}\right)\end{array}$ & 70.7 & 76.9 & 72.6 & 74.5 & - & 74.4 \\
\hline $\begin{array}{c}\text { Average Outdoor Dew Point } \\
\text { Temperature }\left({ }^{\circ} \mathbf{F}\right)\end{array}$ & 62.0 & 68.1 & 63.0 & 64.8 & - & 65.8 \\
\hline $\begin{array}{c}\text { Average Indoor Temperature } \\
\left({ }^{\circ} \mathbf{F}\right)\end{array}$ & 77.4 & 76.6 & 76.3 & 77.1 & - & 76.6 \\
\hline $\mathrm{dT}\left({ }^{\circ} \mathrm{F}\right)$ & -4.1 & 0.2 & -3.9 & -3.2 & - & -2.5 \\
\hline Indoor RH & 51.1 & 55.4 & 51.7 & 51.3 & - & 53.1 \\
\hline Cooling System Runtime (\%) & 31.3 & 69.2 & 55.8 & 32.7 & - & 55.5 \\
\hline Number of Days Included & 30 & 37 & 52 & 42 & - & 45 \\
\hline
\end{tabular}

Table 5 summarizes Phase 3 data using 2-ton heat pumps of average daily outdoor dry bulb and dew point temperature, indoor dry bulb temperature and $\mathrm{RH}$, and system runtime for each experimental configuration for all experiment days when cooling occurred from May 25, 2012 through July 22, 2013 when the outdoor dew point temperature was $70^{\circ} \mathrm{F}$ or higher-in other words, for days that can be considered primarily hot and humid. 
Table 5. Average Outdoor and Indoor Temperatures, Indoor RH, and Cooling System Runtimes for Hot and Humid Days Using 2-Ton Heat Pumps

\begin{tabular}{|c|c|c|c|c|c|c|}
\hline & $\begin{array}{l}\text { S13 } \\
\text { attic }\end{array}$ & $\begin{array}{l}\text { S21 } \\
\text { attic }\end{array}$ & $\begin{array}{l}\text { S21 (45) } \\
\text { attic }\end{array}$ & $\begin{array}{c}\mathrm{S13} \\
\text { indoor }\end{array}$ & $\begin{array}{c}\text { S22 } \\
\text { indoor }\end{array}$ & $\begin{array}{l}\text { S22 (45) } \\
\text { indoor }\end{array}$ \\
\hline $\begin{array}{c}\text { Average Outdoor Dry Bulb } \\
\text { Temperature }\left({ }^{\circ} \mathbf{F}\right)\end{array}$ & 78.1 & 79.6 & 78.8 & 80.1 & - & 77.8 \\
\hline $\begin{array}{c}\text { Average Outdoor Dew Point } \\
\text { Temperature }\left({ }^{\circ} \mathbf{F}\right)\end{array}$ & 73.1 & 71.0 & 70.8 & 71.4 & - & 71.6 \\
\hline Average Indoor Temperature $\left({ }^{\circ} \mathbf{F}\right)$ & 77.9 & 76.6 & 76.6 & 77.6 & - & 77.0 \\
\hline dT $\left({ }^{\circ} \mathbf{F}\right)$ & -0.1 & 3.1 & 2.0 & 2.3 & - & 0.3 \\
\hline Indoor RH & 50.2 & 55.3 & 51.8 & 50.9 & - & 53.5 \\
\hline Cooling System Runtime (\%) & 42.6 & 80.4 & 80.5 & 46.8 & - & 69.1 \\
\hline Number of Days Included & 11 & 20 & 8 & 6 & - & 12 \\
\hline
\end{tabular}

Table 3 and Table 5 include only days with an ambient dew point temperature higher than $70^{\circ} \mathrm{F}$ and show that average indoor dry bulb temperature was the same for Phase 1 and Phase 3$77.1^{\circ} \mathrm{F}$. The indoor temperatures are similar; otherwise, Phase 1 and Phase 3 experiments show significant differences.

- Average ambient dry bulb temperature was much higher in Phase 1 than in Phase 3; the average was $82^{\circ} \mathrm{F}$ versus $78.9^{\circ} \mathrm{F}$, respectively, or $3.1^{\circ} \mathrm{F}$ warmer in Phase 1 .

- Indoor RH was slightly higher in Phase 3.

○ For SEER 13 operation, RH averaged 49.2\% in Phase 1 and 50.5\% in Phase 3.

- For SEER 21 attic, SEER 21 (45\%) attic, and SEER 21 (45\% indoor) operation combined, RH averaged 52.4\% in Phase 1 and $53.5 \%$ in Phase 3.

During hot and humid weather in Phase 1 and Phase 3, indoor temperature averaged about $1^{\circ} \mathrm{F}$ warmer with the SEER 13 system than with the SEER 21 system. This is attributable primarily to differences in thermostats. Even though the thermostats were in all cases set to $76^{\circ} \mathrm{F}$, room temperature varied by as much as $1.5^{\circ} \mathrm{F}$ from one configuration to another depending on which heat pump was operating. The SEER 13 and SEER 21 systems had their own separate thermostats, which were not interchangeable.

During hot and humid weather, the SEER 13 system consistently produced lower indoor RH than the 2-ton and 3-ton SEER 22 and SEER 21 systems averaged over the entire day. However, the SEER 13 system consistently produced warmer space temperatures-typically by about $1^{\circ} \mathrm{F}$. Room dry bulb temperature affects RH. As air temperature increases, RH decreases by approximately $2 \%$ for each degree Fahrenheit rise in temperature when air moisture content is held constant. Some of the lower indoor RH values with the SEER 13 systems were therefore caused by higher indoor dry bulb temperature.

- In Phase 1 (3-ton heat pumps) with attic ducts, the SEER 13 system produced 48.7\% RH. The SEER 21 system produced an average $53.1 \%$ RH in standard control mode and $50.7 \%$ in $\mathrm{RH}$ control mode (set to $45 \%$ ). If the SEER 13 room temperature were $76.7^{\circ} \mathrm{F}$, 
which was $0.7^{\circ} \mathrm{F}$ cooler than the actual $77.4^{\circ} \mathrm{F}$, the SEER 13 space RH would (all other things being equal) have increased from $48.7 \%$ to $49.8 \%$.

- In Phase 1 (3-ton heat pumps) with indoor ducts, the SEER 13 system produced $49.6 \%$ RH. The SEER 21 system produced an average 54.9\% RH in standard control mode and $53.4 \%$ in $\mathrm{RH}$ control mode (set to $45 \%$ ). If the SEER 13 room temperature were $76.7^{\circ} \mathrm{F}$, which was $1.2^{\circ} \mathrm{F}$ cooler than the actual $78.1^{\circ} \mathrm{F}$, the SEER 13 space RH would (all other things being equal) have increased from $49.6 \%$ to $51.6 \%$.

The fixed-capacity 3-ton SEER 13 system with attic and indoor ducts produced indoor RH of about $49 \%$. This is reasonably low considering the system is oversized by $60 \%-90 \%$ relative to peak load (depending on which duct system is being used) and in a very leaky lab house (ACH50 $=10.2$ ) with no mechanical ventilation. The indoor RH sensors were calibrated several times during each experimental period and remained stable throughout. This $\mathrm{RH}$ result suggests that the conventional wisdom of "oversizing of equipment yields poor RH control" should be examined and perhaps further clarified.

- In Phase 3 (2-ton heat pumps) with attic ducts, the SEER 13 system produced 50.2\% RH. The SEER 21 system produced an average 55.3\% RH in standard control mode and $51.8 \%$ in RH control mode (set to $45 \%$ ). If the SEER 13 had produced a room temperature of $76.6^{\circ} \mathrm{F}\left(1.3^{\circ} \mathrm{F}\right.$ lower than the actual temperature), the SEER 13 space RH would (all other things being equal) have increased from $50.2 \%$ to $52.4 \%$.

- In Phase 3 (2-ton heat pumps) with indoor ducts, the SEER 13 system produced 50.9\% RH. The SEER 21 system produced 53.5\% RH in RH control mode set to 45\%. Standard control mode was unavailable because the SEER 22 unit failed and the cooling season weather had ended. If the SEER 13 room temperature had been $76.7^{\circ} \mathrm{F}$, the SEER 13 space RH would (all other things being equal) have increased from $50.9 \%$ to $52.4 \%$.

The SEER 22 and SEER 21 systems in standard control mode produced slightly elevated indoor RH relative to the SEER 22 (45\%) and SEER 13 systems because they had higher cfm/ton and a resulting warmer coil temperature. About two-thirds of the approximate 5\% RH difference (relative to the SEER 13 systems) resulted from a warmer coil. The other one-third was caused by the SEER 21 thermostat maintaining a slightly lower indoor temperature. For each degree Fahrenheit that air temperature was raised, $\mathrm{RH}$ declined by about $2 \%$.

In Phase 1, system runtime during hot and humid weather was approximately twice as long for the SEER 21 system as for the SEER 13 system (Table 3) because the SEER 21 system operated mostly at or near minimum capacity-about 14,200 Btu/h. The system often stayed on for 10 hours at a time on hot summer days and then cycled occasionally during the remaining 14 hours of the day. On a typical summer day, the SEER 21 system ran for about 15.9 hours; the SEER 13 system ran for about 8.6 hours per day. This operation time differential is even greater for the SEER 21 system in RH control mode; SEER 21 operation time is about $6 \%$ longer in the $45 \%$ RH control mode than in the standard control mode. An examination of cycling during Phase 1 revealed that this system's cycling mode was 0.45 cycles/hour at $50 \%$ load factor-an order of magnitude lower than that of typical fixed-capacity systems.

In Phase 3 (as in Phase 1), system runtime was also longer for the SEER 22 system than for the SEER 13 system (Table 5). However, because outdoor temperatures were considerably warmer 
in Phase 1 than in Phase 3 (Table 3 versus Table 5), comparing the runtime of the 2-ton versus the 3-ton systems requires more screening of data for more comparable weather periods.

Table 6 and Table 7 represent hot and humid weather and compare periods with more similar ambient dry bulb temperatures for greater comparability between the Phase 1 and Phase 3 experimental periods. These tables were created from the same data sets presented in Table 3 and Table 5 by progressively excluding the hottest Phase 1 days and the coolest Phase 3 days until average ambient temperature for the sixth or fifth columns, respectively, were essentially the same for each table. Individual experimental configurations still vary considerably. The resulting indoor RH and system runtimes shown in Table 6 and Table 7 can be more meaningfully compared by selecting periods of comparable ambient temperature.

From Table 6, the following summation can be made. In Phase 1 (3-ton systems), SEER 21 had almost twice the system runtime (approximately 90\% higher) than SEER 13. Also in Phase 1, the SEER 13 system produced an average of about $47.2 \%$ indoor RH with attic and indoor ducts, the SEER 21 system produced about 51.5\% RH, and the SEER 21 (45\%) produced about 50.8\% RH.

Table 6. Average Outdoor and Indoor Temperatures, Indoor RH, and Cooling System Runtimes for Hot and Humid Days Using 3-Ton Heat Pumps With Similar Outdoor Conditions*

\begin{tabular}{|c|c|c|c|c|c|c|}
\hline & $\begin{array}{l}\text { S13 } \\
\text { Attic }\end{array}$ & $\begin{array}{l}\text { S21 } \\
\text { Attic }\end{array}$ & $\begin{array}{l}\text { S21 (45) } \\
\text { Attic }\end{array}$ & $\begin{array}{c}\text { S13 } \\
\text { Indoor }\end{array}$ & $\begin{array}{c}\text { S21 } \\
\text { Indoor }\end{array}$ & $\begin{array}{l}\text { S21 (45) } \\
\text { Indoor }\end{array}$ \\
\hline $\begin{array}{c}\text { Average Outdoor Dry Bulb } \\
\text { Temperature }\left({ }^{\circ} \mathbf{F}\right)\end{array}$ & 80.7 & 80.5 & 81.0 & 83.1 & 81.3 & 81.3 \\
\hline $\begin{array}{c}\text { Average Outdoor Dew Point } \\
\text { Temperature }\left({ }^{\circ} \mathbf{F}\right)\end{array}$ & 72.2 & 71.9 & 71.5 & 73.1 & 71.9 & 72.1 \\
\hline $\begin{array}{c}\text { Average Indoor Temperature } \\
\left({ }^{\circ} \mathbf{F}\right)\end{array}$ & 77.1 & 76.5 & 77.1 & 77.8 & 76.6 & 76.6 \\
\hline $\mathrm{dT}\left({ }^{\circ} \mathrm{F}\right)$ & 3.6 & 4.0 & 3.9 & 5.3 & 4.7 & 4.7 \\
\hline Indoor RH & 46.7 & 50.5 & 48.1 & 47.7 & 52.6 & 53.4 \\
\hline Cooling System Runtime (\%) & $35.0 \%$ & $65.4 \%$ & $67.5 \%$ & $33.7 \%$ & $60.2 \%$ & $64.7 \%$ \\
\hline Number of Days Included & 12 & 24 & 7 & 9 & 12 & 6 \\
\hline
\end{tabular}

* The data were screened so that the Phase 1 and Phase 3 data sets have comparable outdoor temperatures.

From Table 7 the following summation can be made. In Phase 3 (2-ton systems), the SEER 22 system with indoor ducts had a system runtime $66 \%$ longer than the SEER 13 system. With attic ducts, the SEER 22 system had system runtime about 33\% longer than the SEER 13 system. However, because the ambient temperature of the SEER 13 attic was somewhat warmer than the SEER 22 attic configurations $\left(81.9^{\circ} \mathrm{F}\right.$ versus $80.5^{\circ} \mathrm{F}$ and $79.8^{\circ} \mathrm{F}$, respectively), this comparison is less useful. Also in Phase 3, the SEER 13 system produced about 48.9\% indoor RH, the SEER 22 produced 54.6\% RH, and the SEER $22(45 \%)$ produced about 51.7\% RH. 
Table 7. Average Outdoor and Indoor Temperatures, Indoor RH, and Cooling System Runtimes for Hot and Humid Days Using 2-Ton Heat Pumps With Similar Outdoor Conditions*

\begin{tabular}{|c|c|c|c|c|c|c|}
\hline & $\begin{array}{c}\text { S13 } \\
\text { Attic }\end{array}$ & $\begin{array}{c}\text { S22 } \\
\text { Attic }\end{array}$ & $\begin{array}{c}\text { S22 (45) } \\
\text { Attic }\end{array}$ & $\begin{array}{c}\text { S13 } \\
\text { Indoor }\end{array}$ & $\begin{array}{c}\text { S22 } \\
\text { Indoor }\end{array}$ & $\begin{array}{l}\text { S22 (45) } \\
\text { Indoor }\end{array}$ \\
\hline $\begin{array}{c}\text { Average Outdoor Dry Bulb } \\
\text { Temperature }\left({ }^{\circ} \mathbf{F}\right)\end{array}$ & 81.9 & 80.5 & 79.8 & 80.9 & - & 80.9 \\
\hline $\begin{array}{c}\text { Average Outdoor Dew Point } \\
\text { Temperature }\left({ }^{\circ} \mathbf{F}\right)\end{array}$ & 71.8 & 71.1 & 70.9 & 71.6 & - & 71.4 \\
\hline Average Indoor Temperature $\left({ }^{\circ} \mathbf{F}\right)$ & 77.2 & 76.6 & 76.7 & 77.6 & - & 77.5 \\
\hline dT (Out-In; $\left.{ }^{\circ} F\right)$ & 4.7 & 3.9 & 3.1 & 3.3 & - & 3.4 \\
\hline Indoor RH & 46.7 & 54.6 & 50.8 & 51.1 & - & 52.5 \\
\hline Cooling System Runtime (\%) & $62.4 \%$ & $83.1 \%$ & $82.3 \%$ & $48.3 \%$ & - & $80.2 \%$ \\
\hline Number of Days Included & 7 & 15 & 5 & 4 & 0 & 6 \\
\hline
\end{tabular}

* The data were screened so that the Phase 1 and Phase 3 data sets have comparable outdoor temperatures.

\subsection{Cooling Energy Impacts of Right-Sized and Oversized Systems}

Data shown previously in Figure 3 and Figure 4 show that the iQ Drive systems (3-ton oversized and 2-ton right-sized, respectively) operate with considerably higher efficiency at lower capacity levels. The experiments of Phase 3 with 2-ton heat pumps installed have sought to verify that in fact oversized variable-capacity systems tend to increase cooling efficiency. This section presents further analysis to determine whether a discernible efficiency difference between rightsized and oversized fixed-capacity (SEER 13) heat pumps can be detected.

Daily cooling energy data plotted against the daily average temperature difference between outside and inside are shown for all 3 -ton cooling test configurations and 2-ton cooling test configurations in Figure 7 and Figure 8, respectively.

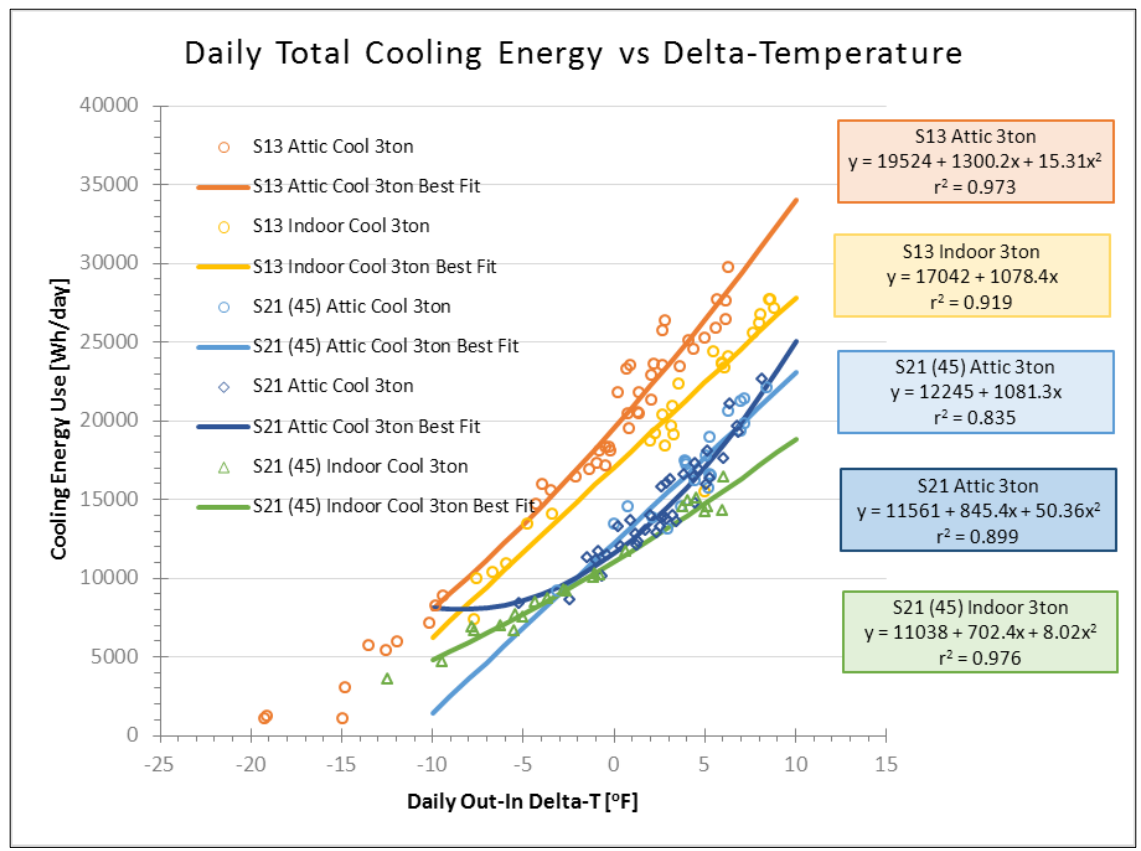

Figure 7. Cooling energy use as a function of dT (outdoor minus indoor temperature), including daily data points, best-fit lines, and best-fit equations for the 3-ton systems (Phase 1) 


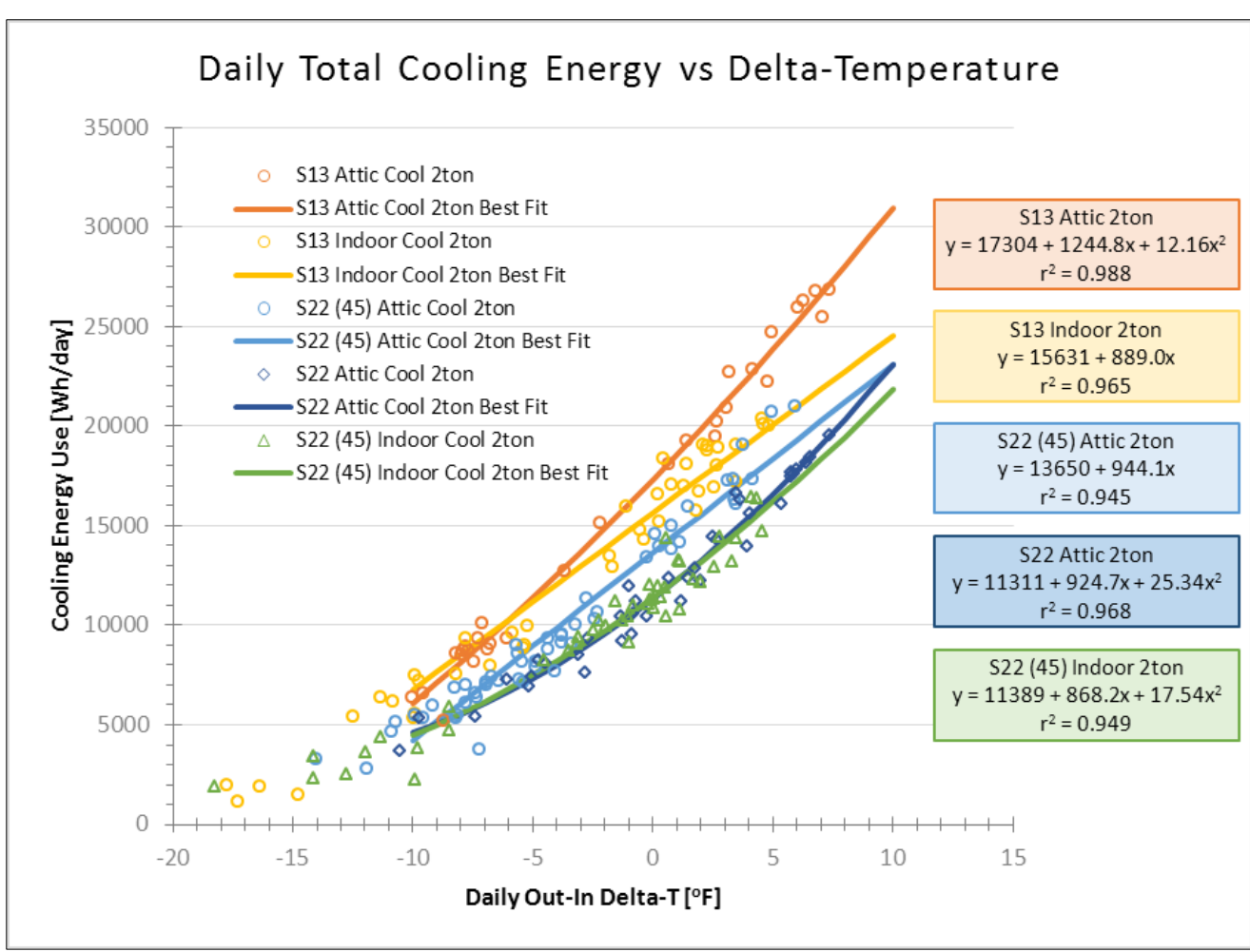

Figure 8. Cooling energy use as a function of $\mathrm{dT}$, including daily data points, best-fit lines, and best-fit equations for the 2-ton systems (Phase 3)

Head-to-head energy performance of the 2-ton versus 3-ton systems is presented in Table 8 and Figure 9 through Figure 13.

Analysis was performed to characterize the relative cooling energy consumption $(\mathrm{kWh} /$ day $)$ versus the dT of the 2-ton SEER 22 and SEER 13 units compared to the 3-ton SEER 21 and SEER 13 units when the attic ducts and indoor ducts were used and when the SEER 22 and SEER 21 units were operated in standard and RH control modes. Various plots and tables are presented in this section to compare daily cooling energy use versus daily average dT for a total of 11 test configurations (see Section 2.2 for a list of experimental configurations). The SEER 22 with indoor ducts and no RH control could not be performed because the SEER 22 two-ton equipment failed 6 months into the Phase 3 period. Thus, the 3-ton SEER 21 with indoor ducts and no RH control also drops out of figures and tables that compare the 2-ton and 3-ton systems.

Considerable effort was put into switching the experiments from one configuration to another throughout the Phase 1 and Phase 3 experimental periods (typically for 7-10 days at a time) so that a range of daily average outdoor temperatures could be obtained for each configuration. For example, during July and August 2010, most days had an average outdoor temperature of $78^{\circ}$ $82^{\circ} \mathrm{F}$ (a narrow range). By running the experiments during cooler summer periods, including parts of April, May, October, and November, a much wider dT range could be obtained, which is important for the regression analysis. For each configuration, dT was typically -11 to +8 (ambient temperature of $66^{\circ}-85^{\circ} \mathrm{F}$ ). Figure 7 and Figure 8 present the relationship between daily cooling energy use (kilowatt-hours) and dT for the Phase 1 and Phase 3 experiments, respectively. 
Analysis was performed to characterize the energy efficiency of the four tested heat pump systems. Comparisons include five configurations:

- SEER 13 2-ton versus 3-ton with attic ducts

- SEER 13 2-ton versus 3-ton with indoor ducts

- SEER 22 2-ton versus SEER 21 3-ton with attic ducts

- SEER 22 (45\%) 2-ton versus SEER 21 (45\%) 3-ton with attic ducts

- SEER 22 (45\%) 2-ton versus SEER 21 (45\%) 3-ton with indoor ducts.

SEER $22(45 \%)$ or SEER $21(45 \%)$ refers to operation of the variable-capacity heat pump systems in RH control mode set to 45\%. The SEER 22/21 (45\%) configurations are important variations because the units' standard control mode is optimized for energy savings and may not always achieve the desired level of indoor RH control.

Table 8 characterizes the cooling energy consumption performance of the fixed- and variablecapacity heat pumps data contained in Figure 7 and Figure 8, including percent energy savings that result from right-sizing the heat pumps with an indoor temperature of $77^{\circ} \mathrm{F}$ and an outdoor temperature of $82^{\circ} \mathrm{F}$ (a typical summer day). The coefficients developed from least square regression analysis are shown in Table 8 . Two models were used in the analysis in this section. Either a second-order polynomial was used in the form:

$$
Y=A+B * d T+C * d T^{2}
$$

Or a linear model was used in the following form:

$$
Y=A+B * d T
$$

The linear model was used if the $\mathrm{C}$ term was not statistically significant (at a $90 \%$ confidence level).

Where:

$\mathrm{Y}$ is the cooling energy use in Wh/day

A is the constant

$\mathrm{B}$ is the first-order coefficient

$\mathrm{C}$ is the second-order coefficient

$\mathrm{dT}$ is the daily average difference in temperature between outdoors and indoors.

Each configuration was tested to determine whether a polynomial fit added to the significance of the regression. The linear model was used for systems that did not pass with a $90 \%$ confidence level. Otherwise, the second-order polynomial fit was used. If a system was determined to use a linear model, the corresponding system at a different capacity was also modeled as linear to preserve the accuracy of the comparison. 
Table 8. Regression Analysis Results and Energy Consumption for 2-Ton (Right-Sized) and 3-Ton (Oversized) Heat Pumps ${ }^{\mathrm{a}}$

\begin{tabular}{|c|c|c|c|c|c|c|c|c|c|}
\hline $\begin{array}{c}\text { Heat Pump } \\
\text { System }\end{array}$ & $\begin{array}{l}\text { Size } \\
\text { (tons) }\end{array}$ & $\begin{array}{c}\text { Duct } \\
\text { System }\end{array}$ & $\mathbf{R}^{2 \mathbf{b}}$ & $\mathbf{A}$ & B & $\mathbf{C}$ & $\begin{array}{c}\text { Energy Use } \\
\text { at } 5^{\circ} \mathbf{F} \text { dT } \\
(\mathbf{k W h} / \mathrm{d})\end{array}$ & $\begin{array}{c}\text { Error }^{c} \\
( \pm)\end{array}$ & $\begin{array}{c}\text { \% Energy } \\
\text { Savings } \\
\text { From } \\
\text { Right- } \\
\text { Sizing } \\
\end{array}$ \\
\hline SEER 13 & 2 & Attic & 0.99 & 17304 & 1244.8 & 12.16 & 23.8 & 0.5 & $9.75 \%$ \\
\hline SEER 13 & 3 & Attic & 0.97 & 19524 & 1300.2 & 15.31 & 26.4 & 0.7 & - \\
\hline SEER 13 & 2 & Indoor & 0.97 & 15631 & 889.0 & 0.00 & 20.1 & 0.6 & $10.51 \%$ \\
\hline SEER 13 & 3 & Indoor & 0.92 & 17042 & 1078.4 & 0.00 & 22.4 & 0.8 & - \\
\hline SEER 22 (45) & 2 & Attic & 0.95 & 13650 & 944.1 & 0.00 & 18.5 & 0.6 & $-4.07 \%$ \\
\hline SEER 21 (45) & 3 & Attic & 0.84 & 12245 & 1081.3 & 0.00 & 17.7 & 0.6 & - \\
\hline SEER 22 & 2 & Attic & 0.97 & 11311 & 924.7 & 25.34 & 16.6 & 0.4 & $\mathrm{~N} / \mathrm{A}^{\mathrm{c}}$ \\
\hline SEER 21 & 3 & Attic & 0.90 & 11561 & 845.4 & 50.36 & 17.0 & 0.4 & - \\
\hline SEER 22 (45) & 2 & Indoor & 0.95 & 11389 & 868.2 & 17.54 & 16.2 & 0.8 & $-9.61 \%$ \\
\hline SEER 21 (45) & 3 & Indoor & 0.98 & 11038 & 702.4 & 8.02 & 14.8 & 0.4 & - \\
\hline
\end{tabular}

${ }^{\text {a }}$ For 10 experimental configurations (with SEER 13 and SEER 22/21 units with and without RH control for the iQ Drive system) for $5^{\circ} \mathrm{F} \mathrm{dT}$, which represents a typical summer day $\left(77^{\circ} \mathrm{F}\right.$ indoors and $82^{\circ} \mathrm{F}$ outdoors)

${ }^{\mathrm{b}} \mathrm{R}^{2}=$ coefficient of determination

${ }^{\mathrm{c}}$ Error is the extent of the $95 \%$ confidence interval for this regression. For example, the energy use at a $\mathrm{dT}$ value of $5^{\circ} \mathrm{F}$ is modeled to be $23.8 \mathrm{kWh} /$ day $\pm 0.5 \mathrm{kWh} /$ day (or $23.3-24.3 \mathrm{kWh} /$ day) at a $95 \%$ confidence level.

${ }^{\mathrm{b}}$ For the SEER 21/22 attic duct configuration, the data showed no statistically significant difference in energy performance between the 2-ton and 3-ton systems.

Figure 9 through Figure 13 present the same cooling energy consumption data that are included in Figure 7 and Figure 8; however, they compare the energy consumption patterns of the respective 2-ton systems versus the 3-ton systems and show the energy-efficiency impacts of right-sizing and oversizing for the five configurations previously listed.

Even though statistical significance supports the polynomial model for the SEER 21 attic 3-ton system, Figure 7 and Figure 12 show a pronounced upturn in predicted energy at low dT for this configuration because the data at lower dT are unavailable. This particular model should be limited to use for $\mathrm{dT}>-3$. Savings were calculated for this report for seasonal averages that have a dT that is significantly higher than the lower ranges shown in the plots of daily cooling energy.

Figure 9 through Figure 13 portray energy-efficiency increases or reductions that result from right-sized or oversized systems. The comparisons of the 2-ton and 3-ton systems may be somewhat incompatible for two reasons:

- The SEER ratings of the iQ Drive heat pumps decrease from 22 to 21 between the 2-ton system and the 3-ton system.

- Although the SEER ratings of the 2-ton and 3-ton fixed-capacity heat pumps are both 13, the energy efficiency of the AHU blower motor declined dramatically from the 2-ton to the 3-ton system. AHU fan energy efficiency decreased from $6.90 \mathrm{cfm} / \mathrm{W}$ (829 cfm using 
$120 \mathrm{~W})$ for the 2-ton system to $2.90 \mathrm{cfm} / \mathrm{W}$ (1,286 cfm using $444 \mathrm{~W})$ for the 3-ton system.

In a typical SEER 13 system, the AHU blower consumes $15 \%-20 \%$ of the unit's total energy. In the 3-ton SEER 13 unit, the blower consumes $17.6 \%$ of the system energy; the blower in the 2ton SEER 13 unit consumes only 5.6\% of the system energy. (See Section 1.2 for more discussion of the energy consumption rates of the AHU fans; also see Figure 5 and Figure 6 to understand the relative efficiency of the SEER 13 heat pumps and the importance of the AHU fan efficiency to system COP.)

Figure 9 shows cooling energy performance (Wh/day versus dT) for the 2-ton and 3-ton SEER 13 heat pumps with attic ducts. Based on the regression analysis, the right-sized (2-ton SEER 13) system used $9.8 \%$ less energy at $\mathrm{dT}=5^{\circ} \mathrm{F}$ per unit of cooling load compared to the oversized (3ton SEER 13) system when the attic ductwork was used (also see Table 8). In Table 8, negative energy savings from right-sizing (right column) means that oversizing reduced the seasonal cooling energy consumption.

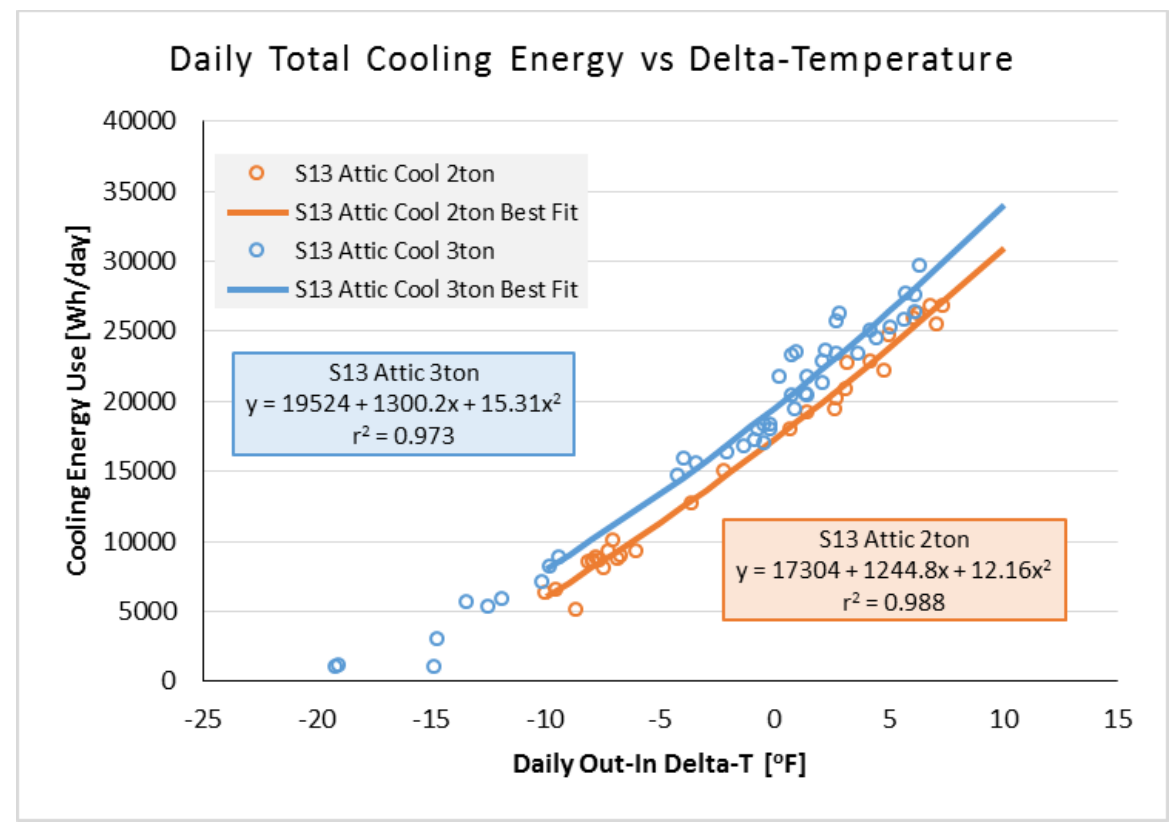

Figure 9. Cooling energy use as a function of dT for the 2-ton and 3-ton SEER 13 units with attic ducts

Figure 10 shows cooling energy performance (Wh/day versus dT) for the 2-ton and 3-ton SEER 13 heat pumps with indoor ducts. Based on regression analysis, the right-sized (2-ton SEER 13) system used $5.8 \%$ less energy at $\mathrm{dT}=5^{\circ} \mathrm{F}$ per unit of cooling load compared to the oversized (3-ton SEER 13) system when the indoor ductwork was used (Table 8).

Figure 11 shows cooling energy performance (Wh/day versus dT) for the 2-ton and 3-ton iQ Drive (SEER 22 and SEER 21) heat pumps with attic ducts and RH control activated (at 45\%). Based on regression analysis, the 3-ton system (with attic ducts and RH control activated) used $4.1 \%$ less energy per unit of cooling compared to the 2-ton system during typical cooling season weather. This plot shows that the 3-ton system had higher relative efficiency on cooler summer 
days (toward the left side of Figure 11 ). At $0^{\circ} \mathrm{F}$ dT, the 3-ton system used $10.3 \%$ less energy per unit of cooling. Over an entire cooling season, $2^{\circ} \mathrm{F}$ might well represent typical load-weighted $\mathrm{dT}$, at which point the 3-ton system used 7.3\% less energy. Therefore, for this test configuration oversizing yields significant efficiency improvement compared to right-sizing.

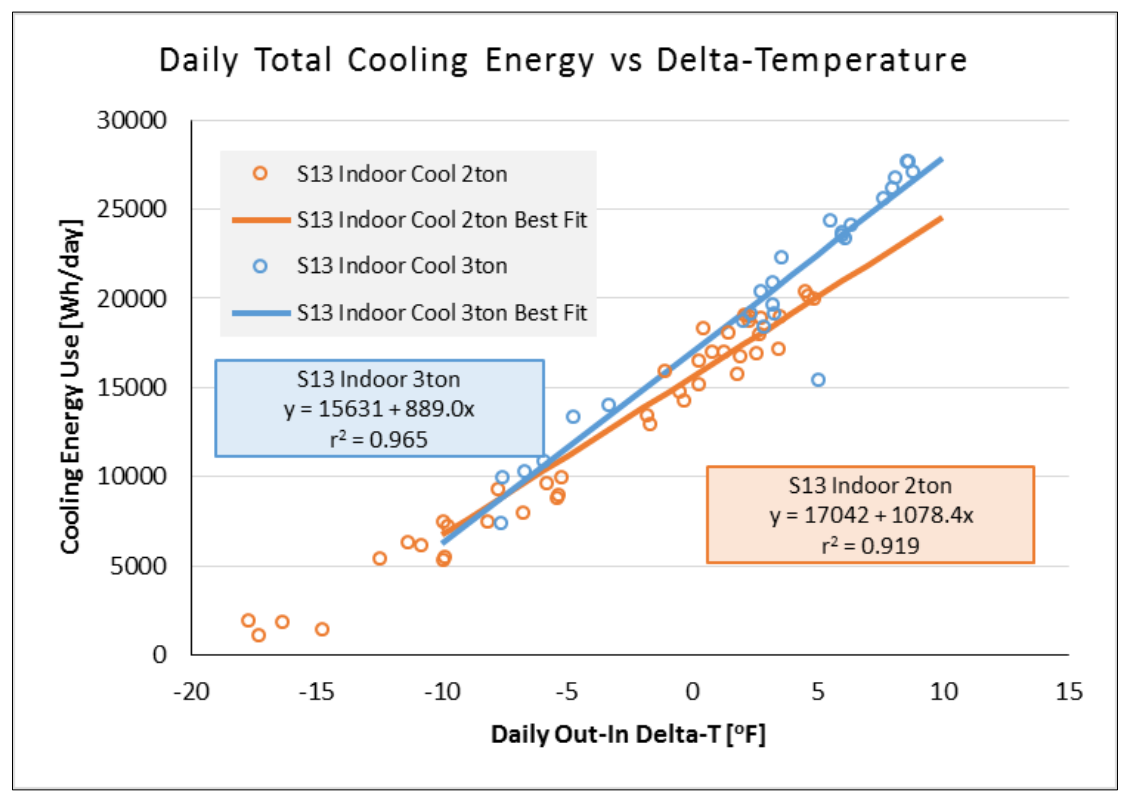

Figure 10. Cooling energy use as a function of dT for the 2-ton and 3-ton SEER 13 units with indoor ducts

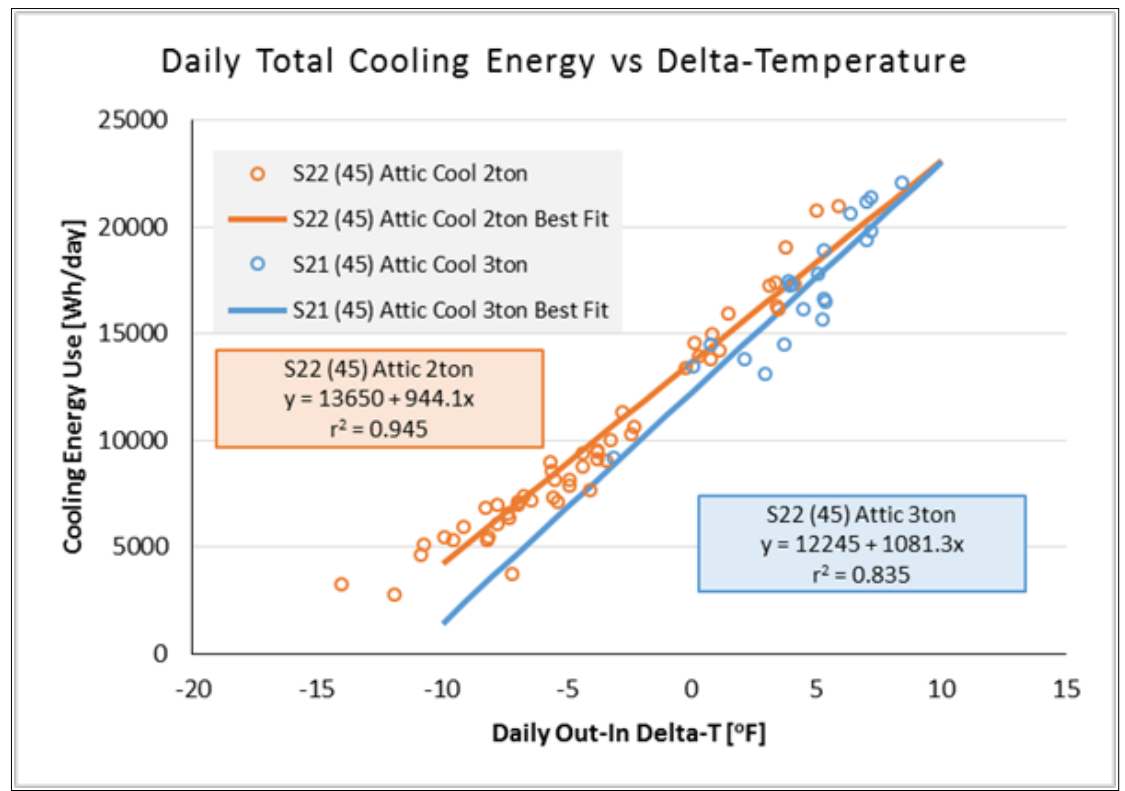

Figure 11. Cooling energy use as a function of dT for the 2-ton and 3-ton iQ Drive (SEER 22 and SEER 21) units with attic ducts with RH control activated at $45 \%$

Figure 12 shows cooling energy performance (Wh/day versus dT) for the 2-ton and 3-ton iQ Drive heat pump systems with attic ducts and RH control deactivated. The available data showed no statistically significant difference between 2-ton and 3-ton systems for this configuration at 
$90 \%$ confidence, so no assertion about the energy savings of an oversized variable-capacity system can be made in this case. The p-value for this comparison was 0.129 , which suggests significance at an $87.1 \%$ confidence level.

Figure 13 shows cooling energy performance (Wh/day versus dT) for the 2-ton and 3-ton iQ Drive heat pumps with indoor ducts and $\mathrm{RH}$ control activated (at 45\%). Based on regression analysis, the oversized (3-ton) system with indoor ducts and RH control activated used 9.6\% less energy per unit of cooling load compared to the right-sized (2-ton) system during typical cooling season weather.

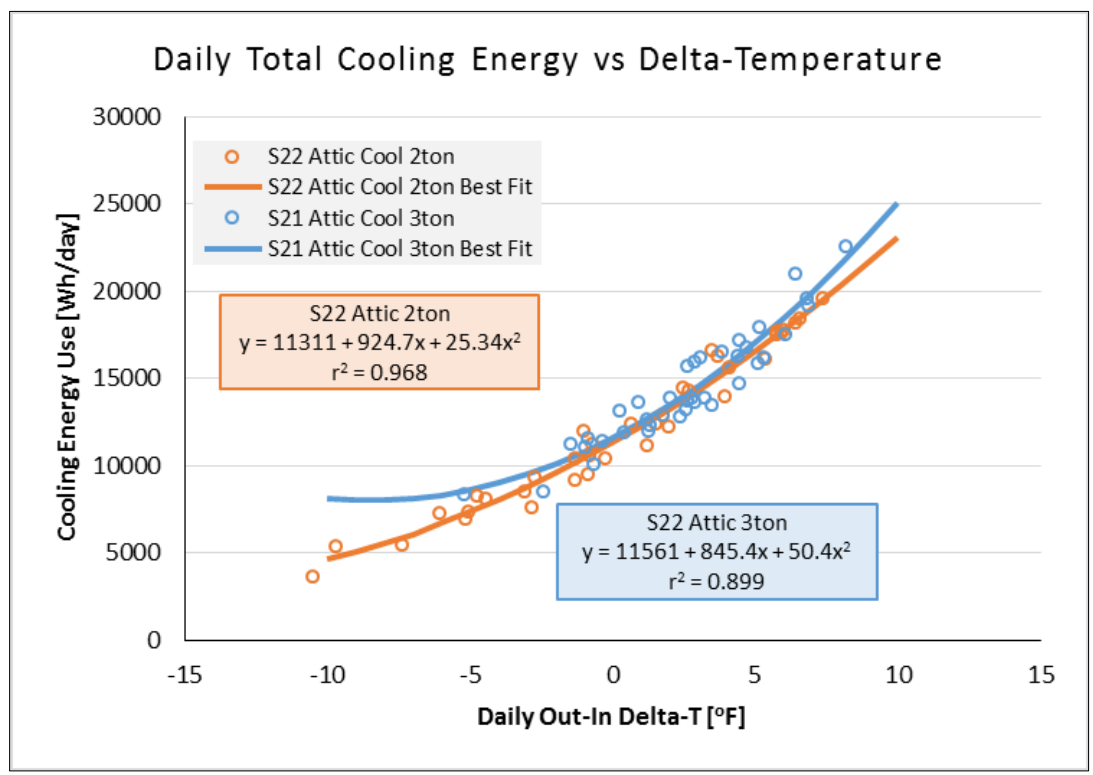

Figure 12. Cooling energy use as a function of $\mathrm{dT}$ for the 2-ton and 3-ton iQ Drive (SEER 22 and SEER 21) units with attic ducts with RH control activated at $45 \%$

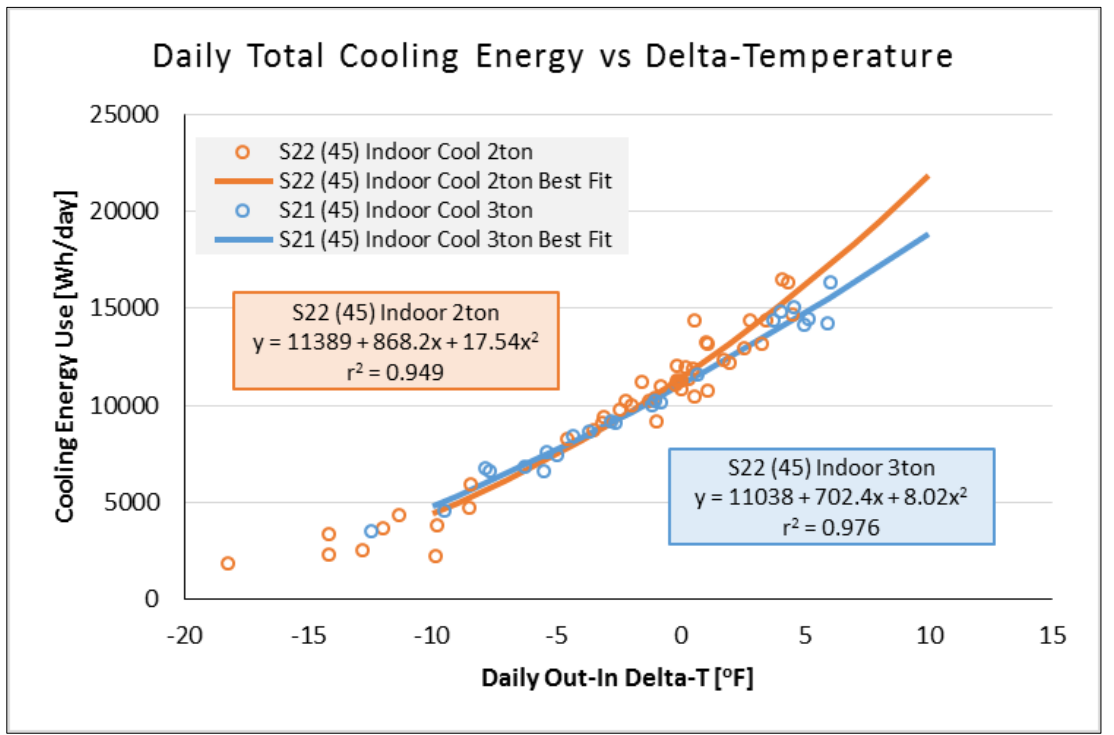

Figure 13. Cooling energy use as a function of $d T$ for the 2-ton and 3-ton iQ Drive (SEER 22 and SEER 21) units with indoor ducts and RH control activated (at $45 \%$ ) 


\subsection{Cooling Energy Impacts of System Sizing for a Typical Summer Day}

Table 8 presents the same information that is included in Figure 7 through Figure 13; daily cooling energy use was calculated for a dT of $5^{\circ} \mathrm{F}$. Because the average indoor temperature set point is considered to be $76^{\circ} \mathrm{F}$, this calculation is based on a summer day with an average temperature of $81^{\circ} \mathrm{F}$. Table 8 summarizes the regression analysis results for five experimental configurations for the 2-ton heat pumps compared to five experimental configurations for the 3 ton heat pumps.

Values for $\mathrm{R}^{2}$ are generally high for these regression analyses; these average 0.94 for the 10 experimental configurations and indicate that approximately $94 \%$ of the variability in daily cooling energy use is predicted by dT alone. Nine of the $10 \mathrm{R}^{2}$ values are 0.90 or higher; the configuration with the lowest $\mathrm{R}^{2}$ value is Phase 1 SEER $21(45 \%)$ attic with an $\mathrm{R}^{2}$ value of 0.84 .

What conclusions can be drawn from the results shown in Table 8? The right-sized SEER 13 unit (which replaced a 3-ton unit with a 2-ton unit) saved an average of $10.2 \%$ compared to the oversized 3-ton system. This is consistent with the authors' expectations. The efficiency apparently improved because:

- The two SEER 13 systems do not have equal energy efficiency. Based on monitored performance, the 2 -ton system is $4.6 \%$ more energy efficient than the 3 -ton system (Figure 5).

- Efficiency losses occurred at the start and end of each cooling cycle and the 2-ton system has fewer cycles, which resulted in smaller cycling losses. If the $4.6 \%$ efficiency advantage of the 2 -ton system were removed, right-sizing would yield $5.6 \%$ cooling energy savings (calculation: $10.2 \%-4.6 \%=5.6 \%$ ).

The savings for the oversized SEER 21/22 system with no RH control was $-2.8 \%$, which indicates that oversizing did not save energy; however, this particular result was statistically insignificant. The data in Figure 12 suggest that this evaluation could have benefited from more 3 -ton system data at lower dT and more 2-ton data at higher dT. All other savings results were statistically significant. Based on the SEER 21/21 with RH control on attic and indoor duct systems, oversizing the SEER 21 (replacing the 2-ton unit with the 3-ton unit) saved $6.9 \%$ cooling energy for the average of the 3 SEER $21 / 22$ systems. This means that on average, the right-sized (2-ton) SEER 22 system consumed about $6.9 \%$ more energy than the oversized unit. That the oversized variable-capacity system is more efficient than the right-sized system is also consistent with the authors' expectations. Even though the oversized variable-capacity system had more start and stop cycles, the substantial increase in system efficiency when the unit operated at lower capacity had even greater influence than the increased cycling (Figure 3 and Figure 4).

The efficiency increase from system oversizing was more substantial than even the indicated $6.9 \%$ because the 2 -ton system is more efficient based on its SEER rating. The 2-ton unit has an efficiency rating of SEER 22 and the 3-ton system has an efficiency rating of SEER 21. Based on the SEER ratings alone (22 divided by $21=1.048$ ), the 2 -ton system is indicated to be $4.8 \%$ more energy efficient. All things being otherwise equal, the 2-ton unit is expected to be nearly $5 \%$ more efficient. So the fact that the 3 -ton system is $6.9 \%$ more efficient than the 2 -ton system indicates that the 3 -ton system overcame the inherent $4.8 \%$ higher SEER rating of the 2-ton 
system and added $6.9 \%$ onto that. Thus, the oversized heat pump apparently improved efficiency by $11.7 \%$ over the right-sized heat pump because it operated on average at about $42 \%$ of full nominal capacity and the 2 -ton system operated at an average of about $63 \%$ of full nominal capacity.

Monitored data also confirm higher steady-state efficiency of the variable-capacity 2-ton unit but significantly higher efficiency of the 3 -ton system when matched at equal absolute capacities. The relative performance of the 2-ton and 3-ton systems can be examined in several ways. Because average ambient dry bulb temperature during cooling system operation was around $80^{\circ} \mathrm{F}$, the $78^{\circ}-83^{\circ} \mathrm{F}$ temperature bin is the most representative of seasonal cooling operation. For this evaluation, regression equations of $y=-5.3893 \mathrm{x}+9.9121\left(2\right.$-ton for $\left.78^{\circ}-83^{\circ} \mathrm{F}\right)$ and $\mathrm{y}=-$ $5.0651 \mathrm{x}+9.4947\left(3\right.$-ton for $\left.78^{\circ}-83^{\circ} \mathrm{F}\right)$ are used to calculate COP, where $\mathrm{x}$ is CF (see equations in Figure 3 and Figure 4, respectively). The following calculations (summarized in Table 9) help explain and account for the efficiency outperformance of the 3-ton variable-capacity system versus the 2-ton system.

The 3-ton iQ Drive system operating at $0.42 \mathrm{CF}$ has approximately the same capacity as the 2-ton iQ Drive system operating at $0.63 \mathrm{CF}$.

- COPs for the 3-ton system were 7.367 at $0.42 \mathrm{CF}$ and 6.304 at $0.63 \mathrm{CF}$ based on the previously listed regression equations. COP was therefore $16.9 \%$ higher at 0.42 versus $0.63 \mathrm{CF}$.

- COPs for the 2-ton system were 7.649 at $0.42 \mathrm{CF}$ and 6.517 at $0.63 \mathrm{CF} ; 17.4 \%$ higher at 0.42 versus $0.63 \mathrm{CF}$. At these two CFs, the 2-ton unit had COPs that were $3.8 \%$ and $3.4 \%$ higher than those of the 3-ton system, respectively, which confirmed the higher efficiency as indicated by the 2-ton system's higher SEER rating (rounding errors occur when SEER ratings are computed).

- During actual seasonal operation, the 3-ton system operates at an average of $0.42 \mathrm{CF}$ and the 2-ton system operates at an average of $0.63 \mathrm{CF}$. A comparison of COP at $0.42 \mathrm{CF}$ for the 3-ton system versus COP at $0.63 \mathrm{CF}$ for the 2-ton system (each with approximately the same absolute cooling capacity) shows a COP of 7.367 for the 3-ton versus a COP of 6.517 for the 2 -ton. The 3 -ton system's COP at $0.42 \mathrm{CF}$ is $13 \%$ higher than that of the 2 ton system at $0.63 \mathrm{CF}$. Also, at these relative CFs, the 2-ton SEER 22 unit has $11.5 \%$ lower efficiency than the 3-ton SEER 21 unit.

Table 9. Regression Equations Used To Calculate COP *

\begin{tabular}{c|c|c|c|}
\hline System & COP at 0.42 CF & COP at 0.63 CF & \% higher COP \\
\hline 3-Ton & 7.367 & 6.304 & $16.9 \%$ \\
2-Ton & 7.649 & 6.517 & $17.4 \%$ \\
\% Higher COP $\rightarrow$ & $3.8 \%$ & $3.4 \%$ & $13.0 \%$ \\
\hline$-5.3893 \mathrm{x}+9.9121\left(2\right.$-ton for $78^{\circ}-83^{\circ} \mathrm{F}$ bin) and $\mathrm{y}=-5.0651 \mathrm{x}+9.4947\left(3\right.$-ton for $78^{\circ}-83^{\circ} \mathrm{F}$ bin) where $\mathrm{x}$ is
\end{tabular}

$* \mathrm{y}=-5.3893 \mathrm{x}+9.9121\left(2\right.$-ton for $78^{\circ}-83^{\circ} \mathrm{F}$ bin) and $\mathrm{y}=-5.0651 \mathrm{x}+9.4947\left(3\right.$-ton for $78^{\circ}-83^{\circ} \mathrm{F}$ bin) where $\mathrm{x}$ is CF; 7.367 COP is $13 \%$ higher than $6.517 \mathrm{COP}$

The preceding analysis shows that the monitored seasonal energy savings of $11.7 \%$ fell short of the $13 \%$ higher efficiency expectation based on the performance mapping shown in Figure 3 and Figure 4 . Some of the difference may have been caused by greater cycling losses that occur because the 3-ton system cycles off more frequently. 
Surprisingly, the SEER 21/22 oversizing evaluation did not find statistically significant savings and linear models had higher confidence than polynomial models for four cases. An alternative method of cooling energy savings analysis was implemented using a multiple linear regression (MLR) approach. This evaluation method uses more variables, including accounting for the efficiency differences of the 2-ton versus 3-ton systems. The MLR results were similar, on average, to the polynomial and linear regression analysis results reported in this section. Although the MLR provided more reasonable results in several cases, it also demonstrated clearly incorrect results for the SEER 21 3-ton with RH control and attic duct system configuration. The authors have thus stayed with the linear and polynomial regression analysis results (see Appendix B for the MLR analysis details).

The MLR evaluation process uses more variables and accounts for the efficiency differences of the SEER 21/22 systems. The average savings of the three SEER 21/22 sets of configurations was $12.4 \%$ based on MLR. The SEER 21/22 test with attic ducts and no RH control had 10.4\% savings from oversizing based on MLR, which is in stark contrast to the polynomial fit that resulted in $-2.8 \%$ estimated savings from oversizing that was reported earlier $(+4.8$ for SEER adjustment $=$ net $2 \%$ ). The average savings from undersizing the fixed-capacity tests was $7.9 \%$ (compared to $10.2 \%$ from the earlier analysis in this section).

The MLR method also resulted in positive savings results for all oversized variable-capacity system tests and for all undersized fixed-capacity system tests. However, initial MLR results demonstrated clearly incorrect results for the SEER 213 -ton with RH control and attic duct system. They predicted lower SEER 21 energy use relative to a predicted 3-ton adjustment to SEER 22, which was not logical. Although MLR is statistically valid to use, the research team later determined that specific combinations of RH control variables had unrealistic impacts. After eliminating some variable combinations, the team found that the model had improved. The fact that some variable combinations can be statistically valid and yet lead to bad results has made the authors cautious about relying on the MLR method. On the other hand, the MLR results are similar, on average, to the polynomial and linear analysis results reported in this section. 


\section{Impacts of Right-Sizing on Peak Cooling Energy Demand}

Analysis was performed to identify the peak cooling demand that occurs with the 2-ton and 3ton, fixed-capacity and variable-capacity heat pumps - with and without RH control active in the variable-capacity systems - and with attic and indoor ducts. Regression analysis was used to determine peak electricity demand as a function of system sizing relative to load. Monitored hourly cooling energy use between 2 p.m. and 7 p.m. from a group of six or more hotter-thanaverage available summer days were selected for each experimental configuration. The cooling energy consumption for each selected hour was plotted versus the outdoor-indoor temperature differential for that hour.

\subsection{Cooling Peak Demand Associated With System Sizing}

Figure 14 through Figure 18 show the cooling peak demand analysis from data obtained from Phase 1 (3-ton systems) and Phase 3 (2-ton systems).

- Figure 14 and Figure 15 show comparisons of peak demand for 2-ton and 3-ton capacity SEER 13 systems when the attic and indoor ductwork, respectively, were used.

- Figure 16 shows comparisons of peak demand for 2-ton and 3-ton capacity SEER 22 and SEER 21 systems when the attic ductwork was used with standard control.

- Figure 17 and Figure 18 show comparisons of peak demand for 2-ton and 3-ton capacity SEER 21 and SEER 22 systems when the attic and indoor ductwork, respectively, were used with RH control set to $45 \%$.

Figure 14 shows that the peak demand produced by the SEER 132 -ton system at $17^{\circ} \mathrm{F}$ dT is $9.2 \%$ lower than that produced by the 3 -ton system when attic ducts were used.

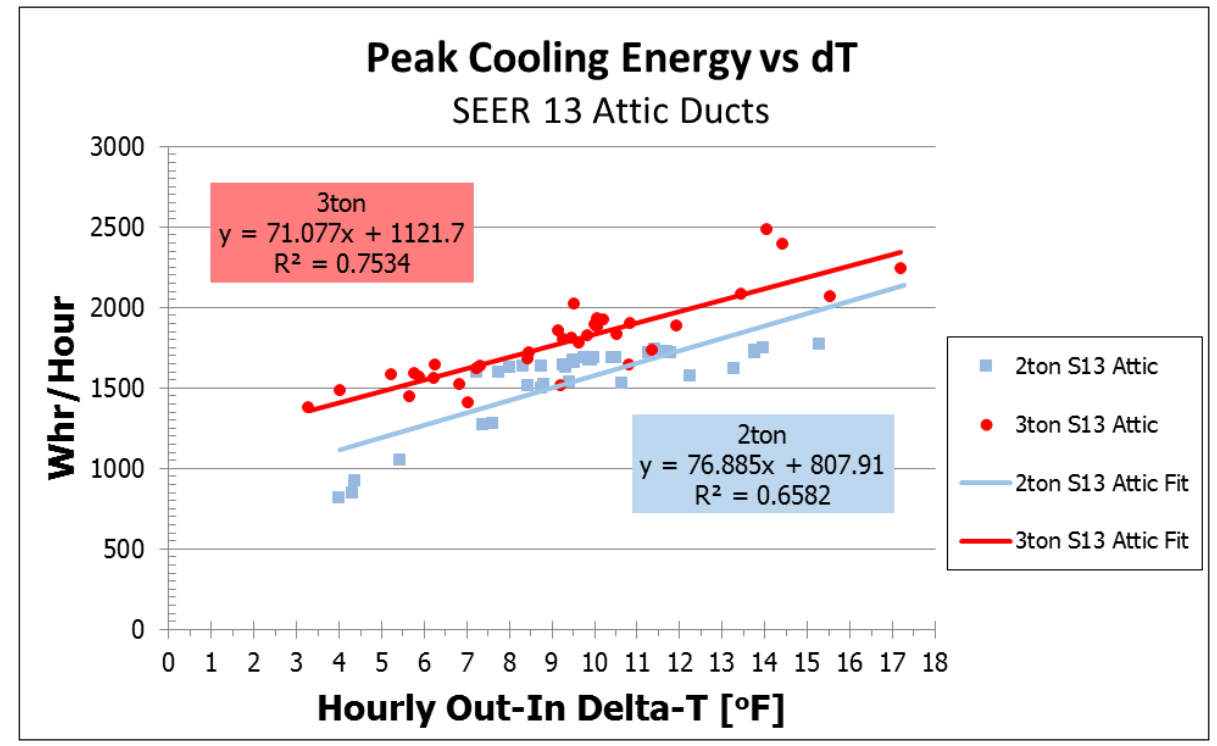

Figure 14. Least-squares regression analysis for 2 p.m. to 7 p.m. hourly data from hot summer days for the 2-ton and 3-ton SEER 13 units with attic ducts

Figure 15 shows that the peak demand produced by the SEER 132 -ton system is $17.1 \%$ lower than that produced by the SEER 13 3-ton system when indoor ducts are used. This result is 
generally consistent with the performance maps of the 2-ton and 3-ton systems (Figure 5), which suggests that the 2 -ton system would be $12.2 \%$ more efficient at $94.5^{\circ} \mathrm{F}\left(17^{\circ} \mathrm{F} \mathrm{dT}\right)$. The authors expected the right-sized system to have lower electricity demand, but the magnitude of the demand reduction (from 3 tons to 2 tons) was surprising.

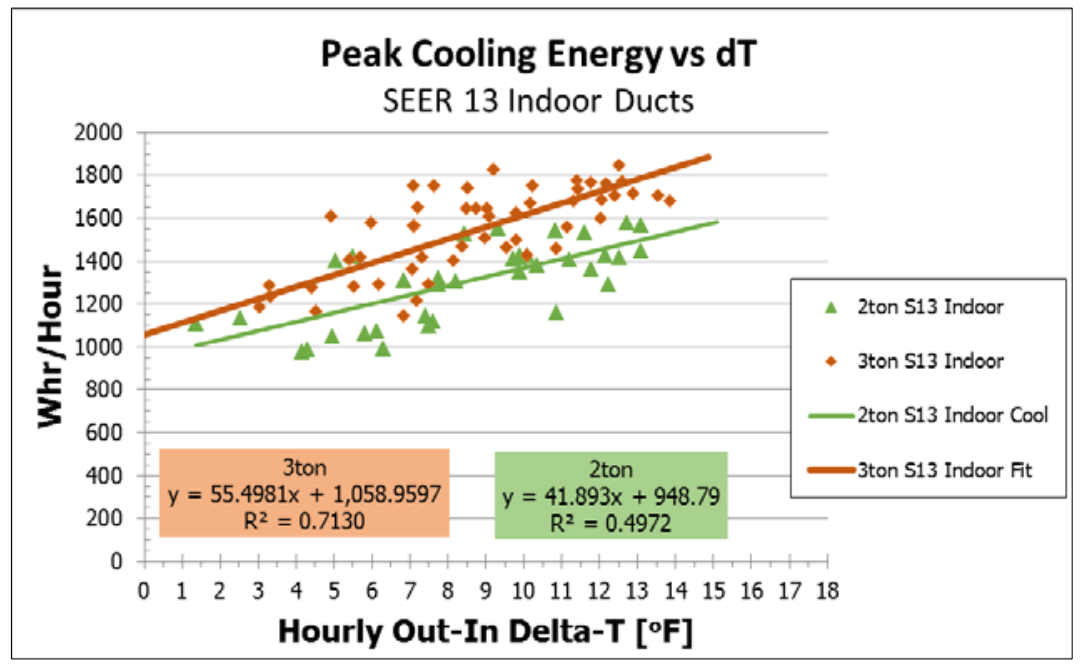

Figure 15. Least-squares regression analysis for 2 p.m. to 7 p.m. hourly data from hot summer days for the 2-ton and 3-ton SEER 13 units with indoor ducts

Figure 16 through Figure 18 show peak demand analysis for the 2-ton SEER 22 system versus the 3-ton SEER 21 system. The results are completely reversed compared to the SEER 13 peak demand analysis. The oversized (3-ton) variable-capacity systems had considerably lower peak demand compared to the right-sized (2-ton) systems.

Figure 16 shows peak demand regression analysis for the 2-ton SEER 22 and 3-ton SEER 21 systems that used attic ducts without RH control. The 3-ton SEER 21 system had peak electricity demand that was $12 \%$ lower than that of the 2 -ton SEER 22 system at $17^{\circ} \mathrm{F} \mathrm{dT}$.

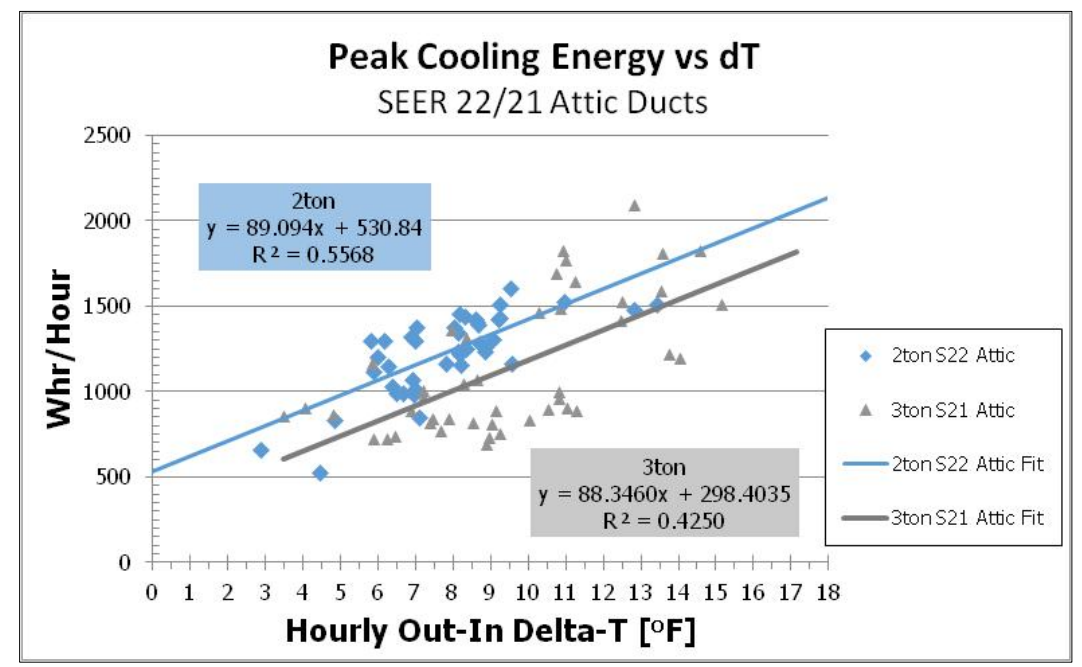

Figure 16. Least-squares regression analysis for 2 p.m. to 7 p.m. hourly data from hot summer days for the 2-ton and 3-ton SEER 22/21 units with attic ducts and without RH control 
Figure 17 shows peak demand regression analysis for the 2-ton SEER 22 and 3-ton SEER 21 systems that used attic ducts with the RH control active. The 3-ton SEER 21 system had peak electricity demand that was $2.5 \%$ lower than that of the 2-ton SEER 22 system at $17^{\circ} \mathrm{F} \mathrm{dT}$.

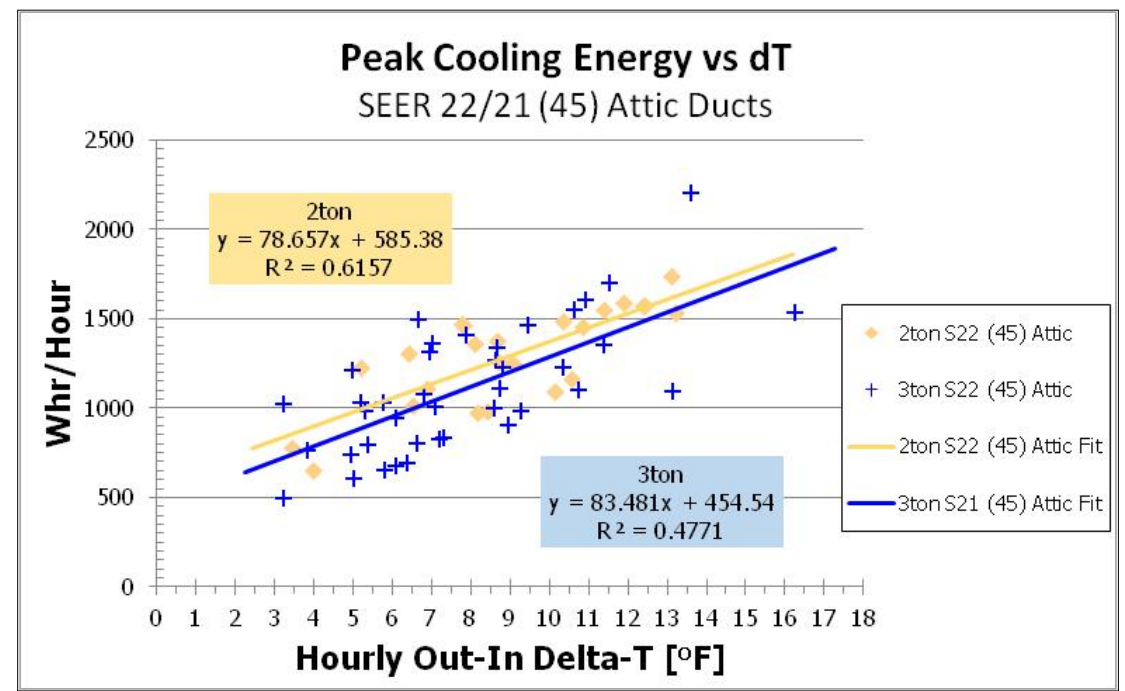

Figure 17. Least-squares regression analysis for hours of 2 p.m. to 7 p.m. from hot summer days for the 2-ton and 3-ton SEER $22 / 21$ units with attic ducts and $45 \% \mathrm{RH}$ control

Figure 18 shows peak demand regression analysis for the 2-ton SEER 22 and 3-ton SEER 21 systems that used indoor ducts with the RH control active. The 3-ton SEER 21 system had peak electricity demand that was $22.7 \%$ lower than that of the 2-ton SEER 22 system at $17^{\circ} \mathrm{F} \mathrm{dT}$.

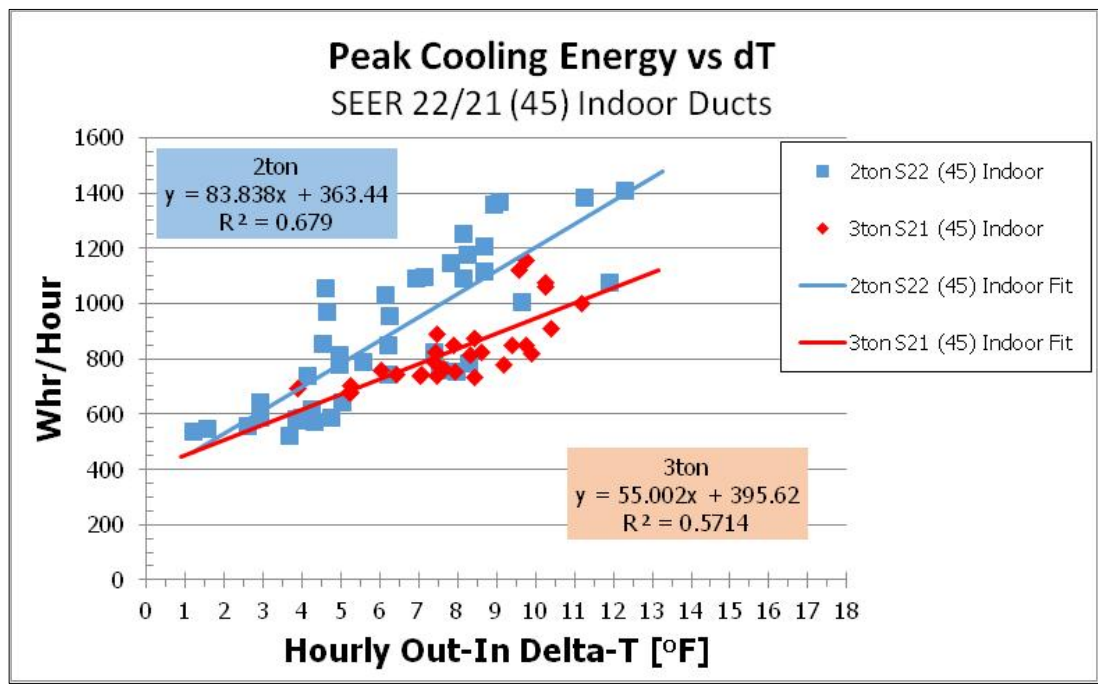

Figure 18. Least-squares regression analysis for 2 p.m. to 7 p.m. hourly data from hot summer days for the 2-ton and 3-ton SEER 22/21 units, with indoor ducts and $45 \%$ RH control

\subsection{Discussion of System Sizing Impact on Peak Cooling Demand}

Right-sizing reduced peak cooling demand for the fixed-capacity SEER 13 heat pumps. Based on regression analysis, the 2-ton SEER 13 unit reduced peak demand by $9.2 \%$ with attic ducts and $17.1 \%$ with indoor ducts (Table 10). However, because the SEER 13 performance maps (as 
shown in Figure 5) indicate that the 2-ton SEER 13 unit was 12.2\% more efficient than the 3-ton SEER 13 unit at $17^{\circ} \mathrm{F} \mathrm{dT}$, the conclusion about sizing is less certain. Using the $12.2 \%$ as an offset, right-sizing appeared to increase peak demand by $3 \%$ (calculation: $12.2 \%-9.2 \%=3 \%$ ) when attic ducts were used and decreased peak demand by $4.9 \%$ (calculation: $12.2 \%-17.1 \%=$ $-4.9 \%$ ) when indoor ducts were used.

Table 10. Peak Demand Best-Fit Equation and Coefficients for Each SEER 13 Experimental Configuration*

\begin{tabular}{|c|c|c|c|c|}
\hline & $\begin{array}{c}\text { S13 } \\
\text { 2-Ton Attic }\end{array}$ & $\begin{array}{c}\text { S13 } \\
\text { 3-Ton Attic }\end{array}$ & $\begin{array}{c}\text { S13 } \\
\text { 2-Ton Indoor }\end{array}$ & $\begin{array}{c}\text { S13 } \\
\text { 3-Ton Indoor }\end{array}$ \\
\hline (A) Wh/h & 807.9 & 1121.7 & 948.79 & 1059.1 \\
\hline (B) $W h / h /{ }^{\circ} \mathbf{F}$ & 76.885 & 71.077 & 41.893 & 55.498 \\
\hline 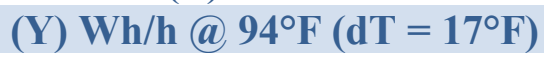 & 2115 & 2330 & 1661 & 2003 \\
\hline $\begin{array}{l}\text { Savings S13 2-Ton Versus } \\
\text { S13 3-Ton With Attic Ducts }\end{array}$ & $9.2 \%$ & - & - & - \\
\hline $\begin{array}{l}\text { Savings S13 2-Ton Versus } \\
\text { S13 3-Ton With Indoor Ducts }\end{array}$ & - & - & $17.1 \%$ & - \\
\hline
\end{tabular}

* In the form of $\mathrm{Y}=\mathrm{A}+\mathrm{B}(\mathrm{X})$ with attic and indoor ducts, where $\mathrm{Y}$ is the peak hour cooling electrical energy use and $\mathrm{X}$ is $\mathrm{dT}\left(\mathrm{X}=17^{\circ} \mathrm{F}\right.$ for this example $)$

For the variable-capacity systems, oversizing clearly yields significant peak demand reduction. For all three experimental permutations of the SEER 22/21 experiments shown in Table 11, the average peak demand reduction from oversizing (from 2-ton to 3-ton systems) was $12.4 \%$. However, the benefit of oversizing was even greater than $12.4 \%$ because the 2-ton SEER 22 system was 3.3\% more efficient at the same load factor (see Figure 3 and Figure 4; 4.02/3.89 for $93^{\circ}-98^{\circ} \mathrm{F}$ bin at 0.83 load factor). The oversized heat pump overcame the $3.3 \%$ higher efficiency of the 2 -ton system and raised that by $12.4 \%$, so the total peak demand gain from oversizing was $15.7 \%$ (calculation: $12.4 \%+3.3 \%=15.7 \%$ ).

What caused the oversized (3-ton SEER 21) system to greatly outperform the right-sized 2-ton SEER 22 system when it was tested in a real house? Cummings and Withers (2011) stated: "The answer appears to lie with the SEER 22 heat pump capacity relative to peak cooling load. The MH Lab design cooling load, when using the indoor duct system, is about 18,000 Btu/h. Therefore, even on hot summer afternoons the SEER 21 unit (with indoor ducts) is only operating at about $50 \%$ of full capacity. As a result, the SEER 21 unit can operate at or just above its minimum capacity $(14,200 \mathrm{Btu} / \mathrm{h})$ during the hours of peak demand." 
Table 11. Peak Demand Best-Fit Equations and Coefficients for Each SEER 22/21 Experimental Configuration*

\begin{tabular}{|c|c|c|c|c|c|c|}
\hline & $\begin{array}{l}\text { S22 } \\
\text { 2-Ton } \\
\text { Attic }\end{array}$ & $\begin{array}{l}\text { S21 } \\
\text { 3-Ton } \\
\text { Attic }\end{array}$ & $\begin{array}{l}\text { S22(45) } \\
\text { 2-Ton } \\
\text { Attic }\end{array}$ & $\begin{array}{l}\text { S21(45) } \\
\text { 3-Ton } \\
\text { Attic }\end{array}$ & $\begin{array}{l}\text { S22(45) } \\
\text { 2-Ton } \\
\text { Indoor }\end{array}$ & $\begin{array}{l}\text { S21(45) } \\
\text { 3-Ton } \\
\text { Indoor }\end{array}$ \\
\hline (A) $W h / h$ & 530.84 & 298.4035 & 585.38 & 454.54 & 315.36 & 395.62 \\
\hline (B) $\mathbf{W h} / \mathbf{h} /{ }^{\circ} \mathbf{F}$ & 89.094 & 88.346 & 78.657 & 83.481 & 82.660 & 55.002 \\
\hline $\begin{array}{c}(\mathrm{Y}) \mathbf{W h} / \mathbf{h} @ 94^{\circ} \mathrm{F} \\
\left(\mathrm{dT}=17^{\circ} \mathrm{F}\right)\end{array}$ & 2,045 & 1,800 & 1,923 & 1,874 & 1,721 & 1,331 \\
\hline $\begin{array}{l}\text { Savings S21 3-Ton } \\
\text { Versus S22 2-Ton } \\
\text { With Attic Ducts }\end{array}$ & - & $12 \%$ & - & - & - & - \\
\hline $\begin{array}{c}\text { Savings S21 (45) 3-Ton } \\
\text { Versus S22 (45) 2-Ton } \\
\text { With Attic Ducts }\end{array}$ & - & - & - & $2.5 \%$ & - & - \\
\hline $\begin{array}{c}\text { Savings S21 (45) 3-Ton } \\
\text { Versus S22 (45) 2-Ton } \\
\text { With Indoor Ducts }\end{array}$ & - & - & - & - & - & $22.7 \%$ \\
\hline
\end{tabular}

* In the form of $\mathrm{Y}=\mathrm{A}+\mathrm{B}(\mathrm{X})$ with attic and indoor ducts, where $\mathrm{Y}$ is the peak hour electrical energy use and $\mathrm{X}$ is $\mathrm{dT}\left(\mathrm{X}=17^{\circ} \mathrm{F}\right.$ for this example $)$ 


\section{Heating Energy Impacts of System Sizing}

Two heating configurations were tested during the Phase 3 experiments: 2-ton SEER 13 with attic ducts and 2-ton SEER 22 with attic ducts. They were compared to the 3-ton SEER 13 with attic ducts and 3-ton SEER 21 with attic ducts, respectively, from the Phase 1 experiments. For the heating season experiments, the heat pump thermostats were set to $75^{\circ} \mathrm{F}$ (as in Phase 1). This set point is higher than a typical winter heating set point $\left(72^{\circ} \mathrm{F}\right.$ is more representative in Florida). This elevated set point temperature was chosen to increase space heating loads and produce longer heat pump runtimes. Even though the thermostat was set to $75^{\circ} \mathrm{F}$, actual indoor temperatures averaged about $76.5^{\circ} \mathrm{F}$ on days when some heating was required (cooling was needed on many days during the winter; other times neither heating nor cooling was required). The sensible internal load was also reduced during the heating experiments, from $27.7 \mathrm{kWh} / \mathrm{day}$ to $21.1 \mathrm{kWh} /$ day (as was done in Phase 1), again to increase the net heating load and heat pump operation. The electric strip heating elements in the heat pumps were disabled so that electric resistance heating would not occur during these experiments, either as supplemental heat (in case the heat pumps had insufficient capacity) or during defrost cycles. Therefore, all the heat produced by the heat pump system was supplied by the heat pump.

Table 12 presents average outdoor and indoor temperatures, average daily dT, average indoor $\mathrm{RH}$, and heating system percent operation time for Phase 1 (3-ton units) heating periods. The average values for temperatures, $\mathrm{RH}$, and runtime are based on the number of space heating days identified in the last row of Table 12 and Table 13. The operation time for the variable-capacity system was $18 \%$ longer than for the fixed-capacity system; however, this was quite different than during the cooling season when the variable-capacity system operation time was nearly $100 \%$ longer than that of the fixed-capacity system (in Phase 1). The likely explanation is that the variable-capacity system in heating mode was pushed into full or near full capacity most of the time because of the large dT (nearly $21^{\circ} \mathrm{F}$ dT between indoors and outdoors).

Table 12. Phase 1 Average Indoor Temperatures, Indoor RH, and Heating System Runtimes for Heating Days From February 11, 2010 Through February 16, 2011

\begin{tabular}{|c|c|c}
\hline & SEER 13 Attic & SEER 21 Attic \\
\hline Average Outdoor Temperature $\left({ }^{\circ} \mathbf{F}\right)$ & 56.5 & 55.6 \\
\hline Average Indoor Temperature $\left({ }^{\circ} \mathbf{F}\right)$ & 76.6 & 76.3 \\
\hline dT $\left({ }^{\circ} \mathbf{F}\right)$ & -20.1 & -20.7 \\
\hline Indoor RH (\%) & 43.6 & 41.8 \\
\hline Heating System Runtime (\%) & 20.9 & 24.7 \\
\hline Number of Days Included & 20 & 42 \\
\hline
\end{tabular}

Table 13 presents average outdoor and indoor temperatures, average daily dT, average indoor $\mathrm{RH}$, and heating system operation time percentage during Phase 3 (2-ton units) heating periods. Some differences can be observed between the Phase 1 and Phase 3 experiments. Outdoor temperature (on heating days) was approximately $2.8^{\circ} \mathrm{F}$ warmer during Phase 3 than during Phase 1 . Indoor temperature was approximately $0.8^{\circ} \mathrm{F}$ warmer during Phase 3 than during Phase 1. dT was $1.4^{\circ} \mathrm{F}$ smaller during Phase 3 than during Phase 1 . Indoor RH was $6 \%$ higher during Phase 3. In spite of the milder weather during Phase 3, the heating system operation time was, on 
average, 31\% longer in Phase 3 than during Phase 1 because the 2-ton system required more operation time to deliver the same space heating.

Table 13. Phase 3 Average Indoor Temperatures, Indoor RH, and Heating System Runtimes for Heating Days From December 21, 2012 Through March 30, 2013

\begin{tabular}{c|c|c}
\hline & SEER 13 Attic & SEER 22 Attic \\
\hline Average Outdoor Temperature $\left({ }^{\circ} \mathbf{F}\right)$ & 59.7 & 57.9 \\
\hline Average Indoor Temperature $\left({ }^{\circ} \mathbf{F}\right)$ & 77.8 & 76.7 \\
\hline dT $\left({ }^{\circ} \mathbf{F}\right)$ & -18.8 & -19.2 \\
\hline Indoor RH (\%) & 50.4 & 47.0 \\
\hline Heating System Runtime (\%) & 26.6 & 33.6 \\
\hline Number of Days Included & 26 & 30 \\
\hline
\end{tabular}

To perform the seasonal heating energy analysis, the research team plotted the daily total heating energy consumption against the average $\mathrm{dT}$, in a fashion similar to that done for the cooling analysis. Figure 19 shows heating energy data for the 2-ton and 3-ton SEER 13 systems. $\mathrm{R}^{2}$ values were 0.878 and 0.977 for the 2-ton and 3-ton SEER 13 test configurations, respectively; these indicate a high correlation in the experimental results.

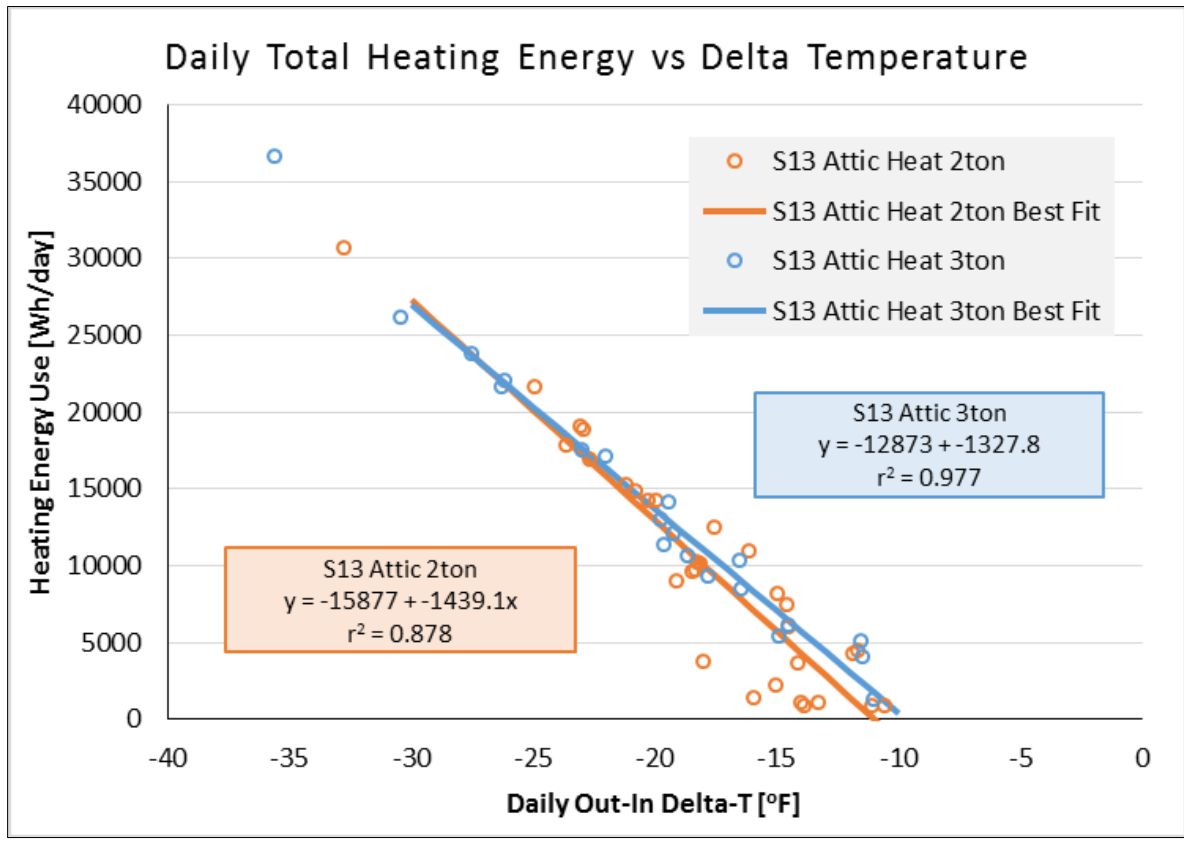

Figure 19. Heating energy use as a function of dT for the 2-ton and 3-ton SEER 13 units

For purposes of discussing relative heating performance, an indoor temperature of $72^{\circ} \mathrm{F}$ is assumed. On a day with an average temperature of $50^{\circ} \mathrm{F}$ (high of $60^{\circ} \mathrm{F}$ and low of $40^{\circ} \mathrm{F}$ ), which might be considered a typical Florida winter day, dT was $-22^{\circ} \mathrm{F}$. Based on the regression analysis equations for the SEER 13 systems, heating energy was $15.78 \mathrm{kWh}$ for the 2-ton system and $16.34 \mathrm{kWh}$ for the 3-ton system. This indicates that the 2-ton system was more energy efficient by a margin of $3.4 \%$ when dT was $-22^{\circ} \mathrm{F}$ (Table 14). Although energy savings from the right-sized fixed-capacity systems is indicated by the regression equations, the difference in 
heating energy is not statistically significant. A paucity of heating data is the most likely cause for the greater statistical uncertainty.

Table 14. Best-Fit Equation Intercepts and Coefficients in the Form of $Y=A+B(X)+C\left(X^{2}\right)$ for the 2-Ton and 3-Ton SEER 13 and SEER 21/22 Systems ${ }^{a}$

\begin{tabular}{|c|c|c|c|c|c|c|c|c|c|}
\hline 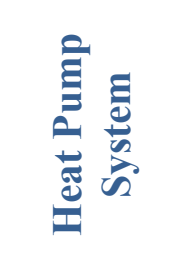 & 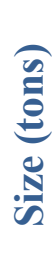 & 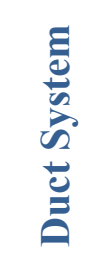 & $\widetilde{\simeq}$ & $\ll$ & $\oplus$ & $U$ & 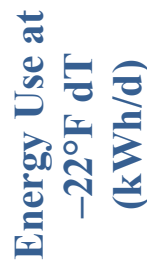 & : & 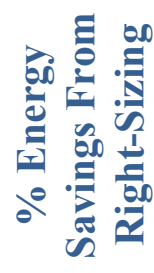 \\
\hline SEER 13 & 2 & Attic & 0.88 & -15877 & -1439.1 & - & 15.8 & 1.4 & $3.4 \%{ }^{\mathrm{c}}$ \\
\hline SEER 13 & 3 & Attic & 0.98 & -12873 & -1327.8 & - & 16.3 & 0.8 & - \\
\hline SEER 22 & 2 & Attic & 0.86 & -9030 & -963.6 & - & 12.2 & 0.9 & $-3.0 \%{ }^{\mathrm{c}}$ \\
\hline SEER 21 & 3 & Attic & 0.96 & -8866 & -939.8 & - & 11.8 & 0.7 & - \\
\hline
\end{tabular}

${ }^{a}$ Where $\mathrm{Y}$ is the daily heating electrical energy use (Wh/day) and $\mathrm{X}$ is the daily outdoor minus indoor temperature difference for the 2-ton and 3-ton SEER 13 and SEER 21/22 systems, all with attic ducts, with daily energy use calculated at $-22^{\circ} \mathrm{F} d \mathrm{~T}$.

${ }^{\mathrm{b}}$ Error is the extent of the $95 \%$ confidence interval for this regression. For example, the energy use at a dT value of $22^{\circ} \mathrm{F}$ is modeled to be $15.8 \mathrm{kWh} /$ day $\pm 1.4 \mathrm{kWh} /$ day (or $14.4-17.2 \mathrm{kWh} /$ day) at a $95 \%$ confidence level.

${ }^{c}$ For the SEER 21/22 indoor duct configuration, the data showed no statistically significant difference in energy performance between 2-ton and 3-ton systems.

Figure 20 shows heating energy data for the 2-ton SEER 22 and 3-ton SEER 21 systems. ${ }^{2}$ values are 0.857 and 0.959 for the 2 -ton and 3 -ton test configurations, respectively, which indicates a relatively high level of confidence in the experimental results.

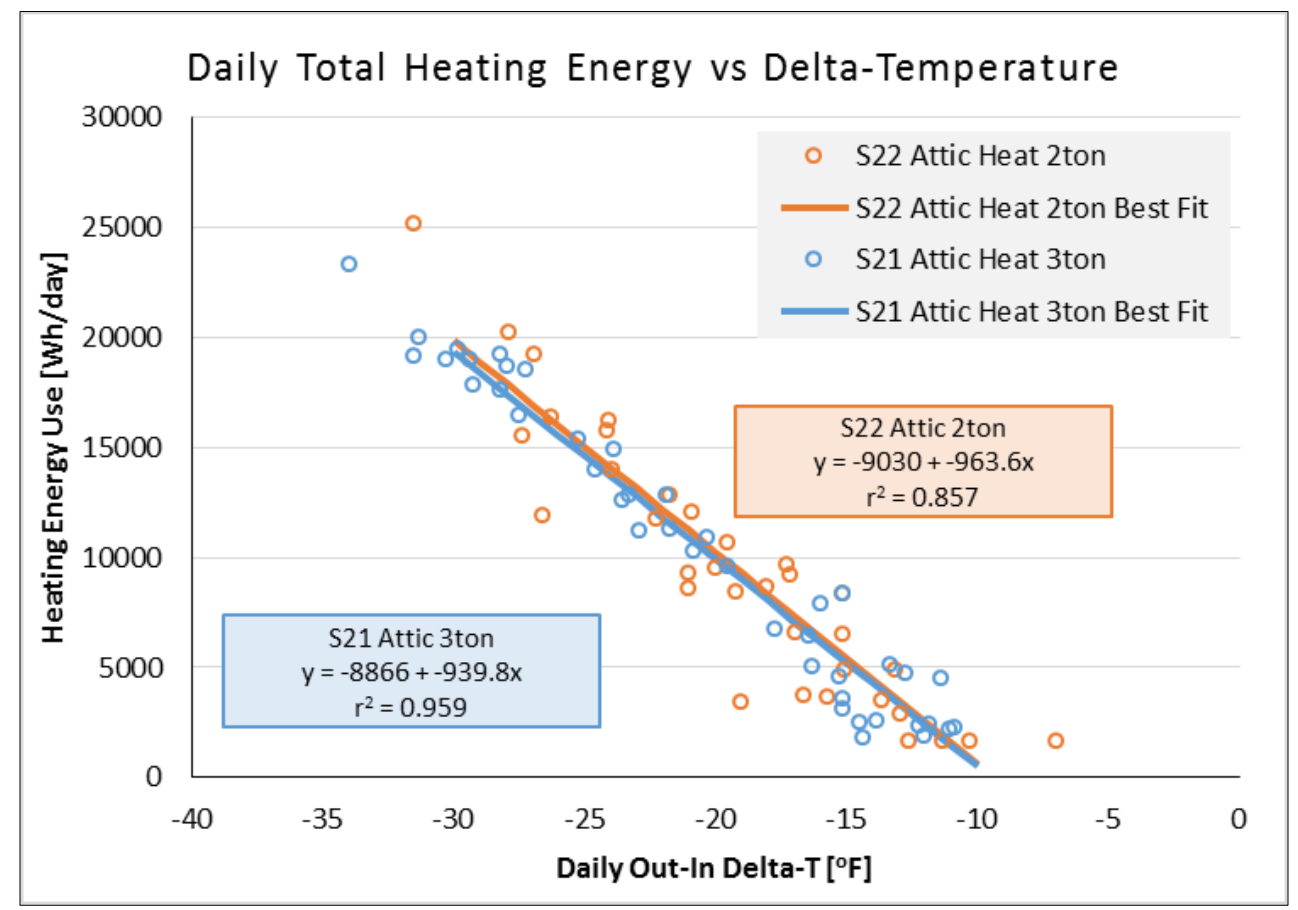

Figure 20. Heating energy use as a function of $d T$ for the 2-ton SEER 22 unit and the 3-ton SEER 21 unit 
Based solely on the regression analysis equations for the SEER 22 and SEER 21 systems and a $\mathrm{dT}$ of $-22^{\circ} \mathrm{F}$, heating energy was $12.17 \mathrm{kWh}$ /day for the 2 -ton system and $11.81 \mathrm{kWh} /$ day for the 3 -ton system. The 3-ton system was indicated to be 3\% more energy efficient on this typical winter day (Table 14). The available data indicate a moderate energy-efficiency advantage for the oversized SEER 22/21 systems. Although 3\% increased efficiency is indicated here, the result is not statistically significant. The inconclusive results could be from a lack of heating data caused by warm heating seasons and a difference between the heating efficiency ratings between the 2-ton and 3-ton units.

This 3\% increase in efficiency for the oversized (3-ton) unit occurred in spite of a lower heating seasonal performance factor (HSPF) rating. The 2-ton SEER 22 heat pump has a $10 \mathrm{HSPF}$ and the 3-ton SEER 21 heat pump has a 9.6 HSPF. Based on the HSPF ratings alone, the right-sized system would be $4.2 \%$ more energy efficient. Because the oversized unit operates at $3 \%$ higher efficiency after it overcame the $4.2 \%$ higher rated efficiency of the right-sized system, oversizing increased operating efficiency by $7.2 \%$ (calculation: $3.0 \%+4.2 \%=7.2 \%$ ). 


\section{Impacts of Right-Sizing on Peak Heating Energy Demand}

Analysis was performed to characterize peak heating electricity demand for the coldest hours of the coldest days at the MH Lab for the 2-ton and 3-ton SEER 13 and SEER 22/21 units. In all cases the heating experiments were carried out using the attic ductwork. Because Florida winters are as a rule fairly short - and the winter of 2012-2013 was warmer than average - no experimental data could be collected for the indoor duct experimental permutations.

Regression analysis was employed to determine peak demand savings in a manner similar to that for cooling. Heating energy use between 2 a.m. and 8 a.m. was selected from a group of 5+ colder-than-average winter days for each experimental configuration. Heating energy consumption for each hour was plotted versus the $\mathrm{dT}$ for that hour. The heat pumps used in the MH Lab have no electric resistance heating, so the compressor provided all the heating to the space.

Figure 21 shows peak-hour regression analysis for the 2-ton and 3-ton SEER 13 systems. For a typical cold $30^{\circ} \mathrm{F}$ winter morning $\left(72^{\circ} \mathrm{F}\right.$ indoors and $\left.-42^{\circ} \mathrm{F} \mathrm{dT}\right)$, peak electricity demand was 1,937 Wh/hour for the 2-ton system and 2,166 Wh/hour for the 3-ton system. The 2-ton system reduced peak demand by $10.6 \%$ compared to the 3 -ton system. Right-sizing yielded reduced peak demand significantly compared to oversized fixed-capacity systems.

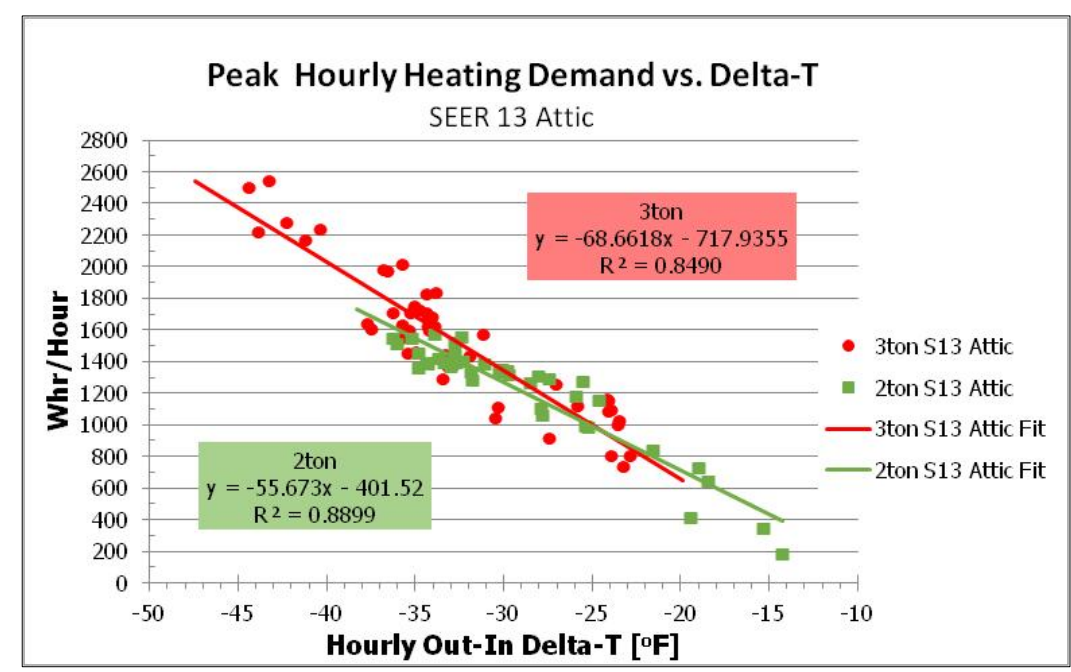

Figure 21. Least-squares best-fit regression analysis for the hours of 2 a.m. to 8 a.m. from cold winter days for the 2-ton and 3-ton SEER 13 systems with attic duct configurations

Regression analysis was done for the 2-ton SEER 22 and 3-ton SEER 21 systems. After finding that the $\mathrm{R}^{2}$ value for 3-ton system was 0.28 , the analysis was altered so that 2-hour average data were then used instead of 1 -hour data, which significantly improved $\mathrm{R}^{2}$ to 0.79 . Figure 22 shows the peak-hour data and analysis for the 2-ton SEER 22 and 3-ton SEER 21 systems using 2-hour data. For a typical $30^{\circ} \mathrm{F}$ winter morning peak period $\left(-42^{\circ} \mathrm{F} \mathrm{dT}\right)$, electricity demand was 1,742 $\mathrm{Wh} / \mathrm{h}$ for the 2-ton system and 1,565 Wh/h for the 3-ton system. The oversized (3-ton) system reduced peak demand by $10.1 \%$ compared to the right-sized (2-ton) system. As with peak cooling demand, the oversized variable-capacity system significantly reduced peak demand; in contrast, the oversized fixed-capacity system significantly increased peak demand. 


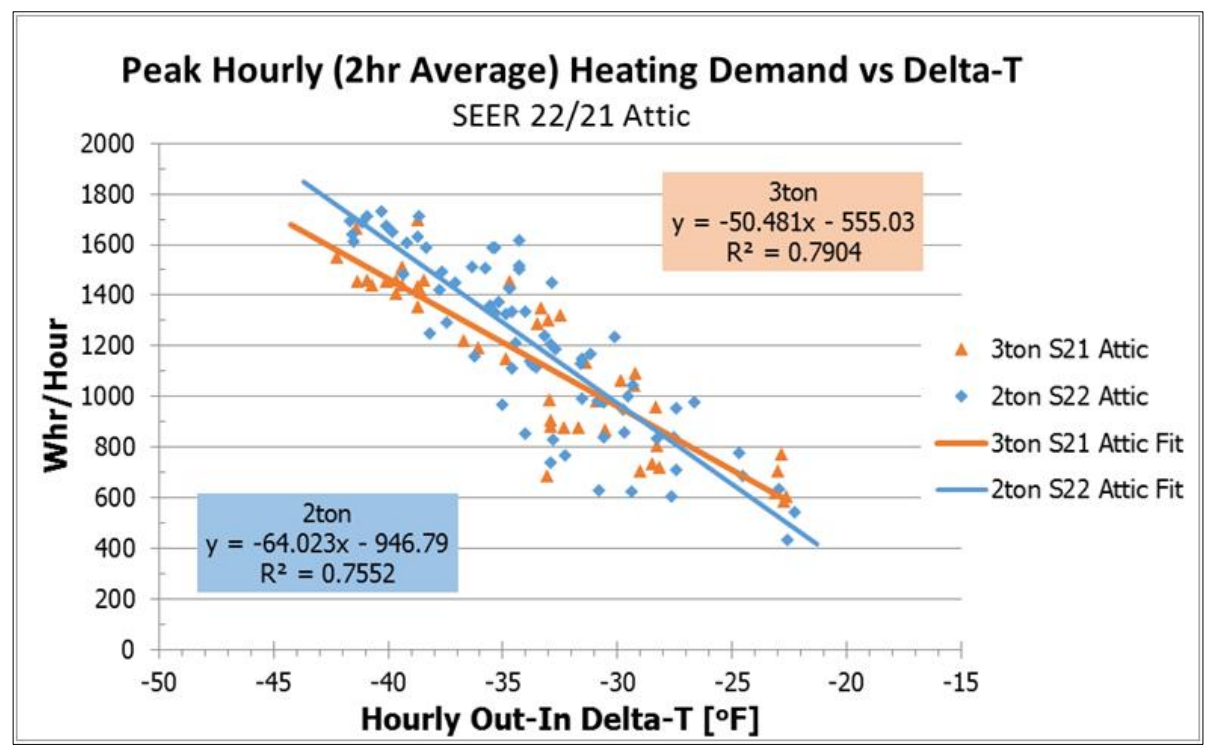

Figure 22. Regression analysis for the hours of 2 a.m. to 8 a.m. from cold winter days for the 2-ton and 3-ton SEER 22/21 systems with attic duct configurations; each data point was the average value for a 2 -hour period

\subsection{Discussion of Heating Peak Demand Reduction}

The regression analysis normalizes peak heating energy use to dT (where indoor temperature is based on an average from five locations in the lab house). Best-fit least squares regression lines are defined by equations in the form of $\mathrm{Y}=\mathrm{A}+\mathrm{B}(\mathrm{X})$, where $\mathrm{Y}$ is the hourly heating electrical energy use and $\mathrm{X}$ is $\mathrm{dT}$ (in the case of Figure 22, the data points represent the 2-hour average). Table 15 presents the equations for all four experimental configurations and peak heating electricity demand; it assumes an indoor temperature of $72^{\circ} \mathrm{F}$ and an outdoor temperature of $30^{\circ} \mathrm{F}\left(42^{\circ} \mathrm{F} \mathrm{dT}\right.$, which would be representative of a peak heating hour in a substantial section of Florida). As a point of reference, the $99.6 \%$ heating dry bulb values (see ASHRAE 2009) are $47.7^{\circ} \mathrm{F}$ for Miami and $37.7^{\circ} \mathrm{F}$ for Orlando.

Table 15. Peak Heating Demand Savings Calculated From the Best-Fit Equation*

\begin{tabular}{|c|c|c|c|c|}
\hline & $\begin{array}{c}\text { S13 } \\
\text { 2-Ton Attic }\end{array}$ & $\begin{array}{c}\text { S13 } \\
\text { 3-Ton Attic }\end{array}$ & $\begin{array}{c}\text { S22 } \\
\text { 2-Ton Attic }\end{array}$ & $\begin{array}{c}\text { S21 } \\
\text { 3-Ton Attic }\end{array}$ \\
\hline (A) Wh/h & -401.52 & -717.94 & -946.79 & -555.03 \\
\hline (B) $\mathbf{W h} / \mathbf{h} /{ }^{0} \mathbf{F}$ & -55.673 & -68.662 & -64.023 & -50.481 \\
\hline$(\mathrm{Y}) \mathrm{Wh} / \mathrm{h} @ 30^{\circ} \mathrm{F}\left(\mathrm{dT}=-42^{\circ} \mathrm{F}\right)$ & 1937 & 2166 & 1742 & 1565 \\
\hline $\begin{array}{l}\text { Savings of SEER } 13 \text { 2-Ton Versus } \\
\text { SEER } 13 \text { 3-Ton }(\mathrm{Wh} / \mathrm{h})\end{array}$ & 229 & - & - & - \\
\hline $\begin{array}{c}\text { Savings of SEER } 13 \text { 2-Ton Versus } \\
\text { SEER } 13 \text { 3-Ton }(\%)\end{array}$ & $10.6 \%$ & - & - & - \\
\hline $\begin{array}{c}\text { Savings of SEER } 21 \text { 3-Ton Versus } \\
\text { SEER } 22 \text { 2-Ton }(\mathrm{Wh} / \mathrm{h})\end{array}$ & - & - & - & 177 \\
\hline $\begin{array}{c}\text { Savings of SEER } 21 \text { 3-Ton Versus } \\
\text { SEER } 22 \text { 2-Ton }(\%)\end{array}$ & - & - & - & $10.1 \%$ \\
\hline
\end{tabular}

* $\mathrm{Y}=\mathrm{A}+\mathrm{B}(\mathrm{X})$, where $\mathrm{Y}$ is the hourly heating energy use and $\mathrm{X}$ is the hourly average temperature difference between indoors and outdoors; $42^{\circ} \mathrm{F}$ dT for this example during a cold Florida night. 


\section{Summary and Conclusions}

Two primary research questions addressed by this research are:

- Does an oversized variable-capacity system (in this case, SEER 22 or SEER 21) yield higher or lower energy-efficiency cooling and heating performance than a right-sized system?

- Does an oversized fixed-capacity SEER 13 system yield higher or lower energyefficiency cooling and heating performance than a right-sized system?

Two corollary questions relate to peak demand:

- Does an oversized variable-capacity system yield cooling and heating peak demand savings relative to a right-sized system?

- Does an oversized fixed-capacity SEER 13 system yield cooling and heating peak demand savings relative to a right-sized system?

The space-cooling data that were collected in these experiments were for hot and humid weather and may be less applicable to hot and dry climates. Also, the space-heating data were from weather that was only moderately cold, so the applicability to areas that are substantially colder (e.g., U.S. Department of Energy climate zones 5 and higher) is limited.

\subsection{Seasonal Cooling Energy Savings}

Based on monitored data, oversized high-efficiency variable-capacity heat pump systems yield significant annual cooling energy savings. The analysis is complicated somewhat by the fact that the 2-ton right-sized system has an inherent efficiency advantage of $4.8 \%$ because of its higher SEER rating (SEER 22 for the 2-ton unit versus SEER 21 for the 3-ton unit). Performance mapping of the heat pumps confirms that the smaller unit does, in fact, have an inherent efficiency advantage. (See Section 3.1 for details.)

An oversized variable-capacity SEER 22/21 system with three experimental configurations yields an average 3.6\% annual cooling energy savings compared to a right-sized SEER 22/21 system when attic ducts are used. This result does not take into account the higher efficiency of the 2-ton system. When the analysis normalizes to account for the $4.8 \%$ SEER advantage of the 2 -ton system, the efficiency advantage of the oversizing increases to a very substantial $8.4 \%$ over that of the right-sized system. One of the three configurations without $\mathrm{RH}$ control had $-2.8 \%$ savings from oversizing; however, this result is not statistically significant. If only the other two configurations are considered, the indicated savings from oversizing is $11.7 \%(6.9 \%+4.8 \%$ SEER adjustment $=11.7 \%$ ).

Based on monitored data, right-sized fixed-capacity SEER 13 heat pump systems yield significant seasonal cooling savings compared to an oversized (50\% larger capacity) fixedcapacity SEER 13 system.

- A right-sized fixed-capacity SEER 13 system yields $9.8 \%$ annual cooling energy savings compared to the oversized SEER 13 system when attic ducts are used. 
- A right-sized fixed-capacity SEER 13 system yields $10.5 \%$ annual cooling energy savings compared to the oversized SEER 13 system when indoor ducts are used.

Conclusion: From a seasonal cooling efficiency perspective, oversized variable-capacity cooling systems should be permitted - and even encouraged - because they save substantial cooling energy. Specifically, the results of this study show that variable-capacity cooling systems that are oversized by $65 \%-100 \%$ save significant cooling energy-especially when air distribution systems that lose relatively little energy to the duct zone environment are used.

\subsection{Peak Demand Cooling Savings}

Oversizing substantially reduces peak demand for the variable-capacity SEER 22/21 systems. For all three experimental permutations of the SEER 22/21 experiments combined (Table 11), the average peak demand reduction from oversizing (from a 2-ton to a 3-ton system) was 12.4\%. However, the benefit of oversizing was even greater than this $12.4 \%$ because the 2-ton SEER 22 system was 3.3\% more efficient at the same load factor based on monitored data (Figure 3 and Figure 4). The oversized heat pump overcame the 3.3\% higher efficiency of the 2-ton system (at $17^{\circ} \mathrm{F} \mathrm{dT}$ ) and raised that by another $12.4 \%$, so the total peak demand gain from oversizing was $15.7 \%$.

A right-sized fixed-capacity SEER 13 heat pump reduced peak cooling demand by $9.2 \%$ with attic ducts and by $17.1 \%$ with indoor ducts (Table 10). However, the SEER 13 performance maps (as shown in Figure 5) indicate that the 2-ton SEER 13 unit is 12.2\% more efficient than the 3ton SEER 13 unit at $17^{\circ} \mathrm{F}$ dT. Therefore, the conclusion about sizing is less certain. Using $12.2 \%$ as an offset, right-sizing apparently increased peak demand by $3 \%$ (calculation: $12.2 \%-9.2 \%=$ $3 \%$ ) when attic ducts were used and decreased peak demand by $4.9 \%$ (calculation: $12.2 \%-$ $17.1 \%=-4.9 \%$ ) when indoor ducts were used.

Conclusion: From a peak demand perspective, oversized variable-capacity heat pumps should be permitted - and even encouraged - because they substantially reduce cooling peak demand.

\subsection{Seasonal Heating Energy Savings}

The variable-capacity 3-ton SEER 21 system was measured to be 3\% more energy efficient than the 2-ton SEER 22 system on a typical winter day (Table 14). The oversized unit produced 3\% higher efficiency after it overcame the $4.2 \%$ higher rated efficiency of the right-sized system, so oversizing increased its operating efficiency by $7.4 \%$ (calculation: $3 \%+4.2 \%=7.4 \%$ ).

The fixed-capacity 2-ton SEER 13 system is indicated to be 3.4\% more energy efficient than the 3-ton SEER 13 system on a typical winter day (Table 14).

The energy savings are not statistically significant for either the variable-capacity or fixedcapacity systems. This is largely because the data sample size is small.

Conclusion: From a seasonal heating energy perspective, oversized variable-capacity heat pumps should not be discouraged because oversizing does not cause short-cycling and shows indications of a $7.4 \%$ efficiency increase. Furthermore, oversizing a heat pump (whether fixedcapacity or variable-capacity) diminishes the number of hours per year that the system goes into electric resistance backup heating, which is a very inefficient means of providing space heating. 
Therefore, in general, from a heating season energy consumption perspective, oversized heat pumps should be encouraged.

\subsection{Peak Demand Heating Savings}

Oversized variable-capacity systems (SEER 22/21 systems) reduced heating peak demand by $10.1 \%$ (Table 15). The right-sized fixed-capacity SEER 13 heat pump reduced peak heating demand by $10.6 \%$ (Table 15 ).

Conclusion: From a peak demand perspective, oversized variable-capacity heat pumps should be permitted - and even encouraged - because they substantially reduce heating peak demand. Furthermore, all types of oversized heat pumps diminish the potential for the systems to go into electric resistance backup heating, which would dramatically increase peak demand.

\subsection{Additional Conclusions Related to Humidity Control}

A commonly held idea is that standard fixed-capacity $\mathrm{A} / \mathrm{C}$ systems do not provide adequate indoor RH control during hot and humid weather. The monitored data showed that the 3-ton SEER 13 system (which was oversized by 65\%-100\% depending on which duct system was used) produced average indoor RH of $49 \%$ during hot and humid weather when either the attic or the indoor duct system was used (Table 3). Also, the 2-ton SEER 13 system produced average indoor RH of 50.5\% during hot and humid weather when either the attic or the indoor duct system was used (Table 5).

Another widely held belief is that oversized fixed-capacity cooling systems do not provide acceptable indoor RH control. The fact that the greatly oversized 3-ton SEER 13 system produced indoor RH that was $1.5 \%$ lower than that produced by the 2-ton SEER 13 system strongly indicates that the parameters that impact RH control warrant careful study.

Some researchers also believe that variable-capacity $\mathrm{A} / \mathrm{C}$ systems cannot properly control indoor RH. The 3-ton SEER 21 system was oversized by 65\%-100\% depending on which duct system was used. The monitored data showed that this system produced average indoor $\mathrm{RH}$ of $52 \%$ when the attic ducts were used and 55\% when the indoor duct system was used (Table 3). Also, the 2-ton SEER 22 system produced average indoor RH of 55\% during hot and humid weather when the attic duct system was used. (Results for the indoor duct system were unavailable-see Table 5). Although RH levels of 52\%-55\% may not be considered ideal by some, the variablecapacity (iQ Drive) system has an RH control algorithm that can be implemented. With RH control set to $45 \%$, indoor RH averaged $51 \%$ with attic ducts and 53\% with indoor ducts (Table 5). Furthermore, the manufacturer could easily implement minor software alterations to the control algorithms, which could produce lower supply air temperatures and considerably lower indoor RH without significant energy-efficiency penalties. (The energy penalty associated with the $\mathrm{RH}$ control active in Phase 1 research was 3\%). 


\section{References}

ASHRAE (2009). American Society of Heating, Refrigerating and Air-Conditioning Engineers "Appendix: Design Conditions for Selected Locations," Chapter 14. ASHRAE Handbook Fundamentals 2009.

Cummings, J.; Withers, C. (2011). Energy Savings and Peak Demand Reduction of a SEER 21 Heat Pump vs. a SEER 13 Heat Pump with Attic and Indoor Duct Systems. NREL/KNDJ-040339-02. Cocoa, FL: FSEC. Accessed 2012: http://www.fsec.ucf.edu/en/publications/pdf/FSEC-CR-1927-11.pdf.

Hendron, R. (2008). Building America Research Benchmark Definition (BARBD). NREL/TP550-44816. Golden, CO: National Renewable Energy Laboratory. Accessed 2012: http://apps1.eere.energy.gov/buildings/publications/pdfs/building_america/44816.pdf.

Nordyne Elite Training (2009). IQ Drive Heat Pump Training Manual. Document \#303D-0409, Technical Training Division. 


\section{Appendix A: Heating and Cooling Capacities}

All the data and descriptive notes in this appendix come directly from the manufacturer.

Performance specifications for the Nordyne iQ Drive heat pumps.

Table 16. System Cooling Capacities: 22 SEER. Ultra High Efficiency, Single Phase

\begin{tabular}{c|c|c|c|c|c|c}
\hline $\begin{array}{c}\text { Outdoor Unit } \\
\begin{array}{c}\text { Model Number } \\
\text { FT4BI }\end{array}\end{array}$ & Indoor Unit & $\begin{array}{c}\text { Range Cooling } \\
\text { Capacity } \\
\mathbf{9} \mathbf{9 5}^{\circ} \text { OD Btu/h }\end{array}$ & $\begin{array}{c}\text { EER @ } \\
\text { Nominal } \\
\text { Capacity }\end{array}$ & SEER & $\begin{array}{c}\text { Nominal } \\
\text { Capacity }\end{array}$ & $\begin{array}{c}\text { Range } \\
\text { SCFM }\end{array}$ \\
\hline $\mathbf{0 2 4 K}$ & B4VM-E24K-B & $11,300-26,900$ & 14.6 & 22 & 23,000 & $500-950$ \\
$\mathbf{0 3 6 K}$ & B4VM-E36K-B & $14,200-40,700$ & 13.0 & 21 & 35,000 & $680-1110$ \\
$\mathbf{0 4 8 K}$ & B4VM-E48K-C & $14,300-48,000$ & 12.5 & 21 & 44,500 & $725-1800$ \\
\hline
\end{tabular}

NOTE: Each system was operated at its nominal capacity.

Indoor conditions were $80^{\circ} \mathrm{F}$ dry bulb temperature and $67^{\circ} \mathrm{F}$ wet bulb temperature (approximately $51 \% \mathrm{RH}, 95^{\circ} \mathrm{F}$ outdoor temperature

Table 17. System Heating Capacities, 22 SEER, Ultra High Efficiency, Single Phase

\begin{tabular}{c|c|c|c|c|c|c}
\hline $\begin{array}{c}\text { Outdoor Unit } \\
\begin{array}{c}\text { Model Number } \\
\text { FT4BI }\end{array}\end{array}$ & Indoor Unit & $\begin{array}{c}\text { Range Heating } \\
\text { Capacity } \\
\text { @ } \mathbf{4 7}^{\circ} \text { OD Btu/h }\end{array}$ & $\begin{array}{c}\text { Nominal } \\
\text { Capacity }\end{array}$ & HSPF & $\begin{array}{c}\text { COP @ } \\
\text { Nominal } \\
\text { Capacity }\end{array}$ & CFM \\
\hline 024K & B4VM-E24K-B & $6,500-24,100$ & 22,600 & 10 & 3.9 & $500-950$ \\
036K & B4VM-E36K-B & $11,300-39,800$ & 34,000 & 9.6 & 3.4 & $680-1,110$ \\
048K & B4VM-E48K-C & $11,400-47,800$ & 46,000 & 10 & 3.6 & $725-1,800$ \\
\hline
\end{tabular}

Minimum operating ambient temperature is $12^{\circ} \mathrm{F}$

NOTE: Each system was operated at its nominal capacity.

Indoor conditions were $70^{\circ} \mathrm{F}$ dry bulb temperature and $47^{\circ} \mathrm{F}$ dry bulb temperature, $43^{\circ} \mathrm{F}$ wet bulb temperature.

Source: Frigidaire FT4BI Series Technical Specifications. http://www.nordyne.com/Literature/931D.pdf 


\section{Appendix B: Cooling and Heating Season Energy Consumption Analysis Using a Multiple Linear Regression Method}

\section{Multiple Linear Regression Analysis Description}

A multivariable regression analysis technique was used to evaluate the daily energy performance of each configuration. The goal was to create the following relationship for each of 12 possible configurations:

$$
\text { Energy }=A+B * d T+C * d T^{2}
$$

Where:

Energy is the total daily energy used by the cooling or heating system in Wh $\mathrm{dT}$ is the average daily difference in temperature between indoors and outdoors in ${ }^{\circ} \mathrm{F}$ $\mathrm{dT}^{2}=\mathrm{dT} \times \mathrm{dT}$

$\mathrm{A}, \mathrm{B}$, and $\mathrm{C}$ are regression coefficients.

Energy was considered as a function of five variables:

$\mathrm{dT} \quad$ Daily average delta temperature (outdoor minus indoor)

SEER $\quad$ Denotes SEER rating. SEER 13 is -1, SEER 21 is 0.778 and SEER 22 is 1

$\mathrm{RH} \quad$ Denotes RH control setting. Normal operation is -1 and RH control activated is 1

CAP Denotes capacity. 3-ton is 1 and 2-ton is -1

DUCT Denotes duct type. Attic ducts is 1 and Indoor ducts is -1

Interactions between each of the four configuration variables (those other than dT) were also considered; all configuration variables and interactions were combined with the dT and $\mathrm{dT}^{2}$ terms for the initial model. For the heating analysis, only SEER rating and capacity were used as configuration variables because RH control is irrelevant to heating operation and only attic ducts were used for heating. Also, the interaction between SEER and RH control was not considered because of the lack of variety of SEER rating for RH control systems (S21 versus S22). Initially 30 regression terms (Table 18) were considered for cooling and 12 terms (Table 19) were considered for heating. The significance of each term was evaluated with a t-test and insignificant terms were removed from the model in a stepwise manner. All tests were performed at a $95 \%$ confidence level. The word "Yes" in each table indicates significance.

A statistical analysis program called $\mathrm{R}$ was used to perform all statistical analysis. Only significant variables were used; the final reduced models were evaluated for each configuration to determine the $\mathrm{A}, \mathrm{B}$, and $\mathrm{C}$ values for the base regression model. These are the same variable coefficients discussed in Section 3.3. $\mathrm{R}^{2}$ values were determined for each configuration; values averaged 0.943 for cooling and 0.922 for heating. The $\mathrm{R}^{2}$ values used for this average do not include the "adjusted" values for the 3-ton SEER 22 models for which no data are available. Only data for the 3-ton SEER 21 systems are included. 
Because the SEER ratings of the 2-ton and 3-ton variable-capacity systems differ, regression constants for a SEER 22, 3-ton system were created to compare similar efficiency rates. For comparison, four other configurations were modeled for cooling. Because the SEER ratings of the 2-ton (SEER 22) and 3-ton (SEER 21) variable-capacity systems differ, 3-ton SEER 22 systems were evaluated to allow proper comparison between the variable-capacity systems. A 3ton SEER 22 system model was created for heating.

Table 18. Cooling Regression

\begin{tabular}{|c|c|}
\hline Variable & Significant? \\
\hline Intercept & Yes \\
\hline SEER & Yes \\
\hline $\mathrm{RH}$ & Yes \\
\hline CAP & Yes \\
\hline DUCT & Yes \\
\hline SEER*CAP & Yes \\
\hline SEER*DUCT & Yes \\
\hline $\mathrm{RH}^{*} \mathrm{CAP}$ & \\
\hline RH*DUCT & Yes \\
\hline CAP*DUCT & Yes \\
\hline $\mathrm{dT}$ & Yes \\
\hline dT*SEER & Yes \\
\hline $\mathrm{dT} * \mathrm{RH}$ & Yes \\
\hline $\mathrm{dT} * \mathrm{CAP}$ & Yes \\
\hline dT*DUCT & Yes \\
\hline dT*SEER*CAP & Yes \\
\hline dT*SEER*DUCT & Yes \\
\hline dT*RH*CAP & \\
\hline dT*RH*DUCT & Yes \\
\hline dT*CAP*DUCT & \\
\hline $\mathrm{dT}^{2}$ & Yes \\
\hline $\mathrm{dT}^{2 *} \mathrm{SEER}$ & Yes \\
\hline $\mathrm{dT}^{2} * \mathrm{RH}$ & Yes \\
\hline $\mathrm{dT}^{2 * \mathrm{CAP}}$ & \\
\hline $\mathrm{dT}^{2} *$ DUCT & Yes \\
\hline $\mathrm{dT}^{2} * \mathrm{SEER} * \mathrm{CAP}$ & \\
\hline $\mathrm{dT}^{2 * \mathrm{SEER} * \mathrm{DUCT}}$ & Yes \\
\hline $\mathrm{dT}^{2} * \mathrm{RH}^{*} \mathrm{CAP}$ & \\
\hline $\mathrm{dT}^{2 *} \mathrm{RH}^{*} \mathrm{DUCT}$ & Yes \\
\hline $\mathrm{dT}^{2} * \mathrm{CAP} * \mathrm{DUCT}$ & \\
\hline
\end{tabular}

Table 19. Heating Regression

\begin{tabular}{|c|c|}
\hline Variable & Significant? \\
\hline Intercept & Yes \\
\hline SEER & Yes \\
\hline CAP & Yes \\
\hline SEER*CAP & \\
\hline $\mathrm{dT}$ & Yes \\
\hline dT*SEER & Yes \\
\hline $\mathrm{dT} * \mathrm{CAP}$ & Yes \\
\hline dT*SEER*CAP & \\
\hline $\mathrm{dT}^{2}$ & Yes \\
\hline $\mathrm{dT}^{2} * \mathrm{SEER}$ & \\
\hline $\mathrm{dT}^{2} * \mathrm{CAP}$ & \\
\hline $\mathrm{dT}^{2 * \mathrm{SEER}} * \mathrm{CAP}$ & \\
\hline
\end{tabular}


The reduced models for cooling and heating are shown below:

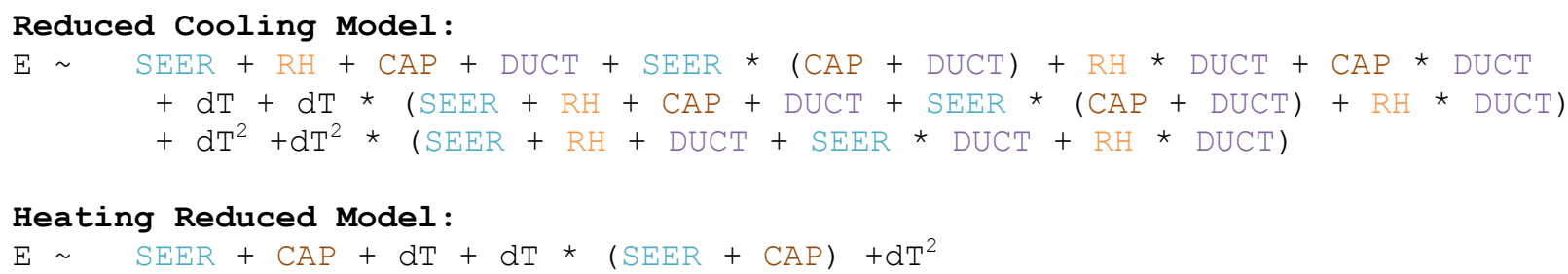

\section{Cooling Energy Results}

The MLR cooling energy evaluation results are shown here in similar fashion as in Section 3. A multivariate regression analysis was performed to characterize the relative cooling energy consumption (Wh/day) versus dT of 2-ton and 3-ton systems in the following configurations:

- SEER 13 2-ton versus 3-ton with attic ducts

- SEER 13 2-ton versus 3-ton with indoor ducts

- $\quad$ SEER 22 2-ton versus SEER 21 3-ton with attic ducts

- SEER 22 (45\%) 2-ton versus SEER 21 (45\%) 3-ton with attic ducts

- SEER 22 (45\%) 2-ton versus SEER 21 (45\%) 3-ton with indoor ducts.

SEER $22(45 \%)$ or SEER $21(45 \%)$ refers to the operation of the variable-capacity heat pump systems in RH control mode set to 45\%. The SEER 22/21 (45\%) configurations are important variations because the standard control mode of these units is optimized for energy savings and may not always achieve the desired level of indoor humidity control.

Table 20, Figure 23, and Figure 24 compare daily cooling energy use versus daily average dT for a total of 11 test configurations. Data for the SEER 22 with indoor ducts and no RH control configuration were unavailable because of seasonal time constraints that were caused by SEER 22 2-ton equipment failure 6 months into the Phase 3 period. Although no data were available for the 2-ton SEER 22 without RH control configuration, the multivariate regression analysis allowed a model to be constructed. However, this configuration has no data, so the predicted results from this particular model should be considered valid.

Table 20 shows the regression coefficients for each configuration as well as the energy use and savings produced by switching from an oversized 3-ton system to a right-sized 2-ton system. Models were created in the form $Y=A+B * d T+C * d T^{2}$ where $\mathrm{Y}$ is the energy use in $\mathrm{Wh} /$ day, $\mathrm{dT}$ is the daily average difference in temperature between outdoors and indoors (outdoor minus indoor), and A, B, and C are the regression constants shown. Negative energy savings from right-sizing (right column) means that oversizing produces seasonal cooling energy savings. 
Table 20. MLR Results for Cooling Energy Use Models Developed for 2-Ton (Right-Sized) and 3-Ton (Oversized) Heat Pumps for Six Experimental Configurations

\begin{tabular}{|c|c|c|c|c|c|c|c|c|c|c|}
\hline $\begin{array}{l}\text { Heat Pump } \\
\text { System }\end{array}$ & $\begin{array}{c}\text { Size } \\
\text { (tons) }\end{array}$ & $\begin{array}{l}\text { Duct } \\
\text { System }\end{array}$ & $\mathbf{R}^{2}$ & $\mathbf{A}$ & B & $\mathbf{C}$ & $\begin{array}{l}\text { Energy Use } \\
\text { at dT }=5^{\circ} \mathrm{F} \\
(\mathrm{kWh} / \text { day })\end{array}$ & Error $^{a}$ & $\begin{array}{c}\% \text { Energy } \\
\text { Savings From } \\
\text { Right-Sizing }\end{array}$ & $\begin{array}{l}\text { Savings } \\
\text { Error }^{\mathbf{b}}\end{array}$ \\
\hline SEER 13 & 2 & Attic & 0.988 & 17,313 & $1,258.9$ & 14.73 & 24.0 & 0.5 & \multirow{2}{*}{$8.8 \%$} & \multirow{2}{*}{$3.9 \%$} \\
\hline SEER 13 & 3 & Attic & 0.974 & 19,467 & $1,289.5$ & 14.73 & 26.3 & 0.5 & & \\
\hline SEER 13 & 2 & Indoor & 0.971 & 15,326 & $1,026.6$ & 13.23 & 20.8 & 0.6 & \multirow{2}{*}{$7.0 \%$} & \multirow{2}{*}{$4.4 \%$} \\
\hline SEER 13 & 3 & Indoor & 0.924 & 16,747 & $1,057.3$ & 13.23 & 22.4 & 0.4 & & \\
\hline SEER 22 (45) & 2 & Attic & 0.971 & 12,901 & $1,008.8$ & 20.56 & 18.5 & 0.5 & \multirow{2}{*}{$-9.6 \%$} & \multirow{2}{*}{$5.6 \%$} \\
\hline SEER 22 (45) & 3 & Attic & $0.748^{\mathrm{c}}$ & 12,104 & 845.2 & 20.56 & 16.8 & 0.4 & & \\
\hline SEER 22 & 2 & Attic & 0.969 & 11,384 & 980.4 & 32.02 & 17.1 & 0.4 & \multirow{2}{*}{$-10.4 \%$} & \multirow{2}{*}{$5.7 \%$} \\
\hline SEER 22 & 3 & Attic & $0.779^{\mathrm{c}}$ & 10,587 & 816.9 & 32.02 & 15.5 & 0.4 & & \\
\hline SEER 22 (45) & 2 & Indoor & 0.945 & 11,511 & 830.4 & 12.41 & 16.0 & 0.7 & \multirow{2}{*}{$-17.2 \%$} & \multirow{2}{*}{$10.1 \%$} \\
\hline SEER 22 (45) & 3 & Indoor & $0.929^{\mathrm{c}}$ & 9,982 & 666.9 & 12.41 & 13.6 & 0.7 & & \\
\hline SEER 22 & 2 & Indoor & N/A & 11,762 & 760.9 & -9.88 & 15.3 & 0.8 & \multirow{2}{*}{$-18.1 \%$} & \multirow{2}{*}{$9.8 \%$} \\
\hline SEER 22 & 3 & Indoor & $0.890^{\mathrm{c}}$ & 10,232 & 597.3 & -9.88 & 13.0 & 0.5 & & \\
\hline
\end{tabular}

${ }^{\mathrm{a}}$ Error is the extent of the $95 \%$ confidence interval for this regression. For example, the energy use at a $\mathrm{dT}$ value of $5^{\circ} \mathrm{F}$ is modeled to be $23.8 \mathrm{kWh} / \mathrm{day} \pm 0.5$ $\mathrm{kWh} /$ day (or $23.3-24.3 \mathrm{kWh} /$ day) at a $95 \%$ confidence level.

b Savings "Error" is the possible increase or decrease in percent energy savings as a result of the $95 \%$ confidence interval for the predicted energy use values.

${ }^{c}$ The $\mathrm{R}^{2}$ values for the 3-ton SEER 22 configurations use the residuals between the SEER 21 3-ton data and the SEER 22 3-ton model developed. The $\mathrm{R}^{2}$ values are artificially lower because the model is not intended to predict the SEER 21 data, but instead SEER 22 data. This discrepancy occurs because SEER 22 models were chosen for the 3-ton and 2-ton systems. 


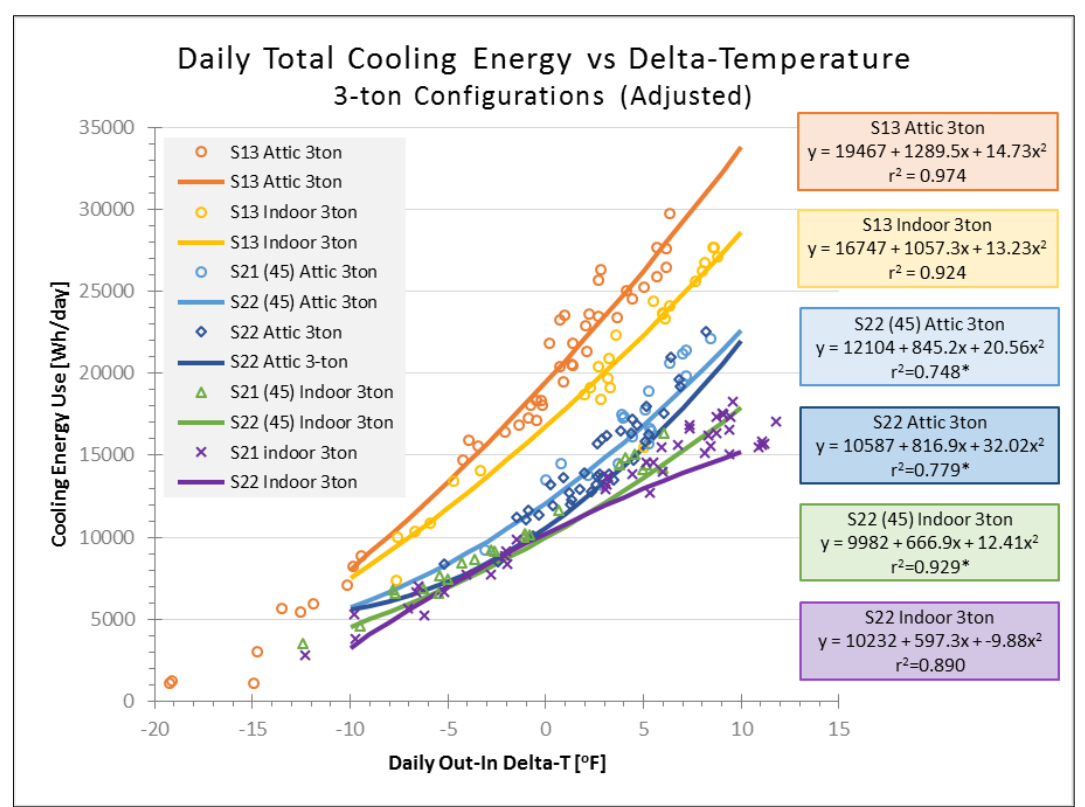

Figure 23. Cooling energy use as a function of $\mathrm{dT}$, including daily data points, MLR best-fit lines, and equations for the 3-ton systems (Phase 1)

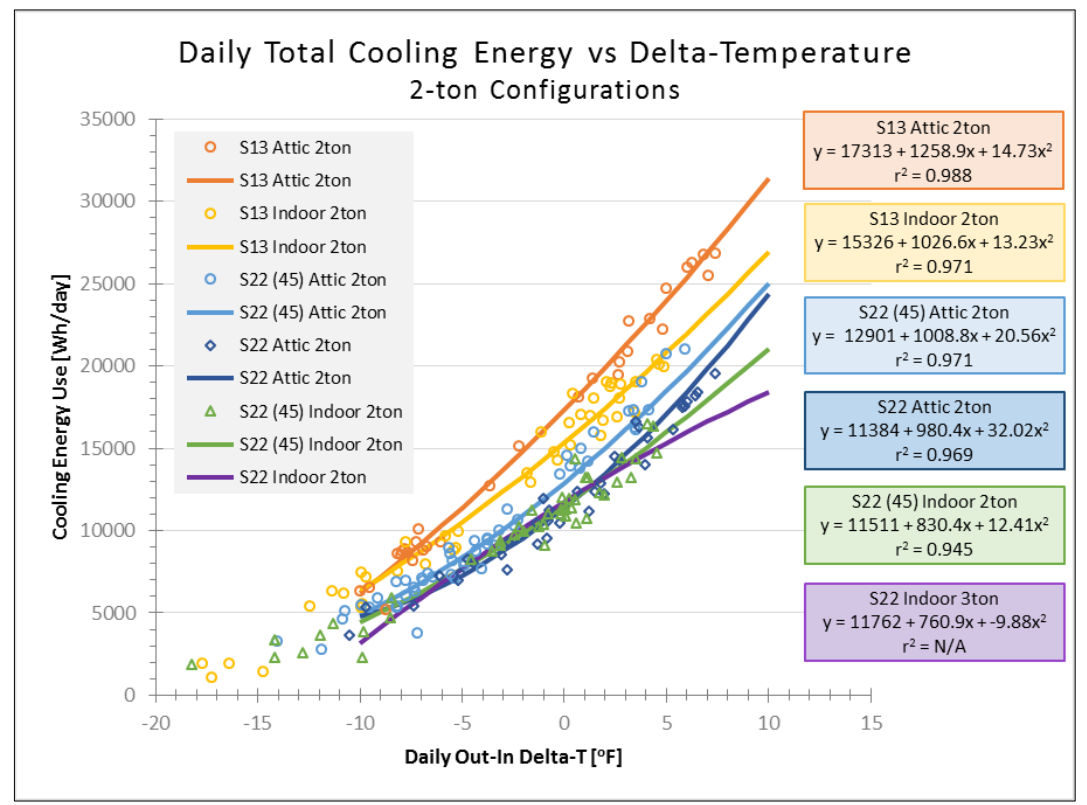

Figure 24. Cooling energy use as a function of $\mathrm{dT}$, including daily data points, MLR best-fit lines, and equations for the 2-ton systems (Phase 3)

Figure 25 through Figure 30 present the cooling energy consumption data contained in Figure 23 and Figure 24. The objective of Figure 25 through Figure 30 is to portray energy-efficiency increases or reductions that result from right-sizing or oversizing the systems based on MLR.

Figure 25 shows cooling energy performance (Wh/day versus dT) for the 2-ton and 3-ton SEER 13 heat pumps with attic ducts. Based on the regression analysis, the right-sized (2-ton SEER 13) 
system uses $8.8 \%$ less energy at $\mathrm{dT}=5^{\circ} \mathrm{F}$ per unit of cooling load compared to the oversized (3ton SEER 13) system when the attic ductwork is used (also see Table 20).

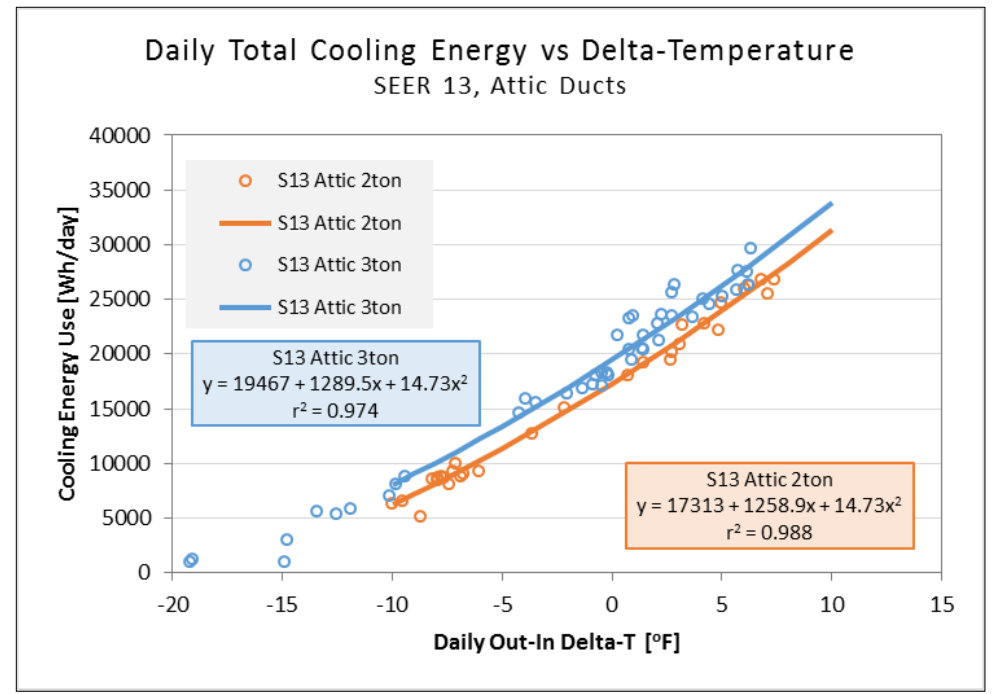

Figure 25. Cooling energy use as a function of dT for the 2-ton and 3-ton SEER 13 units with attic ducts based on MLR

Figure 26 shows cooling energy performance (Wh/day versus dT) for the 2-ton and 3-ton SEER 13 heat pumps with indoor ducts. Based on regression analysis, the right-sized (2-ton SEER 13) system uses $7 \%$ less energy at $\mathrm{dT}=5^{\circ} \mathrm{F}$ per unit of cooling load compared to the oversized (3ton SEER 13) system when the indoor ductwork is used (Table 20).

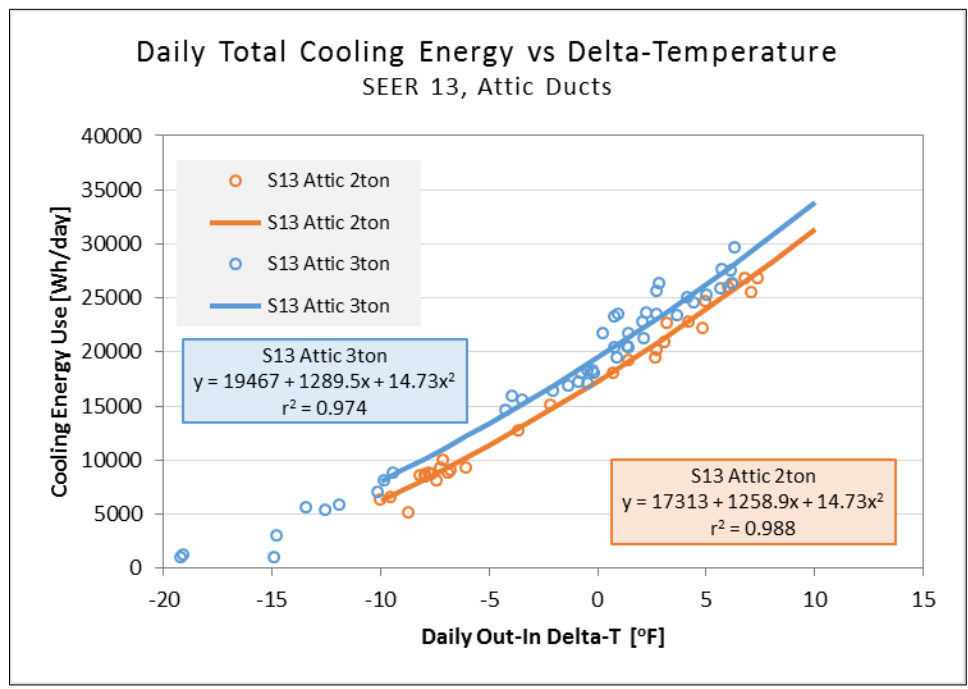

Figure 26. Cooling energy use as a function of dT for the 2-ton and 3-ton SEER 13 units with indoor ducts based on MLR

Figure 27 shows cooling energy data and best-fit lines for the 2-ton SEER 22 (orange line) and 3-ton SEER 21 systems (dashed blue line). Also shown is the 3-ton SEER 22 MLR-generated line (blue solid line). Attic ducts with RH control activated were used for these experimental data. Based on regression analysis, the 3-ton system (with attic ducts and RH control activated) 
uses $9.6 \%$ less energy per unit of cooling compared to the 2-ton system during typical cooling season weather. Therefore, for this test configuration oversizing significantly improves efficiency compared to right-sizing.

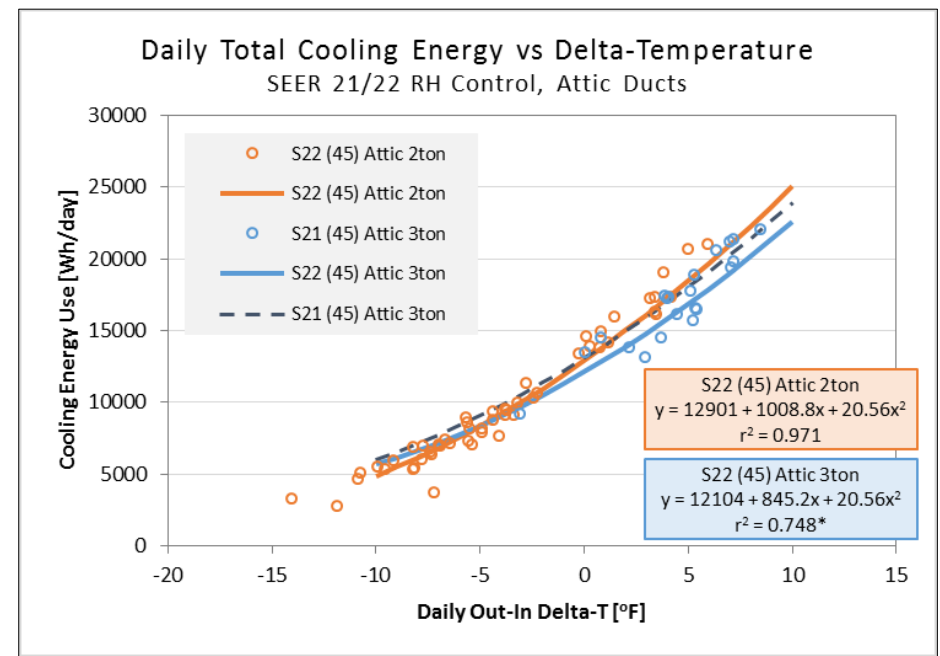

Figure 27. Cooling energy use as a function of dT for the 2-ton and 3-ton iQ Drive (SEER 22 and SEER 21) units with attic ducts with RH control activated at $45 \%$ based on MLR

Figure 28 shows cooling energy data and best-fit lines for the 2-ton SEER 22 (orange line) and 3-ton SEER 21 systems (dashed blue line). Also shown is the 3-ton SEER 22 MLR-generated line (blue solid line). Attic ducts without the RH control activated were used for these experimental data. Based on regression analysis, the 3-ton system (with attic ducts and $\mathrm{RH}$ control deactivated) uses $10.4 \%$ less energy per unit of cooling compared to the 2 -ton system during typical cooling season weather. Therefore, for this test configuration oversizing significantly improves efficiency compared to right-sizing.

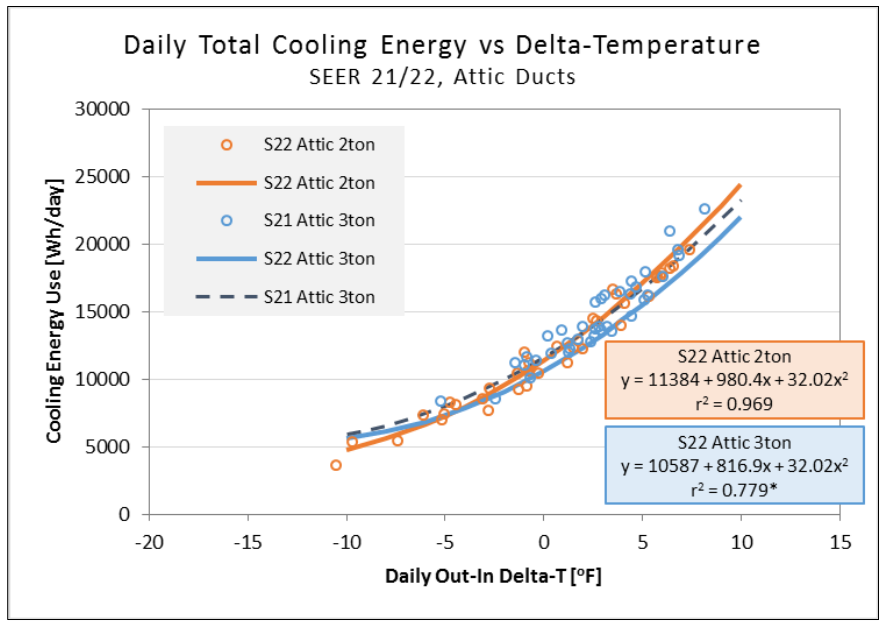

Figure 28. Cooling energy use as a function of $\mathrm{dT}$ for the 2-ton and 3-ton iQ Drive (SEER 22 and SEER 21) units with attic ducts with RH control deactivated based on MLR

Figure 29 shows cooling energy data and best-fit lines for the 2-ton SEER 22 (orange line) and 3-ton SEER 21 systems (dashed blue line). Also shown is the 3-ton SEER 22 MLR-generated 
line (blue solid line). Indoor ducts with RH control activated were used for these experimental data. Based on regression analysis, the oversized (3-ton) system (with indoor ducts and RH control activated) uses $17.2 \%$ less energy per unit of cooling load compared to the right-sized (2ton) system during typical cooling season weather.

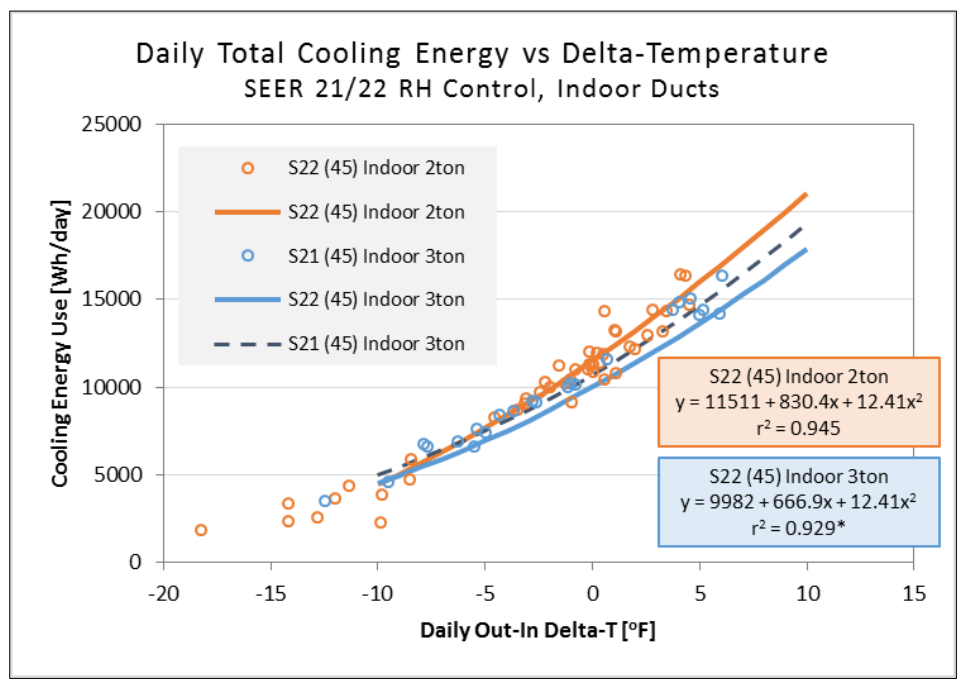

Figure 29. Cooling energy use as a function of $d T$ for the 2-ton and 3-ton iQ Drive (SEER 22 and SEER 21) units with indoor ducts and RH control activated (at $45 \%$ ) based on MLR

Figure 30 shows cooling energy data and best-fit lines for the 2-ton SEER 22 (orange line) and 3-ton SEER 21 systems (dashed blue line). Also shown is the 3-ton SEER 22 MLR-generated line (blue solid line). Indoor ducts without RH control were used for these experimental data. No SEER 22 Indoor 2-ton data could be collected because the equipment failed. Thus, the models created for this configuration are less certain. Based on regression analysis, the oversized (3-ton) system (with indoor ducts and RH control activated) uses $18.1 \%$ less energy per unit of cooling load compared to the right-sized (2-ton) system during typical cooling season weather.

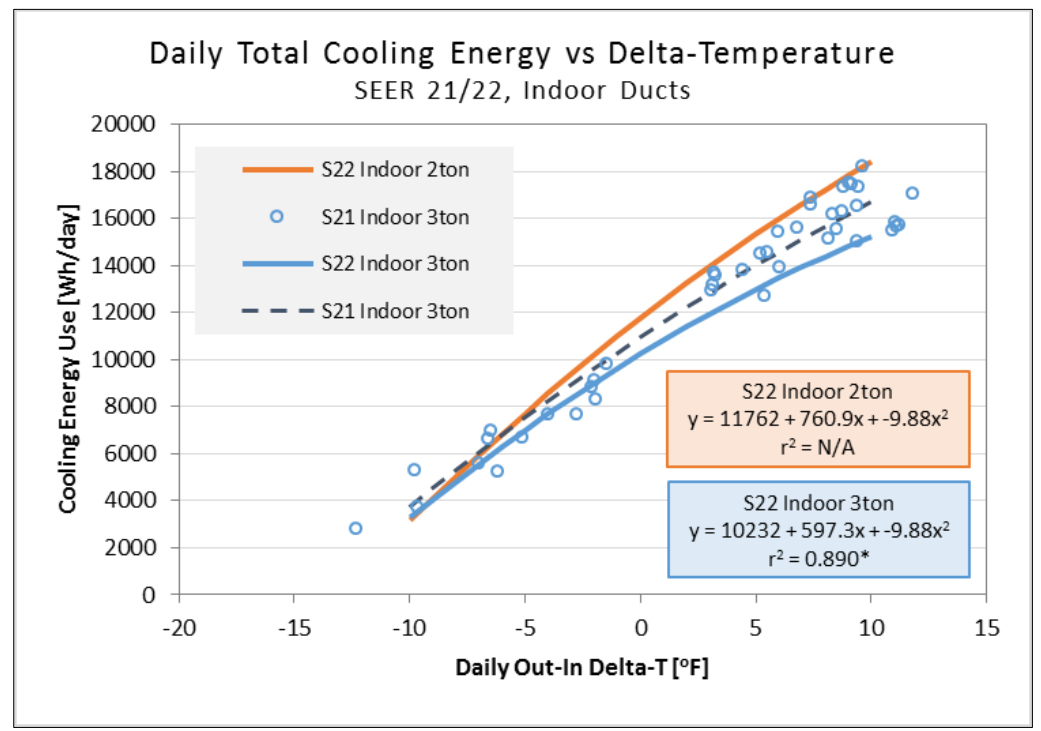

Figure 30. Cooling energy use as a function of dT for the 2-ton and 3-ton iQ Drive (SEER 22 and SEER 21) units with indoor ducts and RH control deactivated based on MLR 


\section{Heating Energy Results}

To perform the seasonal heating energy analysis, the research team plotted the daily total heating energy consumption plotted against the average daily temperature difference between outdoors and indoors in a fashion similar to that done for the cooling analysis. Limited heating weather data were available for these experiments, which created greater uncertainty for heating energy savings from oversizing heating capacity.

Table 21 presents the regression coefficients for each configuration as well as the energy use and savings produced by switching from an oversized 3-ton system to a right-sized 2-ton system. Models were created in the form $Y=A+B * d T+C * d T^{2}$ where $\mathrm{Y}$ is the energy use in $\mathrm{Wh} /$ day, $\mathrm{dT}$ is the daily average difference in temperature between outdoors and indoors and A, $\mathrm{B}$, and $\mathrm{C}$ are regression coefficients. For purposes of discussing relative heating performance, indoor temperature of $72^{\circ} \mathrm{F}$ is assumed. On a day with an average temperature of $50^{\circ} \mathrm{F}$ (high of $60^{\circ} \mathrm{F}$ and low of $40^{\circ} \mathrm{F}$ ), which might be considered a typical Florida winter day, dT is $-22^{\circ} \mathrm{F}$. For the fixed- and variable-capacity systems, oversizing saves energy based on the MLR analysis. The results indicate 3.8\% heating savings for oversizing the fixed-capacity SEER 13 unit and $5.3 \%$ energy savings from oversizing the variable-capacity system.

Table 21. MLR Results for Heating Energy Use Models Developed for 2-Ton (Right-Sized) and 3-Ton (Oversized) Heat Pumps, for SEER 13 and SEER 21/22 Systems

\begin{tabular}{|c|c|c|c|c|c|c|c|}
\hline $\begin{array}{l}\text { Heat Pump } \\
\text { and } \\
\text { Capacity } \\
\text { (tons) }\end{array}$ & $\mathbf{R}^{2}$ & $\mathbf{A}$ & B & C & $\begin{array}{c}\text { Energy Use @ } \\
\text { dT }=-22^{\circ} \mathbf{F} \\
(\mathrm{kWh} / \text { day })\end{array}$ & Error $^{a}$ & $\begin{array}{c}\text { Energy } \\
\text { Savings From } \\
\text { Right-Sizing }\end{array}$ \\
\hline $\begin{array}{l}\text { SEER } 13 \\
(2)\end{array}$ & 0.875 & $-10,831$ & -995.0 & 10.29 & 16.0 & 0.8 & \multirow{4}{*}{$-3.8 \%$} \\
\hline $\begin{array}{c}\text { SEER } 13 \\
\text { (3) }\end{array}$ & 0.981 & $-8,546$ & -863.2 & 10.29 & 15.4 & 0.8 & \\
\hline $\begin{array}{l}\text { SEER } 22 \\
\text { (2) }\end{array}$ & 0.874 & $-6,261$ & -588.2 & 10.29 & 11.7 & 0.7 & \\
\hline $\begin{array}{c}\text { SEER } 22 \\
\text { (3) }\end{array}$ & $0.956^{\mathrm{b}}$ & $-3,975$ & -456.4 & 10.29 & 11.0 & 0.7 & \\
\hline
\end{tabular}

${ }^{a}$ Error is the extent of the $95 \%$ confidence interval for this regression. For example, the energy use at a dT value of $5^{\circ} \mathrm{F}$ is modeled to be $23.8 \mathrm{kWh} /$ day $\pm 0.5 \mathrm{kWh} /$ day (or $23.3-24.3 \mathrm{kWh} /$ day) at a $95 \%$ confidence level.

${ }^{\mathrm{b}}$ The $\mathrm{R}^{2}$ values for the 3-ton SEER 22 configurations use the residuals between the SEER 213 -ton data and the artificially generated SEER 22 3-ton model. The $\mathrm{R}^{2}$ values are artificially lower because the model is not intended to predict the SEER 21 data but instead SEER 22 data. This discrepancy occurs because, for comparison purposes, SEER 22 models were chosen for the 3-ton and 2-ton systems.

Figure 31 shows heating energy data for the 2-ton and 3-ton SEER 13 systems. Right-sizing increased energy use by $3.8 \%$. Although the analysis indicates that decreased capacity increases heating energy use, the error for these results is high, which indicates that the results are not statistically significant. 


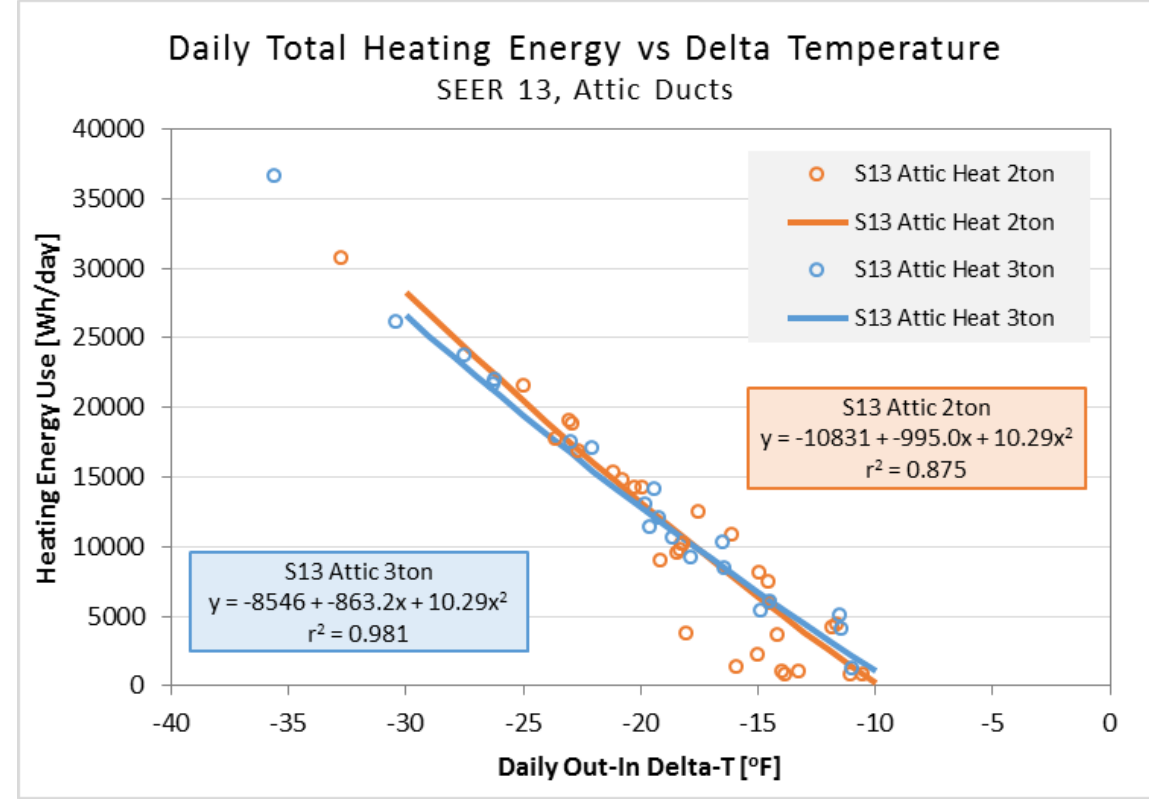

Figure 31. Heating energy use as a function of dT for the 2-ton and 3-ton SEER 13 units based on MLR analysis

Figure 32 shows heating energy data and best-fit lines for the 2-ton SEER 22 (orange line) and 3ton SEER 21 systems (dashed blue line). Also shown is the 3-ton SEER 22 MLR-generated line (blue solid line). The 3-ton SEER 22 system is hypothetical but was modeled by the MLR to allow a comparison of 2-ton and 3-ton systems without the confounding influence of system SEER rating. Analysis finds that the right-sized 2-ton system used 5.3\% more energy than the oversized 3-ton system.

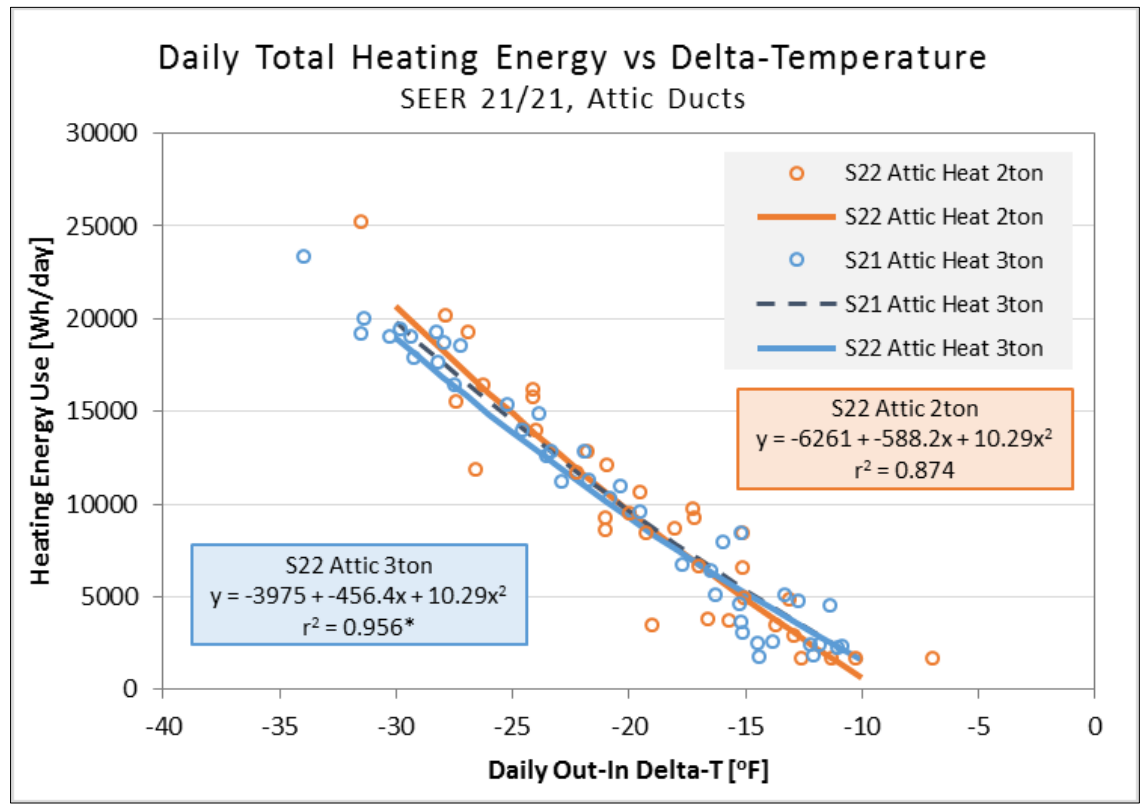

Figure 32. Heating energy use as a function of $d T$ for the 2-ton SEER 22 unit and the 3-ton SEER 21 unit based on MLR analysis 
